\title{
TRUST: A PHENOMENOLOGICAL STUDY OF LEADERS AND VOLUNTEERS IN LDS SEMINARIES AND INSTITUTES
}

\author{
A Dissertation \\ presented to \\ the Faculty of the Graduate School \\ at the University of Missouri-Columbia \\ In Partial Fulfillment \\ of the Requirements for the Degree \\ Doctor of Educational Leadership and Policy Analysis \\ by \\ JOHN LAWSON \\ Dr. Cynthia MacGregor, Dissertation Supervisor \\ MAY 2014
}


(C) Copyright by John Lawson 2014

All Rights Reserved 
The undersigned, appointed by the dean of the Graduate School, have examined the dissertation entitled

TRUST: A PHENOMENOLOGICAL STUDY OF LEADERS AND VOLUNTEERS IN LDS SEMINARIES AND INSTITUTES

presented by John Lawson, a candidate for the degree of doctor of education, and hereby certify that, in their opinion, it is worthy of acceptance.

Dr. Cynthia J. MacGregor

Dr. Jason Anderson

Dr. Beth Hurst

Dr. Robert Watson 


\section{Dedication}

To Liz, for your support and sacrifice.

To Katie, Anna, Sara, Emily, and Sam, who I cannot think of without smiling. 


\section{ACKNOWLEDGEMENTS}

I assumed the completion of a dissertation had more of a closure feel than it really does. What I have found instead is an increased awareness that there is much more to learn and to understand. To be learned is good if we hearken to the counsels of God (2 Nephi 9:29). Throughout this entire process I have felt my mind expanded and my desire

to be better increased. I am grateful to a Heavenly Father who has confirmed truth in my mind and heart and inspired to me to act.

I would never have been able to complete this project without the guidance, encouragement, and patience of Dr. Cindy MacGregor. Taking on someone with only a religious education background meant extra work and time for her. I continue to be impressed by what she knows, but even more by the kind of person she is.

I would also like to thank my committee for their time and efforts in making my dissertation the best it could be. A special thank you to Dr. Bob Watson for always reminding me of the practical implications of what I am studying. Dr. Beth Hurst has the APA manuals memorized. Despite the multitude of errors she found, she always had a smile and words of encouragement. Dr. Jason Anderson's suggestion concerning leadership theory during the research proposal process expanded my views on leadership and what it truly means. Dr. Don Christensen and Dr. Jared Jepson have been patient readers and sounding boards.

Finally, I thank my family who would not let me forget that I am a husband and father first, ahead of being a doctoral student. I have been blessed over the course of this pursuit to not only maintain a strong relationship with my wife, 4 daughters and 1 son, but also increase and reinforce those relationships. We are a better family because of engaging in this educational endeavor together. 


\section{TABLE OF CONTENTS}

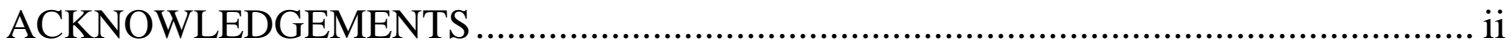

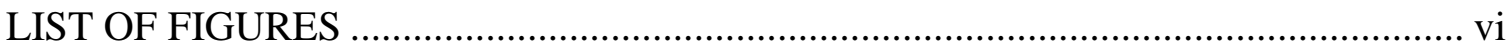

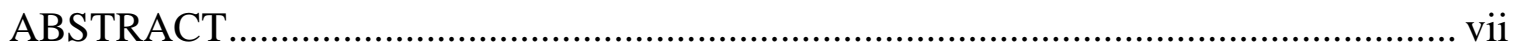

\section{Chapter}

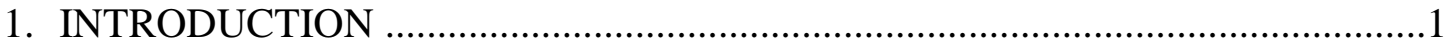

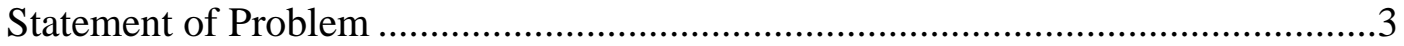

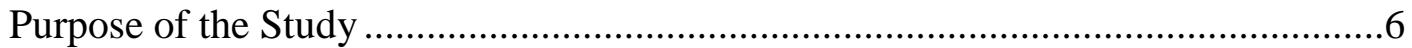

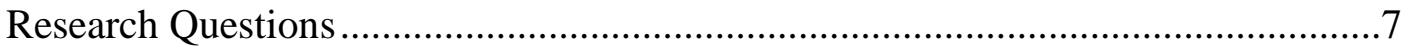

Conceptual Framework ................................................................................

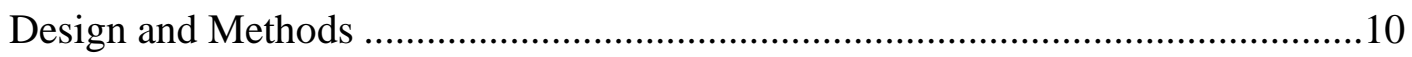

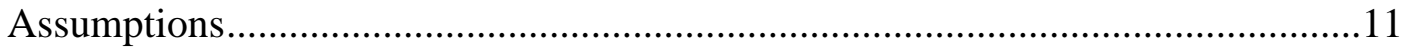

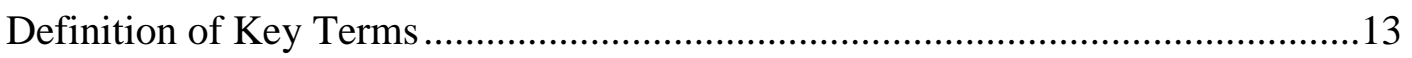

Significance of Research for Leadership Practices............................................15

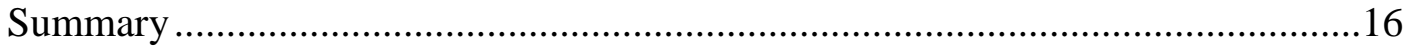

2. REVIEW OF RELATED LITERATURE ........................................................17

Historical Perspective of Leadership and Trust ...............................................19

Theories and Models of Leader-Follower Relationships ....................................28

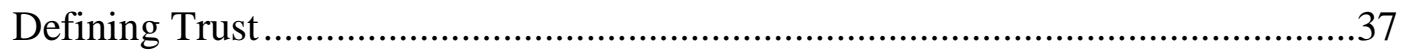

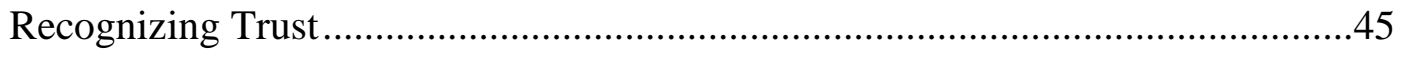

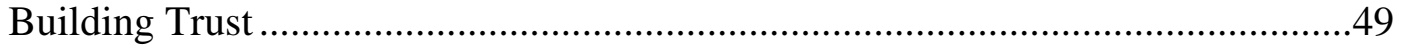

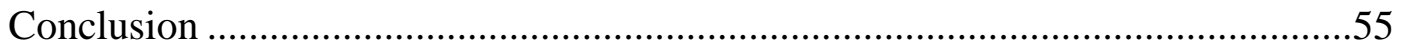




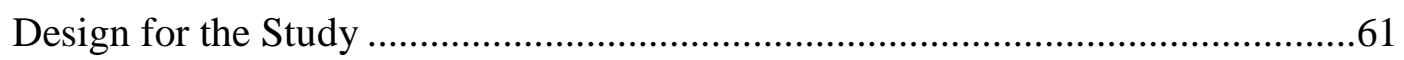

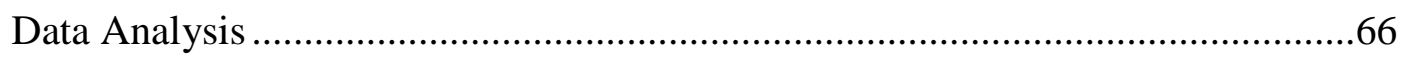

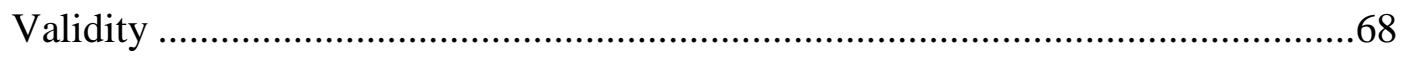

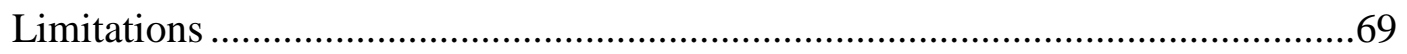

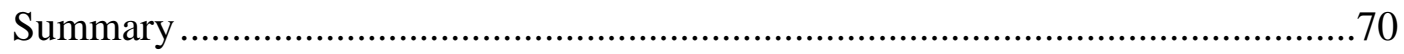

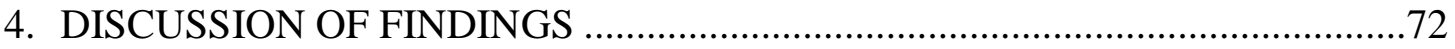

Volunteer Perception of Their Trust of Coordinators .........................................73

LMX-7 Data Results ................................................................. 74

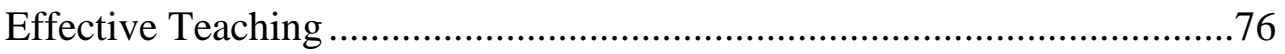

Helpful or Discouraging Training..................................................... 77

Genuine or Self-Serving Administrating …...........................................81

Summary of Volunteer Perception of Their Trust of Coordinators ......................95

Coordinator Perception of how they are Trusted by Volunteers ..........................98

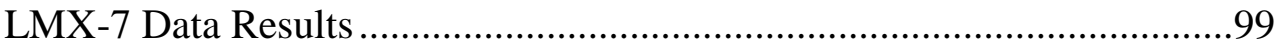

Superior Teaching ..................................................................... 101

Implementation of Coordinator Instruction ........................................105

Maintaining Relationships ..........................................................109

Summary of Coordinator Perception of how they are Trusted by Volunteers .....112

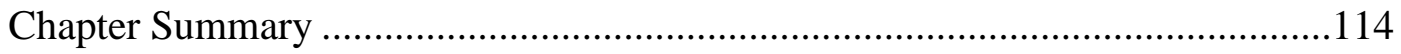




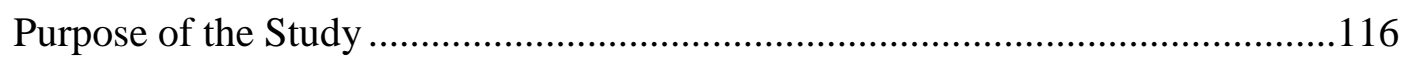

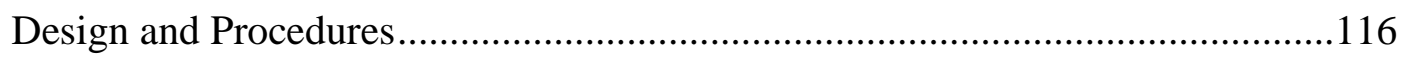

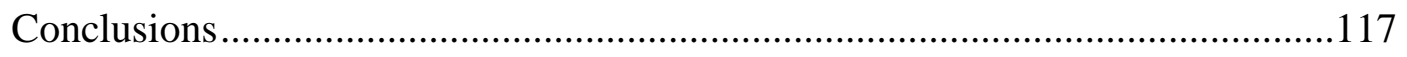

Integrated Findings of the Study ....................................................................119

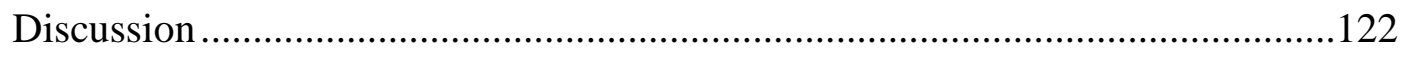

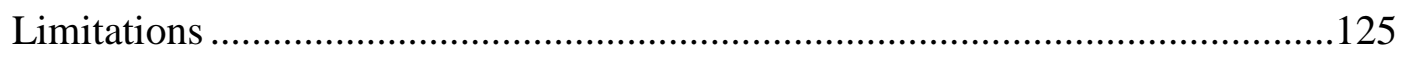

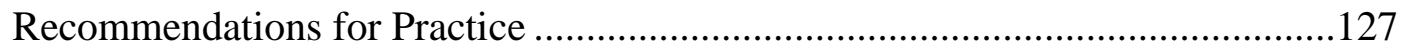

Implications for Future Research.....................................................................129

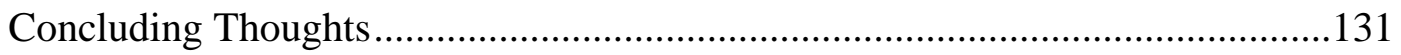

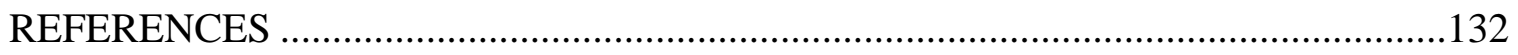

APPENDIX

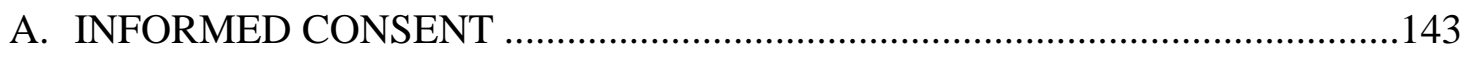

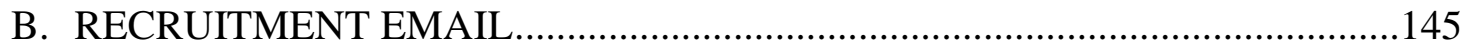

C. MODIFIED LMX-7 QUESTIONAIRE .............................................................146

D. VOLUNTEER INTERVIEW PROTOCOL …………………...........................149

E. COORDINATOR INTERVIEW PROTOCOL ……………………………........150

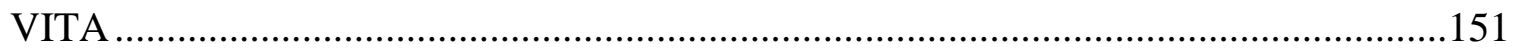




\section{List of Figures}

Figure

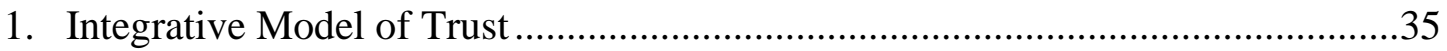

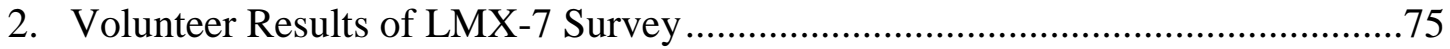

3. Summary of Volunteers Perception of Their Trust of Coordinators ...................97

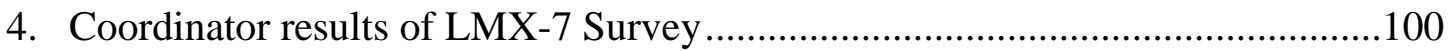

5. Summary of Coordinator Perception of how they are Trusted by Volunteers ....113

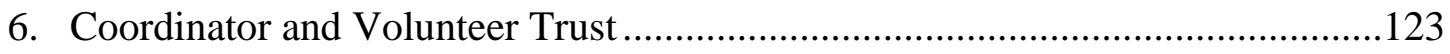




\title{
TRUST: A PHENOMENOLOGICAL STUDY OF LEADERS AND VOLUNTEERS IN LDS SEMINARIES AND INSTITUTES
}

\author{
John Lawson
}

Dr. Cynthia J. MacGregor, Dissertation Supervisor

\begin{abstract}
The researcher conducted a qualitative student to develop a deeper understanding of how volunteers and leaders in the Seminaries and Institute (S\&I) program of The Church of Jesus Christ of Latter-day Saints perceived trust between one another. Participants were coordinators and volunteer seminary and institute instructors from the US Southern Plains area of S\&I. Data were collected from participant interviews and survey responses.
\end{abstract}

The researcher identified three overarching categories as relevant to volunteer perception of trust in coordinators: effective teaching, helpful and discouraging training, and genuine or self-serving administrating. Further the researcher identified three overarching categories as relevant in recognizing the way coordinators perceived they were trusted by volunteers: superior teaching, implementation of coordinator instruction, and maintaining relationships.

The findings of this study have implications for coordinators and volunteers who labor within the S\&I organization. One glaring finding of this study was that the antecedents of trust, namely ability, benevolence, and integrity, were more readily 
perceived among volunteers and coordinators who had personal, informal communication with each other. 


\section{CHAPTER ONE}

\section{INTRODUCTION TO RESEARCH}

One defining and unifying characteristic of human beings is the opportunity to be engaged in relationships with one another. Though this is not a groundbreaking finding or particularly unique and fascinating, the exchanges and interactions that exist within these relationships have been a spark of curiosity and intrigue among philosophers, theologians, scholars, poets, and leaders. As these individuals have considered countless types and forms of relationships, their thoughts and study have become focused on what makes successful relationships. The characteristic of trust is frequently referenced by diverse populations and in diverse disciplines making trust a universal characteristic of relationships and not bound to a specific group, social system, or culture.

Confucius, in the sixth and fifth century BCE in China, believed that rulers need three resources: weapons, food, and trust. He went so far to say that if rulers could not obtain all three, they should prioritize these resources by first giving up weapons and then food but should never relinquish trust. He stated, "Without trust we cannot stand!" (O’Neill, 2002, p. 3).

Confucius was not without detractors in the world of philosophy. Nearly 2000 years after Confucius postulated concerning trust, Machiavelli (1984), an Italian philosopher believed that fear provided a stronger influence in relationships than trust. In writing on leadership, he provided an example of royalty being both loved and feared, but if both were not possible, then he should choose to be feared by his subjects rather than loved. He stated, "Love is held together by a chain of obligation which, since men are 
wretched creatures, is broken on every occasion in which their own interests are concerned; but fear is sustained by a dread of punishment which will never abandon you" (Machiavelli, 1984, p. 54).

Theologians have considered the role of trust in religious faith for centuries. Judeo-Christians find the Bible replete with direct and indirect references to trust. Ironically, the counsel from the pages of this sacred text often indicate that man should not place trust in other men or objects over that of God. In the Old Testament, Jehovah invited believers to, "Trust in the Lord with all thine heart; and lean not unto thine own understanding" (Proverbs 3:4, King James Version). Further, in the New Testament, Jesus Christ rebuked those who place trust in inanimate objects rather than in their relationship with deity when he emphatically proclaimed, "Children, how hard is it for them that trust in riches to enter into the kingdom of God!" (Mark 10:24).

Perhaps trust, as it relates to the world of business, can be observed and traced back to the coffee shops and pubs of 17th century London, England. It was here that the advent of insurance and the idea of stock exchanges began. Merchants, shipping moguls, and bankers would meet in these locales to discuss business mergers, commodity prices, trade secrets, and general information about the state of commerce. Edward Lloyd's coffee house was the customary locale for mariners interested in insuring their sea vessels while Tom's and Causey’s Pub provided a place for mercantile owners to price and purchase fire insurance to protect their business (Michie, 1999). Interestingly, it was the atmosphere of such places that made them informal but reputable places to do business. Individuals within the walls of such establishments were described as being affable and friendly, thus making the process of doing business with others appear to be less risky. In 
other words, because of the disposition of those buying and selling, trust seemed to be a natural sentiment (Dickson, 1993).

Though relationships are often formed by circumstance and choice, such as the relationships found in the Tom's and Causey's Pub, what happens in these relationships is often the result of what is perceived between the individuals involved. More common than recognizing the results of research on trust is the personal recognition and importance humans seem to naturally have for trust in relationships. Trust, in one degree or form, seems to be an inherent part of all human relationships. Though trust between individuals in a relationship is not requisite for relationships to exist, the absence of trust will limit exchanges in those relationships (Cosner, 2009; Moye, Henkin \& Egley, 2005; Tschannen-Moran \& Hoy, 2004).

Often, when trust is studied in light of relationships, it is from the perspective of families and other social groups or interactions. Within the past 50 years however, researchers have begun to look at how trust affects attitudes and dispositions in other areas such as schools, jobs, and places of worship. Not surprisingly, these researchers found benefits to trust in multiple disciplines and circumstances (Deutsch, 2009; Gillespie \& Mann, 2004). One area that researchers have explored, and which is intriguing to view through the lens of trust, is employee motivation. Employee motivation research may be valuable to CEOs of large corporations and to small businesses seeking to develop and grow (Rousseau, Sitkin, Burt \& Camerer, 1998).

Leaders have implemented bonuses of money, stock options, working from home, insurance benefits, and paid vacation in an effort to win the hearts of their employees in order to motivate them to perform at high levels. However, providing 
monetary incentives to an individual who has no monetary needs will not always produce intended results (Barnard, 2011). Similarly, providing future stock options to employees struggling to feed their family and in need of a raise in salary may actually distance them from leaders. These employees may feel their leader is out of touch, while the leader wallows in the thought that they have ungrateful employees. Yet when leaders simply and sincerely trust employees and employees perceive trust, then performance and quality consistently improve (Ernst \& List, 2004).

Large non-profit organizations, such as churches, rely on volunteers to assist in accomplishing their mission and objectives. Often motivated by the mission and objective of the organization, volunteers engage in important and often times, skilldemanding work. Organizations comprised of volunteers sometimes may structurally resemble organizations made up of paid employees. Occasionally, leaders are funded by the organization and given the task of directing the work of the volunteers. These leaders often rely on the same skills and characteristics, including trust, used by leaders in forprofit organizations to promote growth, development and realization of the organizational purposes. Leaders and volunteers in non-profit organizations desire to feel trusted yet may show or perceive trust differently than volunteers or employees in for-profit organizations because of the nature of the circumstances in which they work.

\section{Statement of Problem}

The results of numerous studies such as Chen, Lam, and Zhong, (2010) and Mayer, Davis, and Schoorman (1995) have indicated that trust is a key factor in personal relationships as well as organizational outcomes. The extent of the studies presented, has not stifled researchers' attempts at examining trust; rather it has shifted the way trust can 
be explored. Various scholarly definitions, along with personal and societal views combine to make the study of trust either broad or ambiguous depending on the view of those interested in the topic. The definition of trust used in this current study is,

The willingness of a party to be vulnerable to the actions of another party based on the expectation that the other will perform a particular action important to the trustor, irrespective of the ability to monitor or control that other party. (Mayer et al., p. 712)

Trust is a social phenomenon that occurs between individuals or groups of people; therefore it is difficult to actually measure and also apply those measurements across various organizations (Mayer et al., 1995). Leaders, who implement research-suggested actions related to the issue of trust, may find that the results described within a study are not applicable to their particular organization.

Non-profit organizations may struggle more than others at using previous research to examine issues of trust. The vast majority of research concerning trust in organizations examines it from the perspective of for-profit businesses that provide pay or other extrinsic benefits for services. Organizations such as the Seminaries \& Institutes of Religion (S\&I) organization examined in this study are not structured to provide such benefits, nor would those benefits necessarily create desired outcomes.

The dearth of research surrounding non-profit organizations and trust compounds the problem of determining what findings and what conclusions leaders within S\&I can implement in their own leadership practice. Additionally, there appears to be no research relative to trust done specifically on religious organizations involved in religious education similar to that which takes place within S\&I. Leaders in S\&I interested in 
understanding trust are left to sift through previous research on trust trying to identify any study that seems relevant to their work.

Currently, over 400 coordinators are employed by S\&I to work with and provide leadership for over 40,000 volunteers throughout the world (Seminaries and Institutes of Religion, 2013, p. 2). However, coordinators are relatively untrained in working with volunteers prior to being assigned a specific area. Most coordinators were employed as full-time seminary or institute teachers, and did not have experience working with or training volunteer teachers.

No study was found that determined how or if coordinators and volunteers are able to perceive relationships of trust between each other. Any evidence that is present is anecdotal at best and is not formally collected. Currently, no research-identified indicators have been found that show how volunteers perceive trust with coordinators. Until such indicators become known, administrators will make coordinating assignments based upon a subjective opinion of a desired standard.

\section{Purpose}

The intent of this concurrent mixed methods study was to identify how coordinators and volunteers within S\&I perceive trust between each other and identify the actions these perceptions are based upon. In this study, the LMX-7 (Northouse, 2010) survey was used to measure personal perceived trustworthiness of coordinators and volunteers in S\&I. At the same time, perceptions of trust among these two groups were explored using qualitative interviews conducted by the researcher. The reason for combining both quantitative and qualitative data was to better understand this research problem by converging both quantitative and qualitative detailed data. 


\section{Research Questions}

Within the context of this study the following three research questions were posed as they relate to the constructs of trust perceived by leaders, trust perceived by volunteers, and evidence of action that indicates that trust is present between leaders and volunteers.

1. How do volunteers in a non-profit religious education organization perceive their trust of coordinators in the organization?

2. How do coordinators in a non-profit religious education organization perceive they are trusted by volunteers in the organization?

\section{Conceptual Framework}

An effective leader ponders "What are the needs of the people I lead?" An ineffective leader may ask, "With all of these lazy folks I am in charge of, how will I get anything done?" Bolman and Deal (2008) asserted, "Managers often fail to get things done because they rely too much on reason and too little on relationships" (p. 218). Bolman and Deal's human resource frame combines theories and organizational analysis tools to show how leaders and organizations succeed or fail based upon how they relate with followers. Leaders may be viewed by followers or even view themselves as oppressive, militant and non-communicative. Additionally, they can be viewed as being expectant of employees to put in their time, do what they are told and then go home.

However, the human resource frame also provides ample room for theories that promote the idea that leaders and followers can work together in fruitful and productive ways. According to Bolman and Deal (2008), the basic tenets of the human resource frame are built on the assumptions that:

1. Organizations exist to serve human needs rather than the reverse. 
2. People and organizations need each other: organizations need ideas, energy, and talent; people need careers, salaries, and opportunities.

3. When the fit between individual and system is poor, one or both suffer: individuals will be exploited or will exploit the organizations, or both will become victims.

4. A good fit benefits both: Individuals find meaningful and satisfying work, and organizations get the talent and energy they need to succeed. (p. 102)

McGregor (1960) developed a relational theory, included within Bolman and Deal's (2008) development of the human resource frame, which examined interactions between employers and volunteers and entitled it Theory X and Theory Y. These theories identified two different positions or lenses though which a leader may view followers. Theory X leaders generally distrust followers while Theory Y leaders display high levels of trust with followers. Trust is generally displayed by leaders in the form of collaboration and shared responsibilities. Theory Y leaders rely on followers to get important and meaningful jobs done. They encourage followers to use ingenuity to accomplish tasks rather than relying on specific or rigid guidelines. Followers of a Theory Y leader are viewed as assets to the organization who want to do a good job and promote success within the organization.

McGregor (1960) believed manager distrust of employees is born out of a belief that employees are trying to take advantage of the leader and the organization. Likewise, employees' distrust of managers was created by a sense that managers do not care about subordinates and are only striving to increase the bottom line. Subsequent research based 
upon McGregor's theory has shown outcomes of both Theory X and Y leadership practices (Costigan, Ilter, \& Berman, 1998).

McGregor (1960) only examined general perceptions of workers which left a natural gap in research considering how leaders perceive themselves in relation to trust. The LMX theory (Northouse, 2010), though relatively new and not studied as extensively as other leadership models, addressed the question of how leaders perceive they are trusted by followers. The LMX theory explains how leaders use some followers (ingroups) more than others (out-groups) to accomplish organizational objectives. The theory presents the idea that this imbalance is caused by a leader judgment of followers' capability to complete tasks (Northouse, 2010).

Offering a different perspective, Chen et al. (2010) used LMX as a lens to study perceptions of trust that followers had of leaders and how leaders perceived followers emotional intelligence. This quantitative study provided a different way for research to view LMX. Leader-member exchange studies are usually focused on competence of subordinates, but Chen et al. viewed LMX through the lens of trust. Their research indicated that leaders trusted followers who they perceived to be emotionally intelligent, while followers found competent leaders to be trustworthy as well.

Trust is difficult or simple to study depending on the definitions used to examine it. Until the 1990s many studies viewed trust through a transactional lens. For example, Axelrod (1984) believed that trust could only exist if both parties displayed trust. A later study provided a definition of trust that was used in this study as simply a willingness to engage in risks based upon expected behaviors of others (Schoorman, Mayer \& Davis, 2007). Researchers have the freedom to define and view trust in whatever way they see 
fit. The wide scope by which trust may be viewed can serve to stifle or invalidate studies on trust; however, a varied view of trust may also serve to expand issues of trust among multiple organizations and circumstances.

Research such as Mayer et al. (1995) and Sahin (2012) identified multiple indicators of trust between leaders and followers. Just as trust is perceived rather than objectively identifiable, so too are the indicators that reveal trust. The study of trust will never become definitive or obsolete as long as there are differences in character among individuals and organizations. Leaders who maintain a working knowledge of what trust is and what it looks like in their organization may be surprised when that same knowledge is not applicable in another organization. Research that identifies crossorganizational principles related to trust, while expecting and petitioning leaders to adapt those principles into practice, will be of great worth to individuals seeking to develop and understand trust.

\section{Design and Methods}

The research questions provided previously were addressed using a mixed methods approach. This phenomenological study of leaders and volunteers in the Seminaries and Institutes of Religion program employed three methods of data collection. A slightly modified version of the LMX-7 (Graen, \& Uhl-Bien, 1995) survey instrument was used to collect quantitative data from 17 coordinators and 84 volunteers. Individual interviews were also held with both leaders and volunteers. These interviews were transcribed and analyzed relative to the research questions put for in this study. 


\section{Assumptions}

Inherent in this study were potential problems that were identified and mitigated by the researcher. These problems ranged from conflicts of schedules with participants to personal biases of the author. Both problems associated with the study and biases of the researcher are discussed in the section.

\section{Potential Problems}

The organization researched in this study is directly affiliated with The Church of Jesus Christ of Latter-day Saints (LDS Church). A culture of volunteerism is prevalent within the LDS Church because there are no paid positions in its congregations of worship. This culture creates challenges for researchers because members are not quick to be openly critical of others actions. An oft-heard refrain in the church is, they are doing the best they can or you get what you pay for. Contrary to this cultural norm, coordinators in S\&I are paid for their services yet work mainly with volunteers. It is rare for church members to interact with any paid LDS Church employees at any time during their membership. A potential problem in this study, caused by a culture of accepting another's best efforts, is that of straightforwardness in answers to survey and interview questions. Coordinators generally do not want to be critical of volunteers' performance or characteristics; likewise, volunteers do not want to be critical of coordinators because they may view them as mentors and fellow members of the church.

To address this problem, the researcher made several written and verbal assurances to participants, as suggested by Creswell (2009), that any information provided would be disassociated from their names during the coding process. All data collected was placed on a secure hard drive that is password protected. All participants 
had the opportunity to amend, change, or delete entirely any statement made during interviews.

Another difficult aspect considered during this project was applying secular models related to trust to religious organizations. The author recognized that the models and theories used in this study were originally intended for application in business. The models and theories were adapted for use in this study based upon cross-discipline principles identified by the researcher. Application of principles related to trust vary based on circumstance and discipline; however, the principles analyzed were broad enough to include multiple disciplines, including religious education.

Finally, the relative nature of a qualitative project was considered by the author. Trust, its meaning and how it is perceived, varies among each individual participating in the study. The researcher recognized that a wide view of trust would not add to the discussion on trust. However, the researcher also did not want to stifle or manipulate participants into a boxed definition of trust. To address this problem, the author looked for commonalities among participant responses, and compared them to a pre-determined definition of trust and indicators of trust such as empowerment, benevolence, integrity, and ability (Konczak, Stelly, \& Trusty, 2000; Mayer et al., 1995).

\section{Bias}

The author was a member of the LDS Church and employee of S\&I at the time of this study, and as such, held some biases that were identified and addressed so as to not contaminate results. One bias included his beliefs that prompted the research questions (Creswell, 2009). The author believed that volunteers generally trusted coordinators in S\&I, but that trust was not reciprocated from coordinator to volunteer. In order to 
prevent this personal experiential belief from affecting data gathering and analysis, the author maintained a list of questions to be used in interviews that were judged by the dissertation committee to be non-biased. The author used caution when on occasion he deviated from these questions in order to obtain clarification or further information from participants.

\section{Definitions of Key Terms}

To assist the reader's understanding of the research, key concepts, and terminology, the following terms were defined and noted as important to the study.

Behavioral Trust. Actions engaged in by leaders and followers that indicates that trust is being extended.

Coordinator. A coordinator is an employee within the S\&I organization responsible for overseeing the functioning of the seminary and institute programs in a particular geographic region. Coordinators work with volunteers by helping them with administrative tasks related to their assignments and provide in-service training intended to help improve teaching efforts. Coordinators differ from volunteers in that they are paid professional employees of S\&I.

Latter-day Saint (LDS). The abbreviated title for The Church of Jesus Christ of Latter-day Saints is LDS.

Institute. The term Institute as used in this study represents a religious education program, within S\&I offered to students ages 18-30 years old. Students enroll in scripture-based classes in addition to the post-secondary classes in which they may also be enrolled. Students who may be finished with post-secondary education and those who may not be attending post-secondary education are also encouraged to enroll. Classes are 
usually held in Institute buildings adjacent to major college campuses or in local LDS meetinghouses.

Seminary. The term Seminary as used in this study represents a religious education program that is offered for students ages 14-18 years old. Specific participants in this study were assigned to labor in two types of seminary programs daily (classes held Monday through Fridays generally in the morning before school at local LDS meetinghouses), and home-study (one class held weekly, to review work students had done at home throughout the week). Volunteer teachers are assigned to teach these classes.

Seminaries and Institutes of Religion (S\&I). The LDS Church promotes and maintains world-wide religious education though the seminaries and institute of religion organization. This organization began in 1912 and now maintains a student enrollment of over 740,000 14-30 year olds. The organization also consists of over 2,200 full and part time employees and over 43,000 volunteers (Seminaries and Institutes of Religion, 2013).

The Church of Jesus Christ of Latter-day Saints (LDS Church). The LDS Church defines itself as the latter day version of Jesus Christ's New Testament Church. The Church headquarters are located in Salt Lake City, Utah.

Trust. Mayer et al. (1995) proposed a definition of trust that will also be used for this research as:

The willingness of a party to be vulnerable to the actions of another party based on the expectation that the other will perform a particular action important to the trustor, irrespective of the ability to monitor or control that other party. (p. 712) 
Volunteer. In a general sense, a volunteer is a non-paid individual who has accepted an assignment or task to accomplish. In the context of the data collected in this study, a volunteer is a non-paid individual with assignment to teach seminary or institute classes. Volunteers work closely with the S\&I representative (coordinator) assigned to their particular area to accomplish administrative tasks and seek assistance in improving the way they accomplish assignments.

\section{Significance of Research for Leadership Practices}

Many aspects of volunteerism have been studied throughout various disciplines including religious organizations and education. However, little research related to religious education and volunteerism exists, making this study unique as well as providing a foundation to shape future studies. Adding to this combination is the aspect of trust between professionals and volunteers within religious education organizations.

The data, along with the findings and conclusions of this study, will be of most interest to those within the S\&I organization seeking to understand more fully how to promote trust building interactions between volunteers and coordinators. The conclusions and recommendations based upon analysis of the findings in this study are intended to promote deepened levels of trust between coordinators and volunteers. As observed in the data, these levels of trust do appear in individual circumstances, but have not previously been generally observed or perceived within S\&I.

The findings and the recommendations of this study may appear unique or specialized for S\&I; however, the methods used and models put forth can be universally applied to various leadership practices. Though the organization used in this study was a 
non-profit, religious organization, leaders from any discipline who are interested in trust perceptions and trust behaviors in their organization will benefit from this study.

\section{Summary}

Trust is part of all human relationships, but the way it is perceived varies among individuals. Trust is an integral part of organizational success. A wealth of research exists which examines trust from the perspective of business organizations. The information related to trust in non-profit organizations is much smaller and there is virtually no research related to trust in religious education and administrations.

The study focused on volunteers and coordinators working together in the Seminaries and Institute of Religion program of The Church of Jesus Christ of Latter-day Saints. The relationships between these two groups are assumed to be crucial to accomplishing the objective of the program. The theoretical lens used to view this study was centered on theories and models that would be classified in Bolman and Deal's (2008) human resource frame. These sources were used because they recognized relationships as key to organizational success.

The mixed method design to research was used to collect and analyze data for this study. The author recognized potential problems and personal biases related to data collections and analysis and worked in prescribed ways to ensure objectivity. Rigid definitions were set forth to lessen any potential ambiguity in interpretation. 


\section{CHAPTER TWO}

\section{REVIEW OF RELATED LITERATURE}

Judeo-Christian history declares Adam and Eve as the first humans on earth placed in a role of leadership. Adam was to have dominion over all things in the Garden of Eden and Eve was to assist as a co-leader with her husband (Genesis 2:15, 18). Additional opportunities for leadership were added to this relationship when this first couple had children (Genesis 4:1-2). Though it appears Adam was placed at the head of the hierarchy in the Garden of Eden, his leadership was meaningless without the aid of his wife. Leaders may have authority to act, but also need power to influence. Leadership power may be viewed through the lens of characteristics of the leader and how they are perceived by those who are asked to serve with them (French \& Raven, 1959).

Contrary to the participative view of leadership set forth in many Judeo-Christian beliefs, leadership has also been associated with authority or the ability to impose one's will over another. Winter (1991) believed "Successful leaders and managers must use power to influence others, to monitor results, and to sanction performance" (p. 71). Katzenback and Smith (1992) detailed further that, "Leadership has traditionally been synonymous with authority, and authority has traditionally been understood as the ability to command others, control subordinates, and make all the truly important decisions yourself” (p. 129).

In the Seminary and Institute program (S\&I) of The Church of Jesus Christ of Latter-day Saints (LDS Church), over 40,000 volunteers are led by less than 400 full-time 
employees of the organization. The relationship between leaders and followers in this organization is important to study and understand from a leadership perspective. Power and control are difficult positions to take for a leader who is working with subordinates who are volunteers willingly to sacrifice their time without extrinsic motivators.

Volunteers are more likely to follow someone they perceive as trustworthy rather than someone they feel who leads from a position of power and control (Morgan \& Hunt, 1994).

The current study uses the concept of leadership and trust as seen through the relationship of coordinators and volunteers within the Seminaries and Institute (S\&I) organization. No research has been found concerning trust between these two groups. Compared to other educational organizations, coordinators function in similar ways as principals of schools while volunteers operate in a capacity similar to school faculty. Studies related to leadership and trust between principals and faculties will be part of the research work presented within the context of this literature review.

Through this review, the relevant literature and research will show how individual perceptions of trust influence leader-follower relationships. First, this review describes how and when leadership began to be tied to trust and the resulting history behind this union. Next, leadership theories and models related to trust will be examined, compared, and contrasted. Next, definitions of trust will be examined, compared and contrasted. Next, definitions of trust will be explored and considered. This will be an important discussion because the nature of trust is subjective and relative, and therefore difficult to define. Once trust has been defined, research surrounding how trust has been observed 
will be summarized. This review will conclude with recent research related to how trust can be built among leaders and followers.

\section{Historical Perspective of Leadership and Trust}

The study of leadership, either formal or informally, has appeared to be an interest throughout the recorded history of mankind. However, the amount of time leadership has been studied, pondered, or contemplated has not winnowed a definition applicable in all cases. The contrary seems to be the case. To some, a leader "connotes images of powerful, dynamic individuals who command victorious armies, direct corporate empires from atop gleaming skyscrapers, or shape the course of nations" (Yukl, 2002, p. 2). To others, a leader represents "such a vast range of associations that we must define what we mean by it before we can begin to talk about developing it" (Winum, 2003, p. 41).

This section will provide an expanded view of how research on leadership developed informally and formally over a long period of time. A discussion of leadership definition along with leadership development ideas will begin to narrow this assessment toward examining leadership research relative to trust. The issue of how and when trust began to be part of leadership research will be set forth and will include various definitions and theories. Finally, this segment will conclude with a description of what research into leadership and trust has been done, specifically among volunteers.

\section{Leadership}

The definition of leadership appears to be relative to the circumstance, experience, and perceptions of the definer. Recorded musings and studies in leadership formally began springing up over 2500 years ago. Plato established centers for leadership in the fourth century that sought to educate and develop would-be leaders. 
Selected case studies involving past rulers and kings were used as the curriculum for the course (Korac-Kakabadse, Korac-Kakabadse,\& Kouzmin, 2001). Near the same time period, but unknown to Plato, Kautilya, a philosopher of the Mauryan dynasty, located in modern day India, wrote The Arthrasastra, which became a handbook of sorts with tips for leaders to be successful (Rangarajan, 1992). Sun Tzu's (1963), The Art of War, written sometime between $400 \mathrm{BC}$ and $300 \mathrm{BC}$ remains required reading for military leaders in China and Japan. These are limited examples of numerous recorded thoughts and studies in leadership.

For centuries before these insights were written, leadership was explored and tested in practice. The great pharaohs of Egypt engaged large bodies of followers in work to build marvelous pyramids and fight in epic battles (Gardiner, 1964). JudeoChristian history explores its own connections with these pharaohs as well as examples of Joseph, the son of Jacob and Moses. The Bible is replete with stories of leadership successes and failures.

The history of leadership becomes much more difficult to trace during the twentieth century. This is not because there is a dearth of literature presented on the topic. On the contrary; the abundance of literature indicates there is much about the topic to be understood. Though leadership has been discussed by various individuals for centuries, a look at the history from a more recent perspective will provide ample information to consider for this current study. New theories of leadership emerge while building upon theories established in past research. Many of these emerging theories also conflict with those previously established, offering different opinions and perspectives (Chemers \& Ayeman, 1993; Julius, Baldridge, \& Pfeffer, 1999). 
Leadership, and its varied definitions, may be purposely ambiguous or as simply stated as the researcher feels necessary. For instance, one researcher has presented nine specific, yet different definitions of leadership (Yukl, 2002). However, many scholars choose not to define leadership, rather they judge actions of individuals and describe them as poor or good (Barker, 1997; Sergiovanni, 2000).

A sampling of studies on leadership in the first half of the twentieth century shows that prevalent research identified individuals as natural born leaders rather than trained or made. In fact, for many years it was assumed that individuals could not possibly be taught to be leaders (Clawson, 2002; Daft \& Lane, 2005). Midway through the 20th century, leadership research shifted from the idea that leadership traits occurred naturally, and expanded to view a broader population as potential leaders. Leadership began to be viewed as situational rather than universal in that leadership traits were only useful when applied in specific situations (Daft \& Lane, 2005).

Leadership today is viewed through more than just the lenses of character and traits (Bolman \& Deal, 2008). Emotional and social intelligence have become watchwords in observing and researching leaders (Goleman, 1998). Emotionally intelligent leaders are interested not only in how the work is accomplished but also how those who are accomplishing it feel. They value not only the productivity of each subordinate but also pay attention to the psychology. Leaders who have high levels of emotional intelligence sincerely listen to subordinates. They express empathy and value their moral authority over their formal authority. Similarly, socially intelligent leaders are willing to change or adapt to unforeseen problems, they are not content with their 
current skill sets as leaders and they fully expect to make mistakes and learn from them (Daft \& Lane, 2005; Yukl, 2002).

Over 60 years ago, Stogdill (1948) synthesized 124 different studies regarding the various characteristics of leaders. His research sought to solidify the premise that leaders were chosen on the basis of how they were perceived in social situations. Stogdill concluded that, "The evidence suggests that leadership is a relation that exists between persons in a social situation, and that persons who are leaders in one situation may not necessarily be leaders in other situations" (p. 65). Nearly 30 years after Stogdill (1974) presented this synthesis, he attempted to validate his original conceptualization by synthesizing 163 new studies that backed up his original claim that character and situation matters when it comes to leadership and universal leadership is rare at best.

Stogdill's (1948) first attempt at coordinating studies to identify common traits associated with leaders was followed 10 years later by Mann (1959) who analyzed over 1400 studies all related to personality and leadership. Contrasted with Stogdill's study, Mann looked at personality traits rather than perceptions of leaders in social situations. He felt that personality traits could be used to separate leaders from non-leaders. Mann found six traits that seemed to indicate this separation of leaders for non-leaders: intelligence, masculinity, adjustment, dominance, extraversion, and conservatism. More recently, Kirkpatrick and Locke (1991), added traits to the previously established picture of what leadership looked like. Self-confidence, determination, integrity, sociability, and intelligence (also mentioned by Mann) are all subjective terms used to describe characteristics of the leaders they studied. 
Recognizing the abundance of literature surrounding the topic of leadership, along with attempts to categorize it in some usable fashion, Burns (1978) introduced the constructs of transformational and transactional leadership. Within these two concepts, Burns was able to condense leadership studies, along with their various theories. Burns did not seek so much to identify the characteristics of leaders, but rather identify their interaction with subordinates. Transactional leadership focuses on exchanges between leaders and subordinates while transformational leadership practices are charismatic in nature and attempt to identify and capitalize on what drives subordinates. Burns felt, contrary to Mann (1959) but similar to Stodgill (1948), that leadership was not a result of nature, but rather a phenomena resulting from social and organizational structures.

Burns' (1978) ideas were trail-blazing in nature because he refuted much of what leadership theorists had asserted and attempted to measure for many years in order to determine what makes a leader. Burns believed "we know too much about our leaders, we know far too little about leadership" (p. 1). The implication in this statement was that leadership and leaders are two separate concepts. There are leadership traits and there are behaviors of leaders. He defined leadership as "the reciprocal process of mobilizing, by persons with certain motives and values, various economic, political and other resources, in a context of competition and conflict, in order to realize goals independently or mutually held by both leaders and followers" (p. 425). Burns began looking at leadership through the lens of relationships and then simply described what he saw. This transformational leadership style sparked a movement in leadership research that continues to this day. Leaders in the past were noted as successful by the bottom line of a balance sheet or the accomplishment of standard organizational tasks. Today 
personalities, behaviors, and relationships add to how leaders and leadership are defined (Forbes, 1991).

It has been difficult for researchers to agree upon whether or not individuals can develop traits they have found to be universal in leaders (Bass \& Avolio, 1993;

Brungardt, 1997; Ruvolo, Peterson, \& LeBoeuf, 2004). However, Burns (1978) felt that people could learn behaviors of leaders even if they could not develop the traits of leaders. Regardless of whether or not traits or behaviors can be developed, the recognition or perception of those traits and behaviors by followers has been acknowledged as being essential in order for those traits to have any effect on a leader's influence. Further, a leader who is unable to discern how they or their actions are perceived by followers, may be less effective at understanding the needs of their followers. When traits or behaviors are not perceived or perceived incorrectly, the result may be a lack of trust between the leader and subordinates. In multiple studies, subordinates have indicated that trust is a major factor in determining the influence a leader has in an organization. (Lewicki, McAllister, \& Bies, 1998; Schoorman et al., 2007; Whitener, Brodt, Korsgaard, \& Werner, 1998).

\section{Trust}

The issue of trust has been studied in various disciplines for the past 50 years. Prominent research related to trust began to spring up in the 1980s and 1990s, though some studies have existed since the 1940s. A survey of the extant literature related to trust and leadership show a number of studies from the 1960s related to trust that continue to remain valid today (Argyris, 1962; Likert, 1967; McGregor, 1967). Rotter (1967) was not the first to explore trust, but he appears to be the first to define trust as a 
concept. His work indicated that trust was essential to the success of any social group be it a family or an organization.

The lens through which leadership will be viewed in this study is trust. Trust always involves vulnerability and risk (Schoorman et al., 2007). However, the reverse is not always true. Vulnerability and risk do not always result in a trusting relationship (Sahin, 2012). When followers trust leaders and leaders trust followers, the level of vulnerability and risk with which each party is willing to engage increases. This is often noted by both leaders and followers seeking to selflessly empower one another rather than selfishly holding on to any power previously held. One challenge of developing relationships of trust between leaders and followers is that perceptions of trust can be just as diverse and broad as the individuals who are chosen to lead or assigned to follow (Mayer et al., 1995).

Researchers in the 1940s began to explore the idea that feelings of individuals could have a major impact on organizational outcomes (Mayo, 1945). Trust was first observed through the lens of societal interactions and was subsequently applied in organizations and business. Trust as a concept then began to be used to develop various leadership theories and practices (Kramer \& Tyler, 1996). Exactly when trust was first identified as a principle related to leadership within business is difficult to discover.

Stated specifically or observed overtly, trust can be seen as a catalyst or at least a significant part of many of more recent models (Chen et al., 2010; Mayer et al., 1995; Schriesheim, Castro, \& Cogliser, 1999). In addition to models, as research began to unveil transformational leadership theories, trust seemed to naturally appear within them because these theories centered on relationships. Driscoll (1978) found if leaders want to 
spark a change in their organization, they focus on trust rather than on changing employee behavior. He found many leaders felt the more subordinates participated within the organization the more committed they would become. Driscoll's research partially rejected the idea that simply working to engage more people within the organization led to more productive and efficient outcomes. He concluded participation was meaningless to subordinates if there was not also trust associated with the involvement.

In much of the research related to trust, researchers have looked to multiple disciplines such as psychology, economics, sociology and life sciences to examine evidences and interactions involving trust. This fact adds to the breadth of research involving trust and has made conceptualizing trust a difficult chore (Dirks \& Ferrin, 2002; Rousseau et al., 1998). However, most studies had to settle on a definition of trust in order to proceed. In many of these studies, a sense of helplessness seemed apparent as researchers tried to grapple with trying not to pack enough into a definition of trust, but not so much as to make the definition ambiguous. It seems that in multiple studies involving trust, there appears a standard disclaimer describing a condition in which no one has agreed on anything yet (Lewicki et al., 1998; Mayer et al., 1995).

Armed with models and definitions, researchers have attacked the issue of trust in leadership from many angles. Trust, it seems, will always continue to be studied simply because of its vast applicability to individuals and circumstances. Some research on trust has indicated trust is crucial to organizational success (Golembiewski \& McConkie, 1975; Kramer \& Tyler, 1996), while others have shown how trust correlates little to success (Williamson, 1993). 
Another difficulty noted in the study of trust in leadership is that the construct of many studies are based on previous research; however the constructs of the previous research may not always be compatible with current circumstances. For example, some theories have been set up to examine trust between subordinates and direct leaders. These same theories, however, are also applied to entire organizations in which leaders may never come in personal contact with subordinates or in organizations where the line between subordinate and leaders is very thin (Chen et al., 2010).

An aspect of trust and leadership that remains largely unexplored is the relationship between leaders and volunteer subordinates. Drucker (2005) approached the topic from a business perspective and provided strategies for product marketing, incentives for employees and practices that will help not-for-profits organizations succeed. Though many of the principles espoused may be applied in multiple disciplines, his work is fairly inapplicable to the current research project because his focus was on helping not-for-profit organizations secure funding for operations. Additionally, his views of using volunteers are slanted from a business perspective which does not relate well to other organizations, especially one whose focus is on religious education. No study has been identified that has examined trust and leadership from the perspective of paid leaders working with volunteers in religious education.

\section{Summary}

Leadership has been studied for centuries. Throughout those years, the definitions of leadership have varied as society and circumstances change. Researchers have attempted to show that leadership is either natural occurring trait within individuals or a learned skill. Hundreds of leadership theories have been classified under these two 
premises (Stogdil, 1948). Whether leaders are a product of nature or nurture, the characteristics and actions of leaders have direct impact on the actions and perceptions of those who follow. One of these perceived characteristics is trust.

Within the last 30 years, research the issue of trust relative to leadership has begun to be explored. Trust was first viewed socially and then applied to business and other organizations. Trust now appears to be a crucial element of successful organizations. However, trust between leaders and followers is difficult to measure making studies of trust sometimes appear to be subjective and only applicable to specific organizations.

\section{Theories and Models of Leader-Follower Relationships}

Compassion and concern for individuals can quickly be brushed aside or replaced in organizations by products, profits, and power. However, not all leadership practices seek for the submission of subordinates. Bolman and Deal's (2008) compilation of theories and practices centered in human resource development, referred to as the human resource frame, shows a side of leadership focused on concern for those being led.

A key tenet of the human resource frame is the notion that organizations exist for the purpose of serving human needs. Therefore, the organization needs people more than the people need the organization (Bolman \& Deal, 2008). Noting that the success of the organization is contingent on organizational growth and development, individuals are motivated to use their energy in productive ways. This action usually takes place because the organizational leadership has empowered them to act toward organizational success rather than to be acted upon by organizational functions. Leaders within a human 
resource frame seek out relationships with followers first and then expect results based upon those relationships.

Though trust and leadership may appear to have an obvious correlation, leadership theorists have not always recognized relationship characteristics, such as trust, as imperative to effective leadership. The mid 1800s through early 1900 s produced trait theorists who posed the Great Man notion that theorized that characteristics and traits of individuals were what separated leaders from those who were not chosen to lead. Carlyle (1966) surmised that great leaders were placed in such positions because of their traits and characteristics.

No matter how traits are developed, leaders' individual traits are displayed in their relationships with followers. The leader-member exchange theory (Graen, \& Uhl-Bien, 1995), Greenleaf's (2002) servant leadership theory, McGregor's (1960) theory X and Y, and Maslow's (1954) hierarchy of needs are all theories that address these leadersubordinate relationships. Additionally, Mayer et al. (1995) developed a theory of trust as it relates to leadership relationships and adds a visual construct to how trust, when perceived by leaders and followers, becomes a cyclical process creating more relational trust.

\section{LMX}

Bolman and Deal (2008) asserted that trust is born out of relationships. One theory examining trust, among other relationship characteristics, is the Leader-member exchange (LMX) theory (Graen \& Uhl-Bien, 1995). The LMX theory describes relationships that leaders and subordinates share, funneling the subordinates into two categories, in-groups and out-groups. In-group members work well with the leader and, 
as a result, the leader expresses trust to them in the form of greater responsibilities. Outgroup members simply do what they have been asked to do and do not attempt to do extra work. Though leaders are fair and respectful to out-group members, they do not seek to develop special relationships with these individuals. Because the LMX theory is a relatively new theory, the research that has been done to test the theory has centered mainly on competence of subordinates as an indicator of what develops high quality Leader-Member exchanges (Gerstner \& Day, 1997).

The LMX theory is a theory centered on relationships. However, some scholars have been critical of the LMX theory claiming it actually does not measure or assess relationships effectively (Brower, Schoorman \& Tan, 2000). Brower et al. (2000) have produced a model that implements LMX but focuses it on interpersonal exchanges rather than the large organizational exchanges that had defined LMX theory from its inception. Their research asserted that relationships were a result of perception and, to truly identify leadership through LMX, multiple sources and examples from various relationships had to be established in order to accurately assess leader and member exchanges.

The LMX-7 survey tool has been recognized as the instrument best used to measure degrees of leader-member exchange (Graen \& Uhl-Bien, 1995). As popular as the measure is, researchers have discussed the weaknesses inherent within the questionnaire itself. Some scholars feel that the LMX-7 does not address relationships completely, claiming only one question on the survey attempts to measure relationships (Schriesheim \& Cogliser, 2009). In contrast, the LMX-MDM instrument was developed as a result of the perceived shortcomings of the LMX-7 tool. Liden and Maslyn (1998) classified 120 LMX items according to proposed objective definitions used in 
measurement. The result was 38 items out of the 120 judged were identified as valuable assessments.

Chen et al. (2010) were the first to attempt to explain LMX using trust of leadership and perception of emotional intelligence of employees. They noted that LMX relationships had only been measured based upon subordinate competence. However, they also theorized that trust may play a role in developing high levels of leader and member exchanges. Further, a leader's perception of emotional intelligence of an employee had direct impact as to how much effort the leader extended to develop capability and a positive working relationship with the employee. If a leader perceived high emotional intelligence, they would offer resources to that employee that would help them grow and develop. However, if the leader was not trusted by the employee, a high level LMX would never develop regardless of what the employee received from the leader.

The study put forth by Chen et al. (2010) added to the foundation of the current study because it looked not only at the role of trust from subordinate to leader but also focuses on perceptions. Though the study relates only with how leaders perceive employees, the authors have established that perceptions of leaders turn into actions. Even when those actions are perceived to be appropriate and helpful by the leader, if the employee does not perceive them in the same way, the relationship is not deepened and may cause leaders to wonder why their actions have not produced favorable results.

\section{Servant Leadership}

A theory that fits well into Bolman and Deal's human resource frame is Greenleaf's (2002) servant leadership. A leader who operates by the tenets of this theory 
is observant to the needs and concerns of their subordinates. They rejoice over their followers successes and empathize with their struggles and sorrows. Greenleaf believed servant leaders are placed into leadership roles by those they serve rather than obtaining this stature by force, longevity, or manipulation.

Servant leadership theory posits that leaders have a responsibility to be concerned with the under-served and oppressed. Servant leaders seek to empower subordinates rather than overpowering them with institutional controls and regulations. Greenleaf (2002) noted that servant leaders are recognized by their focus on listening, empathy and their willingness to include all stakeholders within an organization.

Greenleaf (2002) believed servant leadership was an antecedent of trust in both leaders and organizations. Joseph and Winston (2005) found when subordinate perceived the characteristics of servant leadership, they also were likely to trust leaders and organizations. Their study also found that organizations perceived as servant-led had higher levels of trust among stakeholders than organizations who were not perceived as servant-led.

\section{Theory $\mathrm{X}$ and $\mathrm{Y}$}

McGregor (1960) authored the Theory X and Theory Y model of leadership. McGregor believed that most managers harbored Theory X feelings towards those they led. Theory X leaders perceive their subordinates as lazy, apathetic, and unmotivated to accomplish organizational goals. McGregor postulated that when leaders harbor these assumptions about those they lead, the assumptions become a self-fulfilling prophecy through the actions of the Theory X leader. 
Theory X leaders may respond to these assumptions by tightening control and implementing punishments. This form of leadership leads to dissatisfaction among subordinates which in turn stifles desire to improve and progress within the organization. Theory $\mathrm{X}$ leaders may also try to create a false social utopia by avoiding disagreement and debate which only serves to create lack of interest or a "go along to get along" type attitude (McGregor, 1960).

Conversely, McGregor (1960) contended that leaders who led subordinates with a Theory Y approach found greater success. Theory Y leaders created organizational cultures where subordinates are trusted and empowered to create and implement. Theory Y leaders spend very little time converting subordinates to the organizations purpose and mission; rather they construct the mission and purpose of their organization and the individuals working there. Subordinates led by Theory Y leaders often establish goals for themselves that are already in line with the organizational goals.

\section{Maslow}

Maslow's (1954) hierarchy of needs adds to the discussion of trust and how it is perceived as it relates to leadership. One main assumption of this theory centers on the needs of individuals. These needs, as they relate to organizations, must be identified correctly and then met in order for individuals to function at a level that produces results for the organization. It is in this process of identifying and providing for individuals as opposed to organizational needs, that human resource frame is understood. Maslow's theory, seen through a leadership lens, reveals individuals who may rely on the organization to provide for merely physiological needs in the form of a paycheck used to purchase food. Additionally, some individuals rely on an organization to help them self- 
actualize and reach their highest potential. Maslow's theory may be interpreted to show that individuals who have needs which are met will function in meaningful and beneficial ways that ultimately lead to the success, growth, and the longevity of the organization.

The order of the hierarchy progresses from physiological needs through safety, belonging, esteem, and finally to self-actualization (Maslow, 1954). Though the premise behind each need can be applied generally, these needs are not defined the same when viewed narrowly. For example, the need for self-actualization, or having one's potential fulfilled, is not described by everyone in the same way. Individuals view their potential differently from others views based on a multitude of varied circumstances.

Commonalities among individuals may also exist within the construct of the hierarchy because of the relative nature of the defined hierarchal levels.

Recognizing these individual differences, organizations may seek universal needs that apply to everyone no matter what part of the hierarchy they may be located. For example, the argument may be made that trust is not important to individuals whose physiological needs have not been met. Though trust does not physically feed someone, researchers have observed that optimism and motivation is felt when trust is present (Mayer et al., 1995). Leaders who operate under the assumptions of Maslow's (1954) theory and believe that needs of each individual in the organization trump the needs of the organization as a whole, customize their leadership to each person rather than treat everyone the same (Bolman \& Deal, 2008).

\section{Integrative Model of Trust}

Mayer et al. (1995) provided a conceptualized model that included three indicators of trust identified as ability, benevolence, and integrity. Mayer recognized the 
subjective nature of these terms and provided a specific definition for each one. Ability is seen in the knowledge and skills or general capabilities of either leaders or followers. Benevolence is described as the extent in which trustees and trustors feel the other has their best interests in mind. Integrity is simply being ethical, at least in ways that the perceiver of integrity identifies. Individuals that appear void of hypocriticalness are then judged to possess integrity.

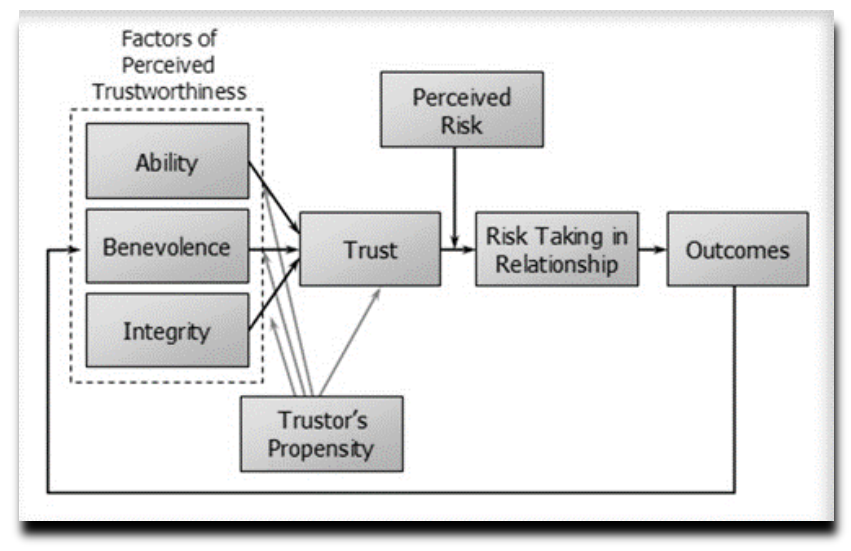

Figure 1. Integrative Model of Trust (Mayer et al., 1995)

The model further explains that when these three characteristics exist, trustors and trustees are more likely to engage in risk taking behavior. Also, leaders and subordinates recognize and accept they are vulnerable to the each other and to outcomes. When these attributes are maintained throughout the risk event and outcome, individual trust deepens and trusting relationships become stronger (Mayer et al., 1995).

\section{Summary}

Bolman and Deal (2010) human resource frame views leadership through a lens of concern for individuals within the organization. Within this frame, Bolman and Deal identify characteristics and theories that promote the idea that organizations exist to help individuals. Maslow's (1954) hierarchy of needs is a hallmark theory of the human 
resource frame because of its emphasis on human needs, both physiological and social. Both leaders and followers rely on each other to fulfill different needs. These needs may be met through a paycheck, but also may be met through interaction. These significance of these interactions can be seen through another human resource frame theory, the leader-member exchange theory.

The LMX theory examines relationships of leaders and subordinates and compartmentalizes them into in-groups and out-groups. In-group members work well with and are respected by the leader. Out-groups are often seen as incompetent or freeloaders (Graen \& Uhl-Bien, 1995). Chen et al. (2010) has used the LMX theory to examine trust and its perception. It is possible for a subordinate to be considered by a leader as being a member of the in-group, while at the same time the subordinate views themselves in the out-group.

Greenleaf's (2002) servant leadership theory also focuses on leader and follower relationships. Servant leaders are concerned about the well-being of their followers. Servant-led organizations ensure all stakeholder have a voice and feel empowered to act. These types of leaders and organizations are trusted by stakeholders at higher levels than those that are not servant-led (Joseph \&Winston, 2005).

Another human resource frame related theory is McGregor's (1960) theory X and Y. This theory concluded that leaders view subordinates as both lazy and apathetic, theory X, or as motivated and valuable to the organization, Theory Y. Theory Y leaders are more likely to trust subordinates and leaders who maintain a theory X approach. Mayer's (1995) recognition of the antecedents of trust such as ability, benevolence, and integrity justifies their identification of the presence of trust. Their 
study not only identified the antecedents but claimed that all three must be present in order for trust to exist. Studies related to trust have the tendency to become ethereal and difficult to conceptualize; however, the identification of precursor characteristics or trust, along with a simple definition, make Mayer's study less ambiguous. Much of the ambiguity is ameliorated because they embraced the relative nature of trust and worked within parameters and definitions they established from the start of their study.

\section{Defining Trust}

Definitions of trust seem to be as numerable as the people who are seeking to provide a definition (Dirks \& Ferrin, 2002; Whitener et al., 1998). However valid or preposterous a definition of trust may seem, it is crucial to have a definition within a study. The subjective nature of trust can become a pitfall for researchers looking to understand it. A clear definition of trust compartmentalizes the study making results specific and purposeful rather than ethereal and unclear (Mayer et al., 1995).

This section will present a definition of trust that will be used for this study. Further, other definitions of trust will be set forth to show how subjective a study related to trust can be. Characteristics that are sometimes used synonymously with trust will be shown to be different than trust comparative to the definition use in this study. Finally, a brief explanation will be given of how past experiences of leaders and followers can affect definitions of trust, along with their propensity to trust others.

\section{Definitions}

Rousseau et al. (1998) sought to combine multiple disciplines that rely on definitions of trust to identify a universal definition of trust. They identified that similar characteristics of trust maybe be found across varied disciplines. These characteristics 
include risk and the ability of the both the trustee and trustor to rely on each other.

Rousseau et al. defined trust as "a psychological state comprising the intention to accept vulnerability based upon positive expectations of the intentions or behavior of another" (p. 395).

Rotter (1967) defined trust as "the expectancy held by an individual or group that the word, promise, verbal or written statement of another individual or group can be relied upon" (p. 651). He believed that trust was essential to human learning. His definition indicates that the learning humans engage in is based on the acceptance of statements and insights of others without any evidence. This definition was similar to Rotter (1967) and Lewicki et al. (1998) when they defined trust in terms of the "confident positive expectations regarding another's conduct" while distrust is displayed when individuals have confident negative expectations regarding the conduct of others (p. 439).

As part of Lencioni's (2002) study, he presented a model that represented five dysfunctions of teams. Interestingly, absence of trust was the basis for the four other dysfunctions which included fear of conflict, lack of commitment, avoidance of accountability, and inattention to results. In order to understand this base point for the other dysfunctions, Lencioni believed leaders and followers needed a proper understanding of what is meant by the word trust. Lencioni believed that the ambiguity surrounding trust has caused the term to be misused thus reducing the impact that trust can have, especially among teams.

\section{Vulnerability}

Vulnerability was not only mentioned by Lencioni (2002) as a requirement for trust to be present, but other research has indicated the presence of this condition (Mayer 
et al., 1995). In leader-follower relationships, Lencioni believed that both parties needed to get used to being vulnerable so they would be able to act without worry about how it was going to affect how they represented themselves to others. This may be difficult process because competiveness seemingly trumps meekness in the workplace. However, when trust is replaced with individuals acting cautiously and suspiciously, organizations waste time and energy. Additionally, morale in the organization dives and high rates of recidivism of subordinates ensues. Mayer et al. (1995) also confirmed that though elements of multiple definitions of trust can be found within multiple studies, no two definitions are alike. Similar to Rousseau et al. (1998), Mayer found that risk and vulnerability are characteristics that seem to be present in all trusting relationships. Vulnerability and interdependence mentioned by Rousseau et al. appear to be close in definition and perhaps synonyms of one another. The definition of trust Mayer et al. (1995) proposed and also used in this study is:

"the willingness of a party to be vulnerable to the actions of another party based on the expectation that the other will perform a particular action important to the trustor, irrespective of the ability to monitor or control that other party" (p. 712). The study done by Mayer et al. (1995) not only defined trust, but also illustrated what trust was not. Through the years of research on trust, characteristics began appearing in much of the research that attempted to explain what trust looked like in order to provide a complete definition. Mayer et al. identified the common characteristics of trust as cooperation, confidence, and predictability. Additionally, they presented evidence that described how each of those characteristics stood independent of trust rather than foundational truths that trust was built upon. 
Differentiating trust from the related concepts is part of the challenge underlying the purpose of this study. Words like trust and leadership are subjective and can easily become synonymous with other words. Words such as confidence, cooperation, dependence, and predictability have all been used to modify or describe trust (Coleman, 1990; Dwyer, Schurr, \& Oh, 1987; Gambetta, 2000; Rotter, 1967). Though these terms have been used to describe trust in other research, they will not be used to describe trust in this current study. These terms, like trust, are relative to the research in which they are presented. This list is not exhaustive, but contains words that have been identified as incorrect synonyms of trust for the purposes of this current study (Mayer et al., 1995).

\section{Confidence}

Confidence and trust have potentially overlapping definitions. Previous research has accepted confidence as suitable synonym for trust. Lencioni (2002) believed trust and confidence were synonymous when he defined trust as, "The confidence among team members that their peers' intentions are good, and that there is no reason to be protective or careful around the group. In essence, teammates must get comfortable being vulnerable with one another" (p. 195). Dwyer et al. (1987) defined trust as the willingness to rely on an exchange partner in whom one has confidence.

However, the term confidence may not be as interchangeable for trust as some studies have claimed (Coleman, 1990; Deutsch, 1960). Luhmann (1998) offered a dissenting opinion, accepted in this study, concerning the connection between trust and confidence. He sought to separate the two characteristics by noting that trust requires risk, while confidence is dependent on a perception that everything will work out the way 
it is supposed to. Trust, in this case, welcomes vulnerability, while confidence seeks to limit it as much as possible to avoid surprises.

\section{Cooperation}

Mayer et al. (1995) identified cooperation as another word often used in place of trust yet disagreed with that usage. They stated that "even though trust and cooperation have at times been treated as synonymous, it is important to distinguish between them. You can cooperate with someone who you don't really trust” (p. 713). Gambetta (2000) reaffirmed this notion when he said:

As the high incidence of paranoid behavior around dictators suggest, coercion can be self-defeating, for while it may enforce cooperation in specific acts, it also increases the probability of treacherous ones; betrayal, defection and the classic stab in the back. (p. 220)

\section{Dependability}

There is also a relationship between dependability and trust (Abdullah \& Hakim, 2006). Kini and Choobinah (1998) use dependability when they define trust "as a belief in the system characteristics, specifically belief in the competence, dependability and security of the system, under conditions of risk" (p. 51). When an individual or organization is perceived as dependable and is utilized as such, vulnerability is created, which can lead to trust but does not always. Economically, vulnerability becomes a result of a dependency created by the individual and organization consistently exchanging a good or service. This dependency may, in some cases, increase the amount of trust because vulnerability is an antecedent of trust (Well \& Kippnis, 2001). Further, dependability only extends to the degree that a particular good or service is being 
provided. The relationship between trust and dependability can be ambiguous because the result of dependability may promote a type of situational trust but does not indicate overall trust of a person or organization.

\section{Predictability}

A common synonym of trust is predictability. Gabarro's (1978) study used prediction to define trust, stated, "The extent to which one person can expect predictability in the others' behavior in terms of what normally expected of a person acting in good faith" (p. 294). Rotter's (1967) definition of trust did not use the term prediction, however, within the definition of trust it was indicated that individuals could rely on others to act in expected ways. However, Mayer et al. (1995) has indicated that a definition of trust must not be limited by being defined using predictability.

Lewis and Weigert (1985) believed that predictions indicate a belief based on evidence that reduces uncertainty. They also described why prediction should not be confused with trust when they said "trust succeeds where rational prediction alone would fail, because to trust is to live as if certain rationally possible futures will not occur" ( $\mathrm{p}$. 969). Thus, trust reduces complexity far more quickly, economically, and thoroughly than does prediction. Further complicating the issue of the relationship between trust and predictability is the notion that one individual who holds a prediction that another will only act in self-promoting ways can and should be trusted. It is possible to predict the actions of another without developing trust in that particular individual or group (Mayer et al., 1995).

Illustrating their concept of trust, Mayer et al. (1995) developed the model of trust, shown earlier, demonstrating that trust exists because of perceptions of how others 
define trust (Figure 1). This model was developed not only by analyzing what trust was, but also to identify what trust is not based on their definition. To Mayer et al., trust is in the eye of the beholder. In other words, trust is present when trust is perceived by the trustee. Mayer et al. discovered a common perception commonality among individuals

who recognized leaders as being trustworthy. Trustworthy leaders had characteristics of ability, benevolence, and integrity. When trust was present, individuals would then engage in risk taking behavior. The outcome of this behavior led to a deeper sense of ability, benevolence, and integrity in the leader.

\section{Propensity to Trust}

This current study however, will not only look at how followers perceive how they are trusted by leaders, but also how leaders perceive their own trust of followers. In relation to this approach, Rotter (1967) based his definition of trust on how well others could rely on the promises made by leaders. In essence, if a leader told the truth he could then be trusted. Since Rotter's initial attempts at defining trust however, other research has indicated that trust does not only hinge upon the words or promises leaders speak or even past experiences with leaders, but also personalities (Kee \& Knox, 1970). Building upon this finding, Mayer et al. (1995) examined closely a propensity to trust as a factor determining if trust exists.

Propensity to trust has been found to be a crucial determinate of trust creation and maintenance (Aubert \& Kelsey, 2003; Mayer et al., 1995). Colquitt, Cott, and Lepine (2007) found that propensity to trust was not a significant factor in indicating if trust was present. It is clear that results measuring the effect of propensity to trust vary. Because of this disagreement, the research contained in this study will not view or attempt to 
measure trustees or trustors propensity to trust, rather, it will simply look at perception in general, recognizing that each individuals perception of what trust looks like will be different. Commonalities among the participants' responses will be explored rather than identifying individual bias or belief and the attempting to determine each respondent's propensity to trust.

\section{Summary}

Definitions of trust are numerous and vary because the relative nature of the term. Many definitions of trust focused on expectancy of others to act in particular ways (Rotter, 1967; Rousseau et al., 1998). Additionally, some research argued that trust was based on positive behavior (Lewicki et al., 1998), and could only be present if vulnerability was present as well (Lencioni, 2002). The combination of many of the definitions explored in this review helped identify a definition to be used in the current study.

This study uses the definition provided by Mayer et al. (1995) that states that trust is:

The willingness of a party to be vulnerable to the actions of another party based on the expectation that the other will perform a particular action important to the trustor, irrespective of the ability to monitor or control that other party. (p. 712)

Further, Mayer et al. (1995) asserted that confidence, cooperation and predictability are not synonyms of trust. Other research has indicated that dependability may also not be an accurate synonym of trust (Well \& Kippnis, 2001). 


\section{Recognizing Trust}

Leaders may be comfortable operating within established parameters and definitions they have established. Those parameters and definitions may be different for followers thereby producing confusion in an organization. Katz (1995) suggested that leaders must seek to develop human skills in addition to technical and conceptual skills in order to be effective. Human skills enable leaders to associate and work with those they lead in ways that will promote organizational objects and growth. Katz believed that, when leaders are aware that their perspectives and backgrounds differ from those they lead, they were then able to adapt to the beliefs and perspectives of those around them. This adaptation can then promote trust between the leaders and subordinates.

Lester and Brower (2003) conducted a study that attempted to measure how subordinate performance related to the trust the leader felt toward the subordinate. The research found that subordinates who felt their leader trusted them performed at a higher level than those who felt their leader did not trust them. Interestingly, in this study subordinates performed at a higher level when they felt trusted, but their perception of how trustworthy their leader was not a significant predictor of subordinate success. In principle, if subordinates felt they were trusted, they performed at higher levels regardless if they felt their leader could be trusted.

A leader's perception of a subordinate, along with a subordinate's perception of a leader, affects the establishment of trust in the relationship. Many studies have explored the perception of competencies of subordinates by leaders. Further, some studies have been related to the LMX model which can be used to examine leader-member interaction based on perceived competencies and relationships (Liden, Wayne, \& Stilwell, 1993). 
Other research has shown leader's perceptions of subordinates capability and emotional intelligence as they relate to trust (Chen et al., 2010; Wong \& Law, 2007). Yet, there appears to be a deficiency of research that has approached leader's perception of their trust of followers outside of studies related to characteristics that make up trust indicators such as empowerment, ability, benevolence, and integrity (Konczak et al., 2000; Mayer et al., 1995).

There is difficulty in measuring perception of trust because humans do not perceive others universally. While one leader or subordinate may perceive trust being extended or received, another may not perceive any evidence of trust. Further, locating any study that has examined whether leaders or subordinates perceived that they themselves had these characteristics has proven fruitless. This current study will address this seeming gap in the literature. In order to address this gap, standards of perceptions related to trust will be presented. Though not exhaustive, these characteristics have been recognized in multiple studies as being present when trust is present. Each of these characteristics can be applied to either trustees or trustors when determining evidence of trust.

\section{Ability}

Ability is a characteristic often recognized when trust exists (Cook \& Wall, 1980; Deutsch, 1960; Kee \& Knox, 1970). For the current study, the Mayer et al. (1995) definition of ability will be used. They stated ability is a "group of skills, competencies and characteristics that enable a party to have influence within some specific domain" ( $\mathrm{p}$. 717). 
French and Raven (1959) identified five sources from which leaders obtain power, specifically, reward power, coercive power, expert power, referent power, and legitimate power. Expert power refers to an individual's ability to be perceived as someone who has particular knowledge of a process or system. When leaders have this type of knowledge they may be perceived as knowledgeable, capable, successful and skilled; therefore, eligible to be trusted (Mayer et al., 1995). Additionally, research has indicated that when a leader is perceived as having ability, subordinates do not necessarily have to like them in order to trust them (Campbell, 1990).

\section{Benevolence}

Mayer et al. (1995) along with others have identified benevolence as another characteristic evidenced when trust exists between leaders and subordinates. (Cook \& Wall, 1980; Deutsch, 1960; Kee \& Knox, 1970). This current study will use Mayer et al. definition of benevolence. This definition states that benevolence is "The extent which a trustee is believed to want to do good to the trustor, aside from an egocentric profit motive" (p. 718).

Collins (2001) noted the success of leaders who were less flamboyant or who stayed out of the spotlight or celebrity status but rather focused on kindness to individuals. He found leaders who were "self-effacing, quiet, reserved, even shy" (p. 12) were leaders who were more likely to turn good organizations into great ones. Selflessness and humility are elements of benevolence that, when perceived by subordinates, make leaders more likely to be trusted and followed (Chopra, 2002). 


\section{Integrity}

Integrity was the third characteristic Mayer et al. (1995) hypothesized as being recognizable when trust was also present. They defined integrity as "the trustor's perception that the trustee adheres to a set of principles that the trustor find acceptable" (p. 719). Implied in this statement is that perception of characteristics such as, ability, predictability and benevolence is dependent on individual observation rather than an objective measurement.

Mayer et al. (1995) are not the only researchers to identify integrity as an indicator of trust. Becker (1998) stated that integrity included a "commitment in action to a morally justified set of principles and values" (p.157). Simons (2002) expanded on this definition when he added that integrity was based on "the perceived pattern of alignment between an actors' words and deeds" (p. 19). Simmon's definition was similar to Mayer et al. (1995) who also believed that integrity was a behavior that was perceived. This perception of integrity is based on judgments on how a leader or subordinate behaves relative to how the person perceiving the action understands the objective of the organization. However, faithfulness to an organizational purpose does not indicate integrity. Rather, if a leader or subordinate is outspoken against the organization's purpose and acts in accordance with what they have stated, they may be still be perceived by others as having integrity and as such may likely be trusted by others.

\section{Summary}

Recognizing trust in relationships can prove difficult if leaders are not aware of the perspectives and backgrounds of subordinates (Katz, 1995). Likewise, subordinates perception of leaders influence the level of trust they feel (Lester \& Brower, 2003). 
Measuring a subjective characteristic also makes recognizing trust difficult. Mayer et al. (1995) have attempted to measure the presence of trust by noting antecedents they believe will always appear in trusting relationships. Those characteristics are ability, benevolence, and integrity. Once trust is recognized, leaders and subordinates may work in ways to build trust within their relationship.

\section{Building Trust}

Extending Driscoll's (1978) findings that trust creates change faster than change programs create change, Zucker (1986) believed that trust could be created when subordinates were extended contracts. However, an increase in money or extension of a job in the contract did not seem to be the part of the contract that built trust. Trust appears as the result of the relationship that is built when those contracts are made. Fukuyama (1995) believed that a simple contract or legislation does not create trust. His research indicated that trust is built previous to the extension of contract or economics incentives. He stated that trust cannot be "legislated into existence" by organizations or governments (p. 5).

Organizations that have a solid trust base between leaders and subordinates have a competitive benefit (Tan \& Lim, 2009). Research has indicated that subordinates may perform well even when they do not feel a leader is trustworthy, yet paradoxically, subordinates desire to feel trust by this same leader (Lester \& Brower, 2003). In schools, teachers are likely to improve their ability to teach when they trust the principal (Youngs \& King, 2002). This may be because individuals who feel high levels of trust toward leaders are more likely to be less guarded concerning struggles they may be having. Additionally, when they feel trust, they are not afraid of being made to feel unintelligent 
or incompetent. When a principal senses that he or she is trusted by teachers, he or she extends more trust to the faculty and does not feel the need to implement strict control measures or rules (Tschannen-Moran, 2001).

\section{Principals working for teachers}

The statement that teachers feel more satisfied with their job as trust levels increase comes as no surprise. The trust that exists between teachers and principals has also been linked to the amount of impact teachers feel they have with students, their progression as professionals, and their success when they transition from classroom to administrative positions (Hoy \& Tschannen-Moran, 1999; Tschannen-Moran, 2001).

Within a school, no person has more ability to promote and influence a trusting culture than a principal. Obviously, based on position, the principal assumes some degree of formal authority over the faculty and staff of the school. However, successful principals rely on the skill and expertise of the teachers to promote learning within the school. Teachers look to the principal to provide them with the resources they need to accomplish the purpose of the school. When teachers perceive that principals are working in ways to accomplish the same goals they have, the effectiveness they have at helping students increases (Bryk \& Schneider, 2004). Conversely, when teachers sense an adversarial approach to leadership by the principal, they feel vulnerable, fearful and ultimately distrust the principal (Tschannen-Moran, 2004).

Teachers expect a principal to lead. Principals who set high standards for achievement are more likely to be trusted. Further, principals that take the side of teachers when there are disputes with parents, students, and even school boards, as well 
as speak truthfully and bluntly are also more likely to be trusted (Glover, 2007; Goleman, 1998; Tan \& Lim, 2009).

\section{Promoting vulnerability}

Building trust requires individuals to be vulnerable with each other. Lencioni (2002) assumed that this vulnerability, which eventually lead to trust, is developed over time as experiences are shared, assignments given are completed, and a sincere effort is made by leaders and followers to get to know and appreciate the attributes and skills of one another. Lencioni noted that leaders are required to lead the charge when it comes to displaying vulnerability. This may cause the leader to suffer some ego deflating moments but will encourage subordinates to engage in the same risks. Additionally, leaders can create a culture that accepts admissions of weakness or acknowledgement of failure (Lencioni, 2002).

\section{Empowerment}

Consideration then may be made as to why subordinates felt trusted. One concept that appears in research surrounding trust building is that of empowerment. Some research defines being empowered as confidence in capabilities, knowledge and skill Bandura (1977). Conger and Kanungo (1987) identified the empowerment, which takes place from leaders to employees, as a way to inspire employees to achieve at higher levels and does not necessarily involve delegation. Burke (1986) suggested that empowerment exists only when leaders share authority with others in relational transactions.

Delegation, either by inspiring or authorizing followers to act, is an action that may be perceived by leaders as empowering behavior. Leaders should be careful to 
recognize delegation that leads to trust and allows followers to do things their way. This may be difficult for leaders who view themselves as someone who needs to make most or all decisions within the organization (Quinn \& Spreitzer, 1997).

Principals of schools who enlist the expertise and skill of teachers to develop and implement curriculum changes, hiring practices, and professional development have been found to be perceived as trustworthy among faculty members. However, leaders do not simply inspire or authorize without ensuring that followers have the ability to act in the circumstances they are placed. Structures and conditions that encourage social trust to exist are aligned with school goals as well and promote participatory leadership among the faculty (Spillane, Halverson, \& Diamond, 2001).

Empowerment is perceived among subordinates when they see leaders engage in information sharing (Xue, Bradley, \& Liang, 2011). Information sharing does not only include keeping subordinates informed to organizational goals and events, but it also involves providing feedback on organizational and personal performance. When this feedback is offered in a way that helps subordinates feel valued or part of the team, perception of empowerment increases. Subordinates who are able to recognize how their work directly impacts the organization, they are likely to feel empowered (Quinn \& Spreitzer, 1997).

Leaders who seek to empower, enable subordinates to make decisions that can ultimately affect outcomes. Konczak et al. (2000) found the type of decisions that leaders enabled subordinates to make were crucial to perception of empowerment. Empowering leaders sought input from subordinates in three main areas: organizational goals, tasks 
and vision. Further, subordinates who were then expected to act on the plans or tasks they had developed by their leaders felt empowered.

Careful leaders, seeking to build trust, provide feedback to the entire organization and to specific individuals. Subordinates may become overwhelmed with instructions or feel attacked personally when feedback is offered. Often, these anti-empowered feelings are a result of subordinates feeling like they have little direction or training concerning a specific task or role they are to fulfill. Subordinates feel empowered when leaders view mistakes and setbacks as opportunities to learn and get better. Subordinates feel empowered when leaders understand and are involved in the tasks that need to be completed. When subordinates feel that leaders understand how and why certain mistakes were made, they are less likely to resent leaders and more likely to feel empowered (Konczak et al., 2000).

Quinn and Spreitzer (1997) produced a qualitative report echoing the confusion surrounding the definition of empowerment and noted that an objective measurement of empowerment is impossible. However, in findings from the interviews, about half of senior management felt empowerment occurred when they delegated tasks. The other half viewed empowerment as engaging in risk taking and relying on subordinates to get crucial jobs done. Those leaders who engaged in risks with subordinates accepted that subordinates would sometimes make decisions based on the idea of asking for forgiveness rather than permission. The other leaders who believed in empowerment through delegation did not like the idea of employees making decisions outside of what they felt were clear parameters. For purposes of this current study, the author will view 
empowerment through the lens of risk between leaders and followers rather than delegation from leader to follower (Quinn \& Spreitzer, 1997).

Konczak et al. (2000) developed the leader empowering behavior questionnaire (LEBQ) to subordinates working in a consumer products field to rate the empowering behavior of their leader. Sub-sections of the survey included questions concerning delegation, accountability, decision making, information sharing, skill development, and coaching. The research indicated that the model was effective at rating empowering behavior of the leaders. The model was subjected to the meaning and interpretations of the authors who centered their research on the Conger and Kanungo (1987) definition of empowerment. The definition states, "a process of enhancing feelings of self-efficacy among organizational members through the identification of conditions that foster powerlessness and through their removal by both formal organizational practices and informal techniques of providing efficacy information" (p. 474).

\section{Summary}

Organizations intent on changing culture will do well to focus processes and practices that build trust (Driscoll, 1978). Leaders and followers feel greater satisfaction in their work when they feel they can trust one another (Tschannen-Moran, 2001). In order for trust to be built, leaders and followers must be willing to be vulnerable to one another, accepting weaknesses and failures (Lencioni, 2006).

Trust may be built as leaders empower subordinates to make decisions related to their role within the organization (Conger \& Kanungo, 1987). Additionally, subordinates feel empowered when information is shared openly and honestly (Xue et al., 2011). 
When this information is often used to create goals and plans, subordinates feel they can trust leaders to sincerely listen to them in the future (Konczak et al., 2000).

\section{Conclusion}

Though the definitions of leadership are varied and seemingly countless, researchers should not get discouraged (Yukl, 2002). The relative nature of leadership and trust can either be viewed as stifling or liberating. Leaders who chose not to be stifled recognize they are individuals and not clones or robots operating in the same conditions all of the time. They become more fluid and can adapt and work with new followers in new situations. Leaders of the past often saw the bottom line and their commitment to achieve a profit by whatever means necessary, as the standard of their success. In more recent times, effective leaders have recognized that subordinates are the key to the bottom line and that results hinge upon them instead of the subordinates hinging on the results. Relationships between leaders and followers matter, and, relationships built upon trust produce more efficient and satisfactory conditions.

Whether leaders who can operate in these modern organization are born, made by themselves or by society will continue to be debated (Burns, 1978; Kirkpatrick \& Locke, 1996; Stodgill, 1948). However, what research is continually showing is that leaders will be judged not only by what characteristics they have, but what they do with those characteristics (Bass \& Avolio, 1993).

The issue of trust has only been seriously broached by leadership theorists within the last 30 years. Like definitions of leadership, definitions of trust are often ambiguous, contradicting, subjective, difficult to measure, and may not be universally applied (Colquitt et al., 2007; Lencioni, 2002; Mayer et al., 1995). Yet trust, like leadership, 
should continue to be studied because trust, or the lack of trust, has been shown to often be the difference in the success and failures of projects and organizations (Kramer \& Tyler, 1996; Lencioni, 2002).

Though all relationships do not contain trust, a relationship of some sort is required in order for trust to be present. Bolman and Deal's (2008) human resource frame focuses on relationship theories that each have elements of trust. Theories and models in this frame include the leader-member exchange theory (Graen \& Uhl-Bean, 1995), McGregor's (1960) Theory X \&Y, Maslow's (1954) Theory of hierarchy of needs and Mayer et al. (1995) integrated model of trust. While these theories, and the models associated with them, represent only a small portion research, they have been chosen because they fit well with the nature and context of this current study.

The subjective nature of trust lends itself to multiple and varied definitions. Most research on trust in leadership puts forth definition of trust to act as a lens by which the study can be analyzed. The definition of trust for this study come from Mayer et al. (1995) who have defined trust as:

The willingness of a party to be vulnerable to the actions of another party based on the expectation that the other will perform a particular action important to the trustor, irrespective of the ability to monitor or control that other party. (p. 712)

In addition to defining what trust is, there is value in defining what trust is not in order to avoid confusing the term and to narrow the scope of the study. For example, confidence, dependability, predictability, and cooperation are all words that have been associated with definitions of trust in previous research. These terms however can also 
be shown, as they are in this study, to be ineffective at describing trust. None of these terms indicate any sense of vulnerability or risk which must be present in order for trust to exist. There are however, characteristics that, when displayed, lead individuals to perceive trust in others. These terms are ability, benevolence, and integrity (Mayer et al., 1995). These terms are defined to show how they are related to trust.

Leaders and subordinates both maintain perceptions of one another. Both have perceptions of one another concerning trust. The majority of studies on perception of trust view the perception from the standpoint of subordinates' perception of leader trustworthiness (Chen et al., 2010, Colquit et al., 2007, Mayer et al., 1995). Leaders who are seen by subordinates as having ability, benevolence, and integrity are likely to be trusted (Schoorman et al., 2007). No study was identified that sought to identify how leaders perceive they are trusted by subordinates.

Subordinates who feel their leader trusts them perform at higher levels than those who felt their leaders do not trust those (Lester \& Brower, 2003). Recognizing when trust is present or not is crucial to leaders who desire their subordinates to engage in optimal levels of work. Trust is also recognized in leaders who empower subordinates to act independently rather than in rigid and prescribed ways (Konczak et al., 2000). In addition to empowering subordinates, leaders who share information and provide positive coaching and skill development among subordinates are perceived as trustworthy.

Trust has been shown to be a crucial, yet often overlooked element in organizational success despite the vast amount of research which has been done on the subject. Leaders of organizations, including administrators of secular and religious education programs may be able to affect the trust culture more than anyone else (Bryk \& 
Schneider, 2004). Thoughtful leaders will consider what their view of trust is and examine how subordinates view it as well. Once leaders recognize how subordinate view trust, they may act in ways that will build trust which will lead to greater organizational results (Youngs \& King, 2002). 


\section{CHAPTER THREE \\ RESEARCH DESIGN AND METHODOLOGY}

The degree to which trust affects organizations is not undervalued by those who study groups and leaders. Covey (2006) stated,

Trust impacts us 24/7, 365 days a year. It undergirds and affects the quality of every relationship, every communication, every work project, every business venture, every effort in which we are engaged. It changes the quality of every present moment and alters the trajectory and outcome of every future moment of our lives, both personally and professionally. (p. 2)

Leaders may merely mention trust in passing, or reference it as an essential part of doing business and then move on to what they really feel affects the bottom line (Gambetta, 1988). However, multiple studies confirm that issues related to trust do affect organizational outcomes, sometimes more dramatically than expected (Wyatt, 2002).

Studies on trust are voluminous and analyze a wide range of organizational disciplines and leadership styles. Yet, among this vast landscape of resources, very little research exists in the field of non-profit organizations. Even less exists related to religious education programs; and no research has looked specifically at trust in the Seminary and Institute (S\&I) positions of coordinator and volunteer teacher within the LDS Church. Through this study, trust, as is perceived by coordinators and volunteers, will be identified. Factors that play into coordinators' and volunteers' perceptions of trust will also be illuminated. 
In Chapter One of the current study, definitions and dilemmas related to identifying trust and its place in organizations were explored. In Chapter Two, those definitions and dilemmas were paired with a demonstrated need for research to be done concerning trust in religious education programs, namely the S\&I organization of the LDS Church. Chapter Three will combine the lenses of Bolman and Deal's (2008) human resource frame, McGregor's (1960) Theory X and Y, and the Leader-member exchange theory also known as the LMX theory of leadership (Northouse, 2010) in order to form the framework for this study. Using these three theoretical frames, the research design, participants, data gathering, data analysis procedures, and the study limitations will be explained and summarized.

\section{Purpose}

The purpose of this study was to fill the void in current research related to perceptions of trust among volunteers and coordinators in S\&I by identifying what characteristics and actions they maintain that are perceived as trustworthy. The current study was not an analysis of the benefits or problems associated with perceptions of trust; however, this study viewed trust as a necessary component in achieving organizational goals and objectives. Additionally, the results of this study sought to determine what factors contributed to coordinator trust of volunteers and volunteer trust of coordinators.

\section{Research Questions}

Within the context of this study the following three research questions were posed as they relate to the constructs of trust perceived by leaders, trust perceived by volunteers, and evidence of action that indicates that trust in present between leaders and volunteers. 
1. How do volunteers in a non-profit religious education organization perceive their trust of coordinators in the organization?

2. How do coordinators in a non-profit religious education organization perceive they are trusted by volunteers in the organization?

\section{Design for the Study}

This study of coordinators and volunteers in the LDS Seminary and Institute (S\&I) program of the US Southern Plains area was a phenomenological exploratory project (Creswell, 2009). The study sought to identify how trust was perceived among coordinators and volunteers. In a sense, this project may also be viewed as a form of program evaluation because the relationships between coordinators and volunteers have been identified by the organization as crucial to organizational outcomes (Creswell, 2009; Church Educational System, 2003).

The methods implemented in the research were mixed, relying on both qualitative and quantitative data gathered in order to answer the stated research questions (Johnson, Onwuegbuzie, \& Turner, 2007). The two research questions in the study relied heavily on qualitative data collected, while the answer to the third question depended mainly on quantitative survey data. A mixed-methods approach broadens the understanding of perceptions of trust related to coordinators and volunteers in S\&I. To date, trust has not been examined either qualitatively or quantitatively in any S\&I related study. Further, the mixed method approach to this study was used to provide a variety of ways participants could provide data for the study from simply taking a survey to participating in an interview (Emerson, Fretz, \& Shaw, 2011). 


\section{Participants and Sampling Procedures}

The participants used in this study were coordinators and volunteers in the S\&I organization assigned to the US Southern Plains Region (USSP) when the research was conducted. Though S\&I is a worldwide organization, the researcher was asked by S\&I administrators to study a regional sample of coordinators and volunteers. Each of these individuals came from similar geographical areas and societal cultures.

A convenience sample (Creswell, 2009) of 25 coordinators employed by S\&I in the same region were used in this study. A recruitment script was sent via email to each coordinator alerting them to the opportunity to participate. Each email also stated they had the option to not participate. The following day another email was sent with a link to a survey used for the study. A preliminary question to the actual survey instrument used, asked the coordinators to indicate if they were interested in participating in an interview. Based upon their affirmative indication, they were then invited to participate in those opportunities. The selected coordinators for the study work daily with volunteer teachers. Every S\&I coordinator has sufficient opportunity to interact with volunteers, so ample data related to the subject of the study was available and relevant.

A convenience sample (Creswell, 2009) of 89 volunteer teachers with S\&I was used to participate in this study. The volunteers all served in the same region as the coordinators used in this study. The names and contact information of volunteers was collected by the author from the S\&I area office located in Dallas, Texas. A recruitment script was sent to each volunteer who had a valid email address alerting them to the opportunity to participate in the study. An option to not participate was also included in the initial email. No particular attribute, characteristic, location (other than the general 
region this study covered) or circumstance determined participation. A follow up email was sent the next day with a link to a survey used for the study. Further, a preliminary question to the actual survey instrument used asked volunteer teachers to indicate if they were interested in participating in interviews related to the study. Based upon their affirmative indication, they were then invited to participate in those opportunities.

\section{Data Collection}

Several steps were taken to assure this study maintained a sound design before and during the data collection stage. The summary of these steps are presented in the sections that follow while a brief description is given here. First, from the literature reviewed, it was apparent that no quantitative instrument had been developed for use to measure perceptions of trust within a unique organization such as S\&I. This required the researcher to identify what tools had been used to measure trust perception in other disciplines, choose a suitable instrument, and then adapt the instrument to be used with participants in the current study. Second, a variety of statistical procedures were considered in analyzing the results of the survey to determine how trust is perceived.

The researcher chose to use a concurrent embedded strategy (Creswell, 2009) in order to integrate and compare both quantitative and qualitative data. This model allowed the researcher to collect and analyze qualitative and quantitative data in order to gain a deeper perspective. Planning and preparation for the interviews, which comprised the qualitative portion of this mixed methods study, were done in accordance with current guidelines for qualitative research (Creswell, 2009). 


\section{Quantitative Data Collection Procedures}

Quantitative data for the research was collected through the use of the LMX-7 Questionnaire (Graen \& Uhl-Bien, 1995; Appendix B). The wording of the survey questions were changed slightly to make them connected to the S\&I organization and a section for short answers was added. Both groups were asked to assess the quality of exchange using a five-point Likert scale. The survey instrument consists of seven items that characterize the overall effectiveness of the relationship between the coordinators and volunteers. The researcher felt that identifying the strength of relationship would help to identify perceptions of trust within both coordinator and volunteer groups.

There were 26 coordinators and over 1200 volunteers in the USSP area of the S\&I program at the time this research was conducted. An email was sent to each of the 26 coordinators and over 300 randomly selected volunteers informing them of the potential to be involved in this study. The email contained a letter regarding informed consent (Appendix A) as well as a link to the survey instrument questionnaire on Qualtrics, an online research program. In this manner, a comprehensive sample of all applicable coordinators and volunteers in the US Southern Plains Region (USSP) was achieved.

\section{Qualitative Data Collection Procedures}

Qualitative research holds potential for rigorous and methodologically sound inquiry into examining the questions put forth in this study (Creswell, 2009). The objective of the qualitative date collection procedures described in this section was to provide participants an opportunity to be a voice and a model to the findings of the study.

Interviews. There were 16 interviews conducted, seven of which were with S\&I coordinators and nine with S\&I volunteers. The author conducted each interview after 
having collected an informed consent form and explaining again at the time of the interview the options the interviewee had to refrain from participation. Questions generated for the interviews (see Appendix D) sought to provide insights into the research questions presented in this study. Each interview lasted between 45-60 minutes and an audio recording of each interview was arranged. Each interview was transcribed by the researcher.

\section{Human Subjects Protection}

Each participant was given the opportunity to review an informed consent form (Appendix A) before beginning the survey or interview. The form explained the purpose of the study, the amount of time required by participants, an explanation of what would be done with the data, and potential risks involved in participating. Participants agreeing to continue in the study were asked to sign the form either electronically when taking the survey, or on a hard copy form available before the interview.

The University of Missouri's Internal Review Board (IRB) approved the structure of the interviews as well as the contents of the questionnaire used in the study.

Additionally, the author received approval for the questionnaire used in the study from the S\&I educational research committee. The information collected from the survey was stored to an internet-based survey collection system called Qualtrics. This online survey system was used to retrieve the data from all respondents and was password protected so that only the researcher could obtain the data. Transcripts and audio recordings of the interviews, as well as all other notes were stored in a locked file cabinet only accessible by the researcher. 


\section{Data Analysis}

The concurrent embedded model (Creswell, 2009) was used in data collection because of the mixed method approach to research. The model allowed the researcher to conduct a survey in order to gather quantitative results while at the same time gathering qualitative data as well. In this phenomenological study, the researcher was able to obtain a broader view and understanding of data related to the research questions through the use of this model. Qualitative and quantitative data was analyzed according to traditional methods, but the concurrent embedded model permitted qualitative data to describe quantitative data and quantitative to describe qualitative.

\section{Quantitative Data Analysis}

Data obtained through use of the LMX-7 (Graen \& Uhl-Bien, 1995) instrument was analyzed using a scoring system developed by the authors of the instrument. Each response to a question was given a point total. Point totals were arranged in two ways; first, the combined sum of points from all questions on the survey was collected. Second, the combined sum of points from individual questions was also collected. The scoring system associated with the LMX-7 survey gives a descriptive term identifying what level of leader-member exchange existed. Identifying the level of leader-member exchange will provide insight into how volunteers and leaders perceive their relationships one with

another. These questions highlight the presence of three antecedents of trust identified by Mayer et al. (1995) as ability, benevolence and integrity. Questions on the LMX-7 survey not only deal with perceptions of these indicators of trust, but also recognize behaviors associated with these characteristics. These leader-member exchange insights 
were then compared and contrasted with the collected qualitative data in order to understand insights offered during the interviews..

\section{Qualitative Data Analysis}

The researcher analyzed significant statements and descriptions along with quantitative survey data. Creswell (2009) detailed a process, followed by the researcher, in which data analysis could be done. This process was adapted for use in the concurrent embedded strategy used for data collection and analysis in this study.

Organization. The data obtained in interviews was transcribed. Any notes taken during interviews with volunteers and coordinators were collected. Each data source was then arranged depending on what source the data was collected.

Coding. The researcher transcribed the audio recordings of the interviews and used Creswell's (2009) “qualitative code-book" (p. 187) to develop a thematic focus for the main ideas related to the construction of the interview questions. The author chose to code the interviews in the following manner: (a) ability (b) integrity (c) benevolence.

Descriptions. The coding process allowed the researcher to generate a description of the study participants as well as a rendering about places and events observed. These descriptions added clarity to the data presented in the findings. They also contributed to an illustration of settings and people, which promoted a thick and rich view of the data.

Interpretations. The researcher made interpretations of the data by considering and comparing data to the literature, theories, and quantitative data gathered for the project. The researcher considered not only what insight emerged from the data, but also 
what those insights meant. The interpretations raised new questions not considered by the researcher which are located in later sections of this study.

\section{Validity}

Accepted methods of establishing validity of findings of both qualitative and quantitative data were implemented in this mixed methods study. The survey instrument (LMX-7) used in this study also maintained a scoring system that has been used in multiple studies. The content of the survey questions remained the same but small changes in wording were added in order to be adapted to this study. Transcripts were checked to insure that they did not contain obvious mistakes.

One of the most important ways validity was established in this study was through the member checking process (Creswell \& Miller, 2000). Participants were given the opportunity to check how their responses were portrayed by reading the completed findings section before the dissertation was published. Findings were provided in advance of publication to participants for their review. Participants' comments were relied on heavily throughout Chapter Four of this study. The words of the participants were able to add credibility to this study not only in what they said, but also by their involvement in the review of the raw data and findings.

The coding of the transcripts was compared to previously determined definitions established for the study to ensure consistency of interpretation. A member of the dissertation committee cross-checked the codes in order to establish inter-coder agreement. Members of the dissertation committee reviewed data collection and analysis practices and offered expertise and insight as experienced researchers (Creswell, 2009). 


\section{Limitations}

The mixed method nature of the study, though chosen because of its ability to provide broad understanding of the data, has inherent weaknesses and limitations. The nature of a mixed method study required an extensive data collection process. One problem associated with such a venture was that the researcher was relatively inexperienced in quantitative and qualitative methods of research. Some criticism exists that researchers should either pick a qualitative or quantitative model instead of trying to combine the two. The mixed methods approach to research is still a relatively new design and the researcher found difficultly in interpreting and analyzing quantitative data in a qualitative way (Onwuegbuzie \& Johnson, 2006).

Another limitation revolves around the size of the organization studied. The S\&I program of the LDS Church is a worldwide organization with thousands of employees. As such the task of developing a complete organizational evaluation in relationship to trust was impossible to accomplish financially and logistically as part of this dissertation. The researcher was limited to a specific region to study, thereby making findings dependent on a static social and demographic sample.

Finally, the analyses process the researcher engaged in was subjective in nature. The researcher questioned if it was possible for one individual to observe and identify another individual's perception of trust through statements made in an interview. Though recognizing trusting behavior seemed obtainable, recognizing when someone perceived trust was difficult. 


\section{Summary}

Upon completion of the review of literature, it was apparent that few, if any, studies had viewed perceptions of trust in non-profit religious education programs. However, the review of literature did highlight the overall need for leaders to identify actions that aid in perception of trust. Bolman and Deal's (2008) human resource frame, accompanied by LMX theory (Northouse, 2010) and McGregor's (1960) Theory X and Y were essential in identifying and studying perceptions of trust within coordinator and volunteer relationships.

The mixed research design and methodology used in this study was dictated by the purpose of the study as well as the research questions. The purpose of this study was to fill the void in current research related to perceptions of trust in volunteer religious education programs by identifying what actions of volunteers and coordinators in S\&I are perceived as trustworthy. The research questions considered how coordinators and volunteers perceived trust and what indicators influenced those perceptions.

The analysis of the data began with the information collected from the LMX-7 (Graen, \& Uhl-Bien, 1995) survey instrument. Qualitative research in the form of transcripts from interviews was also collected and analyzed. The data gathered from the analyses of these sources allowed for the researcher to see themes related the purpose of the study and research questions emerge.

The ensuing chapters of the dissertation are organized in such a way as to analyze the data in Chapter Four and draw inferences and conclusions from the analyses in Chapter Five. These chapters offer limitations of the study as well as inferences that may 
be drawn and conclusions that may be made as a result of the research.

Recommendations for future research will also be addressed. 


\section{CHAPTER FOUR \\ PRESENTATION OF FINDINGS}

The purpose of this study was to fill the void in current research related to perceptions of trust among volunteers and coordinators in S\&I. This study sought to fill this gap by identifying characteristics and actions of coordinators and volunteers that are perceived by one another as evidence of trust. This chapter will present the findings collected from survey data and interviews by the researcher.

The mixed method of data collection consisted of 101 participants who completed a modified version of the LMX-7 survey. Additional data was collected in interviews with 7 coordinators and 9 volunteers. The length of each interviewed varied from 15 to 50 minutes. Survey respondents and interviewees were from the US Southern Plains region of the S\&I organization. More specifically, while the majority of the interview participants were from Texas, others came from Oklahoma and Arkansas. Survey data was anonymous, and respondents to the survey will be referred to as survey respondents throughout this chapter. Data collected in interviews was confidential. To protect the identity of those who contributed in the interviews, participants will be identified as volunteer or coordinator followed by a number to distinguish between interviewees.

As the researcher reviewed the data collected, general overarching themes began to emerge relative to the following research questions:

1. How do volunteers in a non-profit religious education organization perceive their trust of coordinators in the organization? 
2. How do coordinators in a non-profit religious education organization perceive they are trusted by volunteers in the organization?

The emergent themes were collapsed into major categories that answered each of the research questions. Within the analysis of the categories several sub-themes emerged. The remainder of this chapter addresses the two research questions in light of these emergent categories. Data collected from the interviews and observations are used to explain and support the answers to each research question.

\section{Volunteer Perception of Their Trust of Coordinators}

This section will contain findings collected in survey and interview data. Result of survey data will be presented first. Results from interview data will appear directly after the survey data.

In order to answer the first research question, volunteers teachers responded to questions contained in a LMX-7 survey. Questions from the survey were used to determine the level of exchange between volunteers and coordinators. Point values of 1 (low exchange) to 5 (high exchange) were assigned to each response. The researcher analyzed point total for individual questions as well as point totals for the entire survey.

Additionally, volunteers were interviewed concerning their opinion of the coordinator assigned to assist them. The researcher formulated these questions to elicit responses that would help him determine whether the antecedents of trust, namely ability, benevolence, and integrity were visible. Categories of effective teaching, helpful or discouraging training and genuine or self-serving administration emerged from the data. 


\section{LMX-7 Survey Data Results}

The LMX-7 survey (Graen \& Uhl Bien, 1995) administered to volunteers measured exchanges between volunteers and coordinators. Results from the survey indicated volunteers sensed a healthy relational exchange with their coordinator. An overall score of 26.52 was calculated which placed volunteers well into the high level of leader-member exchange category. Figure 2 provides a summary of the volunteer LMX7 results.

Volunteers responses to question 1, 5, and 6 (Appendix C) yielded average scores of over 4. Question 1 received the highest score of all questions, 4.07, which indicated volunteers felt there was a High chance coordinators would use their influence to help volunteers. In question 5, volunteers scored a 4.01 which indicated they agreed that coordinators would defend them if a decision they made was ever called into question. Question 6 received the second highest score of the survey, 4.06, and indicated that coordinators mostly recognized volunteer potential.

Responses that recorded a score of lower than 4 were questions 2,3,4, and 7. Question 2 sought to determine how volunteers viewed their working relationship with their coordinator and yielded a result of 3.74. This score placed volunteers between better than average and extremely effective. Question 3 asked volunteers to indicate if they believed the coordinator was satisfied with the way they fulfilled assignments. Volunteers collectively rated themselves at 3.54 which placed them in between sometimes and fairly often. Question 4 prompted volunteers to consider how well they thought coordinators understood volunteer needs. The score for this question was 3.89 which placed it in the quite a bit category, but very close to a great deal. The lowest 


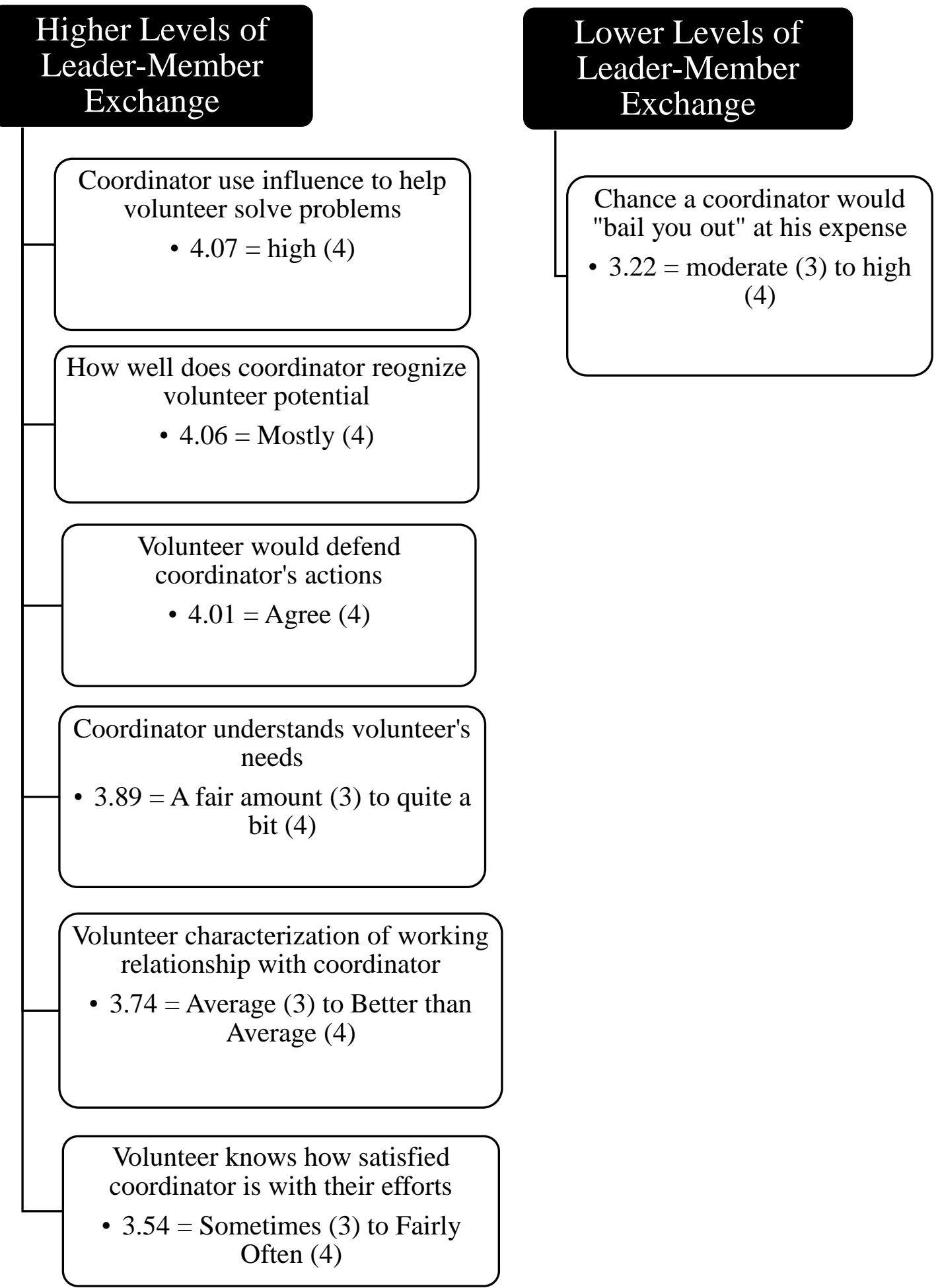

Figure 2. Volunteer results of LMX-7 survey. 
point total was attached to question 7. A score of 3.24 indicated that volunteers felt there was a high chance coordinators would help them out of difficult situations even at the expense of the coordinator.

\section{Effective Teaching}

Volunteers who participated in this study were overwhelmingly positive in the way they described the teaching abilities of the coordinators who assist them in their assignments. Volunteers are able to observe coordinators teach in classroom and training settings. One of the categories to emerge from the transcripts was that of effective teaching. Within this category the sub-themes of Model teaching and Impactful teaching emerged.

Model Teaching. All survey and interview data collected indicated volunteers overwhelmingly believe coordinators are good teachers. Sometimes the praise volunteers shared also came with contemplative thoughts such as one survey respondent who lamented, "Not being a trained professional teacher, I lack the experience that he has." Another survey respondent added, "I have seen him engage the kids in a lesson where they don't even recognize they are being taught and they remember what was taught. I would like to teach like that."

The researcher asked each of the volunteers interviewed how they felt the coordinator they were assigned to work with would do if they had the same assignment. All participants responded in ways that indicated they felt the coordinator would do a better job than they were currently performing. Volunteer 1 posited:

I think he is a model teacher. He instructs us in the way that he would instruct the

kids. So, he uses us as real life models. He actually goes through the steps of 
teaching us how to teach. I have seen him interact with kids and the way that he engaged them was also a model for us, the teachers.

Volunteer 3 stated, "I think he is fantastic. I've been very impressed with his ability to teach in the way that encourages us to think deeper...he is able to inspire a class."

One volunteer (7) had the coordinator offer to teach her class. This practice of coordinators teaching in classes while volunteers watch is not a common practice in the US Southern Plains region of S\&I. Volunteer 7 agreed to the offer made by the coordinator and was impressed with how the students responded. She said, "He is a really sharp guy, I didn't expect a whole lot but I was blown away with how effective he was as a teacher."

Impactful teaching. The ability of a coordinator to teach in a way that left lasting impressions upon students was noted by 2 of the 9 volunteers interviewed. Volunteer 1 stated:

I saw him teach in a large group setting. The way he presented the lesson, they [students] did not realize they were actually getting a lesson, but it stuck. I've got two kids in my class, and we recently talked about the lesson, they didn't realize it was a lesson, but their take-away from it stuck. He is good teacher.

Volunteer 9 concurred when he shared; “I don't think I have ever seen him teach where I have not been inspired to do something better, or to be something better."

\section{Helpful or Discouraging Training}

One of the overall categories that emerged during the analysis of the transcripts was that of the training provided by coordinators. Volunteers were somewhat mixed in 
their opinion of how well coordinators provided training. Within this category, the following sub-themes emerged: Training encourages and Training discourages.

Training encourages. Training meetings provide volunteers opportunities to form opinions and relationships with the coordinator who is responsible for instruction. A survey respondent believed that "several times" the training the coordinator provided, "has been a direct answer to prayer." Volunteer 5 indicated that these meetings are where she began to view the coordinator as, "Kind of like a mentor. When the seminary teachers meet for a monthly meeting, he gives pointers and kind of excites the teachers and offers ideas on where to get information and how to improve teaching skills." Volunteer 2 sensed the coordinator was, "Very smart and knowledgeable in what he says and he is very focused on it. I can tell he studies a lot. I imagine he studies a lot about teaching and the gospel." One survey respondent believed the coordinator they worked with maintained, "A wealth of information and knowledge that could help me overcome any problem I have." Another stated, "Whatever contact I have with him is very positive and I generally come away from training meetings with new ideas and confidence that I could come to him if I had a problem and receive the help that I need."

Many volunteers look to the coordinator as the expert on teaching, but a few noted the coordinator incorporates their discoveries and practices into the training he provides. Volunteer 3 stated, "I once shared with him an idea and he brought it up in one of our training meetings. He clearly listened to me." A survey respondent said, "I am a first year teacher, but he has passed on ideas I have had to other teachers and reiterates his trust in me that I can improve." Volunteer 4 was impressed that during a training 
meeting, the coordinator "encouraged me to do things that work in my class and not just become a clone of him. He said, if it works here, keep doing it."

Volunteer 3 described receiving personalized training that came in the form of feedback after her class. She welcomes the coordinator into her class because she knows she will be better for it. She said:

He gives direct feedback. Whether phone conversations, texts, email, or person to person. He is always positive and always helpful. Even when he has seen where I could improve, he will give suggestions, but has shared his gratitude for my efforts. And when he has seen successful efforts on my part, he, and I believe very sincerely, and not just generally or vaguely, compliments or acknowledges such efforts.

A survey respondent, who also participated in training by the coordinator, felt their confidence was bolstered to the point where they felt they could succeed at the assignment. "Just about the time I think I will never match up with his qualifications, he shares a situation from his teaching days that shows he dealt with the same issues we do."

Training discourages. Though none of the interviewees indicated they believed the coordinator did a poor job training, 3 of the 9 expressed frustration that the training did not translate into improved classroom performance. Volunteer 2 expressed his confidence in the training the coordinator provided, but blamed himself when the training did not translate into success in the classroom.

A lot of his ideas are really good ones, so I want to implement them, but sometimes I am not able to like I want to. Sometimes in in-service you get this rosy view and then you go to your classroom and you are like, I am not sure how I 
am going to do this. It seems so easy there, but here you know, I don't have that relationship with the students yet that I need I guess.

Participants who responded to the survey seemed to speak more critically of the training than did those who were interviewed. One survey respondent said, "The coordinator I work with now puts too much emphasis on cutesy teaching gimmicks and administrative processes, at the expense of helping the faculty develop solid teaching skills and providing an example of focus on doctrinal background." Another survey respondent bemoaned, “There are many times I leave training feeling completely overwhelmed by the enormity of the task. I don't think he realizes that I feel that way. The training doesn't seem to be tailored to our specific needs. It seems more general." Another volunteer felt training was not helpful, but tried to not directly blame the coordinator. The respondent wrote, "It's difficult for him to really know the challenges facing my small class of students or my personal challenges in teaching."

Other volunteers also questioned if the manner in which the coordinator offered feedback was really the most effective way to help them improve. The survey respondent said:

I currently have a hard time trusting him to enter my home to "observe" my class. This is because he has been over-zealous about teacher evaluations. Instead of feeling like he is observing my class and genuinely wanting to encourage me to be a better teacher, I feel that he is critiquing me, and I don't trust him to have a genuine interaction with my students.

Volunteer 8 was particularly discouraged by the training his coordinator provided during a class visit. The visit seemed "cold and unappreciative." Volunteer 8 shared the 
circumstances of the visit which he felt told the story of the discouraging training the coordinator provided:

So when he comes to our class to quote unquote observe, the last two times he brought along with him a sheet or a checklist and during class he's like marking it and stuff, like filling it out and it's kind of hard, I do my best to block it out because I feel like this is not my paid job I feel like I am doing my best. And then after that, he sends out an email to everyone to pick a topic to work on to get better and them email him to let him know what it was so that the next time he came to visit he could focus on that one thing and observe that one particular thing to teach us so that we could be better at it...it's not a comfortable learning environment for me.

\section{Genuine or Self-Serving administrating}

Volunteers seemed to become more passionate as questions turned to how their coordinator functioned in an administrative role. Respondents to the survey as well as interviewees noted both positive and negative aspects to the way the coordinator administered the seminary and institute programs. Within this category the following sub-themes emerged: Inspired administering, Informal communication, Unrealistic expectations, Genuine concern, Responding to needs, Coordinator disinterest, superficial validation, Allegiance to policy and Fickle and unguided decisions.

Inspired administering. One observation that emerged regarding genuine administrating was the inspired advice which volunteers' perceived coordinators to give. Volunteer 6 noted a particularly difficult situation in which a coordinator was able to administer effectively: 
Three weeks ago one of my students' father passed away. So I was put into a situation of what should I do and how should I handle it. I had received an email from my coordinator yesterday that let me know what I needed to do and expressed confidence that I could help this student. I felt uplifted and inspired by the things he said.

Volunteer 5 shared, "I feel like I am more comfortable going to him for questions than I am my stake leader." Another volunteer (4) was concerned that her coordinator had forgotten her concerns, but was encouraged by his apology:

There was one time I sent him an email and I usually get an answer within 24 hours, but most of the time it is within a couple of hours. This one time, I didn't receive an email back and it was a frustration email kind of like this is what is going on and this is what is happening. I didn't get a response back for about a week. Then he apologized and said 'I read this and was thinking about it' and it kind of slipped his mind and then he wrote back and pretty much said I was handling it the right way and to let him know how things go. The next couple of times I emailed him, I had an answer within an hour.

A high level of engagement impressed one survey respondent, "When I come to him with a problem, he makes it his problem too. He's very supportive, and helps me look for solutions."

Informal communication. Coordinator emails were mentioned 24 times throughout the survey data as forms of positive communication volunteers received. One volunteer (9) remembered receiving a personal, unsolicited email from a coordinator that helped her feel appreciated and closer to the coordinator. Another volunteer (2) felt 
special personal interaction outside of formal training has led to a beneficial relationship with the coordinator:

Communication has been the key to establishing a good working relationship. Had I not had a couple of extra assignments that required me to work with my coordinator, I would have a much different relationship. I have visited his work place and have called him on a couple of occasions for advice. The contact outside of ordinary meetings and functions has helped me feel I have developed a solid relation with my coordinator.

For many volunteers the only interactions they have with the coordinator are in formal training meetings, however, when the opportunity has been presented to spend time informally with coordinators, the volunteers have responded positively. Volunteer 4 related, "He was actually at our church building Friday of last week. All the teachers just gathered in the hallway and just were able to talk after class easily with him." One survey respondent expounded on this feeling:

I spent about 2 hours with my coordinator one day and really enjoyed my time with him learning about seminary and seminary in the area but also learning about him and his family so I feel like after that I can reach out to him about anything. Now we know each other beyond in-service because we have had some one on one time. He is my boss, or he is my leader, he is someone in charge, but I also feel he is a friend.

A few survey respondents attributed their success in the classroom directly to the personal contact they have either formally or informally with the coordinator. Other volunteers sensed that personal contact would be helpful, and feel their contact with the 
coordinator is either non-existent or minimal at best. A survey respondent noted, "There is a camaraderie and understanding, but we don't interact directly often enough for me to say I have a better than average relationship with him." Another respondent reported, "I see him once a month in teacher training. It is difficult for him to really know the challenges facing my small class of students or my personal challenges in teaching." An additional respondent explained, "I don't know that he knows me much as an instructor or teacher. I have not invited him into the class to participate, I think it would help if he did come."

Unrealistic expectations. Some volunteers sensed coordinators were disconnected from the plight of volunteer teachers. Some sensed coordinators had unrealistic expectations they put on volunteers to accomplish administrative tasks. One volunteer lamented in a survey response, “I don't think the coordinator understands or even knows of the challenges specific to my ward [church congregation]." Volunteer 8 described this disconnect:

I think most full-time seminary workers do not fully understand what a demanding calling it is for those of us who are employed in other jobs. I sense a 'Utah mentality' from virtually all of the S\&I workers and I believe the seminary burden is added to unnecessarily. It is ridiculous.

The sentiment that coordinators often promoted unrealistic expectations resonated with other volunteers as well. The survey response illustrated this feeling:

Sometimes I feel the coordinator forgets how much is asked of a called teacher [volunteer]. They continue to ask them to do more menial things which can take away from their real purpose. One teacher I know is working 50-60 hours a 
week. She has three children at home and needs to run a household. When they ask teachers to attend more meetings or complete more surveys etc. I feel that sometimes the focus has been lost.

Genuine concern. The majority of volunteers who participated in this study felt the coordinator they were working with truly cared about them. A survey respondent observed, "He coordinates over 60 teachers. That is a lot of teachers to keep track of; he knows my name and face." Another explained, "We communicate daily and work well with one another. We know each other well and we talk frankly about any topic related to seminary." Some indicated they could not provide specific examples but felt their coordinator cared when they were in his presence. Other volunteers were able to describe moments when they witnessed genuine concern on the part of the coordinator was in the way he responded to their needs and concerns.

In some instances, volunteers have been deeply affected by the genuine concern the coordinator has shown for them. One volunteer commented, "He is very encouraging and always supportive in his interactions both in person and over the phone. He was the one who made me feel like I could actually do this calling which I felt I was inadequate for." Volunteers are able to sense how the coordinator feels about them and it affects the way they approach the coordinator in return. A survey respondent explained:

Through my interactions with the coordinator, I have found him to be a man of God and filled with the Spirit. I believe that he cares about me and my students. I know that he has our best interests in mind and I trust the decisions that he makes on our behalf. 
Two other volunteers agreed and they responded, "I feel his genuine love and concern for the students we are in charge of as well as concern for how I am doing and how I feel I am doing in my calling." And, "I just feel like he wants us all to succeed, and will do whatever is in his power to do that."

Volunteer 9 personal experience with her coordinator convinced her that the coordinator was unpretentious and real. Her class had prepared diligently for a scripture finding and application competition with other seminary classes. There was a preliminary qualifying activity that her class did not complete due to circumstances beyond their control and the class was not invited to attend the competition. They were devastated. Volunteer 9 approached the coordinator after the competition and shared her frustration. She was encouraged by his response. She said, "He was receptive, asked if I had any ideas. I shared with him my idea and he brought it up in one of our training meetings and asked if anyone else had an idea. So clearly he listened, and I appreciated his dialogue."

A survey respondent stated simply, "He does not seem judgmental or dismissive." Volunteer 2 had the opportunity to test a promise made by a coordinator and found that he kept it even though it may have been inconvenient. He recalled:

My coordinator has said he is always available for us. I tested that one time with him. I was worried about a student of the opposite gender who was always staying after class, even if her parents were in the parking lot." She shared very personal things with the volunteer which made him nervous. Not knowing what to do, "I called the coordinator very late at night to say, 'What do I do?' He was willing to help and he gave some great suggestions and I implemented them and 
you know, and it was helpful for me to feel like I had that protection and help $24 / 7$.

Other volunteers acknowledged sincere commitment of the coordinator they work with in the following comments. "I feel he truly has our best interests as his primary motivation. Even when what he counsels us to do as teachers is personally challenging, I do my best and would defend him to others." Another volunteer remarked, "I feel like I can be completely candid with him. If I think something is stupid, I tell him. He is always willing to listen, and I feel like he takes my concerns seriously. Even if he doesn't agree, he is considerate to the fact that it is something that is hard for me." The perception of sincerity, lack of hypocrisy, and unspoken judgment are important aspects of volunteers' perception of coordinator integrity in their personal interactions.

Responding to needs. Volunteer 5 was new to her assignment when an important worldwide training meeting was held. She was going to be out of town in another state and would not be able to attend the satellite broadcast of the meeting. Her coordinator made arrangements for her to attend the meeting live. She was amazed and grateful at the personal interest he took in her and her situation. A survey respondent stated simply, "I feel like my coordinator is approachable and appreciative. Those things make me feel valued and that he's there for me."

Promptness in responding also was noted by a few participants as an important part of their perception of the authenticity of the coordinator. One volunteer surveyed recalled: 
When I have brought specific needs to his attention, he addresses them in depth. He has never said, 'I'll get back to you on that,' and then never followed up. He addresses my problems and needs at the moment I bring them to his attention. Another survey response added, "When I come to him with a problem, he makes it his problem too. He's very supportive, and helps me look for solutions."

Volunteers noted when coordinators were proactive in responding to needs and concerns. One survey respondent remarked, "I was challenged with making progress with my class and asked if he would come teach so that I could see something modelled. He cheerfully did this and I was grateful." Another volunteer confirmed this finding when they wrote, "He cares for us, he wants to know how we are doing and takes the time to help us with any concerns that we might have." A different respondent went so far as to say, "I can't think of anything that he has ever said or done that hasn't been helpful, true and meaningful."

The help provided by coordinators has been a relief to volunteers struggling to accomplish the objective of S\&I. Volunteer 7 remarked:

As a first year early morning seminary teacher, I had a difficult group of boys and needed help. I had tremendous help and support from the coordinator, helping me understand how to love these boys and how to be a better teacher in the further to avoid such problems in years to come.

Volunteers like volunteer 7 may rely on coordinators to help them in what sometimes is an uncomfortable experience. A survey respondent expressed, "I have always gotten answers I need, and been provided with more than sufficient guidance and direction to fulfill my assignment." Another volunteer (4) recognized there were not a lot 
of people in their church congregation who could relate to the challenges she was facing with the assignment to teach. She was grateful that, "When I sent him an email voicing my frustration in several different areas, I received a return email addressing each item with some thought and possible ideas to try." Many volunteers in this study have recognized and judged words and actions of coordinators as being evidence of how they genuinely feel.

Coordinator disinterest. As shown in the previous section, the genuine concern coordinators show volunteers is recognized and appreciated. Three volunteers interviewed did not sense that concern however. The sub-theme of coordinator disinterest was also identified in the interview transcripts of volunteer 7,8 , and 9 . The researcher identified survey statements of 12 volunteers who indicated they sensed their coordinator's lack of interest.

The interest of coordinators was a way that volunteers could perceive how genuine or self-serving the coordinator was. Some of the participants viewed coordinators as to busy to be concerned about them and so were cautious to approach them. One survey respondent believed the coordinator has "too many people to work with and probably does not want the extra trouble." Others felt the coordinator only had time to meet with them in large in-service meetings. One volunteer (8) explained why he did not approach his coordinator with problems:

If I have a problem, I will typically go speak with fellow seminary teachers just because, I don't know, it seems like the coordinators, they have not only been coordinators of the seminary program but full time institute teachers and helping 
coordinate the institute program as well. It seems like a big job. I don't really expect them to micro manage.

Another respondent questioned the coordinator's understanding of concerns, but acknowledged his effort to improve, "I am not sure he understands all that is involved in early morning seminary, but he is learning fast." Some volunteers were conflicted about labeling the coordinators efforts to help as insincere. In fact, one volunteer (7) questioned if his critical feelings were accurate because he recognized the sincere humble nature of his coordinator.

A few volunteer participants indicated the coordinator seemed disinterested or less than genuine. Volunteer 8 expressed the following:

Maybe once or twice have I sensed that the coordinator was interested in me, but that was not taken as very sincere. Also, group thanks a few times during inservice, but it doesn't really account for anything. I don't have a very high level of trust with the coordinator to begin with.

Another volunteer explained their concern relative to how they perceived the coordinator interest in them and wondered if it was just a personality characteristic of the coordinator. Perhaps the social skills of the coordinator were to blame:

It took him a long time to learn my name, I mean, he just does not know details about me or I don't know. When he does ask me things, it feels very forced. It's like, I've read that you are supposed to this or that, it's like a people skills thing.

Superficial validation. The sub-theme of hidden agendas speaks to volunteers who expressed concern that their performance affected the way the coordinator responded to them. Interview transcripts show 3 volunteers $(7,8,9)$ questioned 
coordinators intentions as being self-serving. A volunteer who responded to the survey explained:

If I have submitted my reports on time I feel ok about how the coordinator feels about me. If I did not do something to prepare for our monthly in-service I feel like I have let him down. When I am asked to do multiple things, even if the whole group is being asked to do the same things, I feel like my coordinator is dissatisfied.

Another volunteer could not tell how the coordinator felt about her ability as a teacher when he came to visit her class. Though the visit indicated the coordinator was interested, it also left the volunteer wondering how the coordinator felt she was doing:

I see the coordinator in my classroom once a year when he comes to observe my interaction with my students. He usually spends a few minutes after the students leave to discuss the dynamics of the class, the topic of discussion for the morning and then sometimes makes a suggestion for improvement. He is always diplomatic and supportive, but I am not really certain with his level of satisfaction with my teaching. I need improvement, I know this, and I am simply a called volunteer teacher, but I am unsure where I stand in his estimation of my teaching skills.

Questioning the authenticity, true feelings and intentions of the coordinator was not isolated only to when a coordinator was making class visits to volunteers. A volunteer noted how a coordinator felt about them from what he did not say: My coordinator says he is satisfied verbally, but sometimes I feel that his silent cues, how genuine I perceive his words to be, indicate otherwise. With 
my previous coordinator I felt genuinely accepted. I felt that no matter what I did wrong, as long as I was trying to be better then he would have been satisfied.

Volunteer 8 also compared a previous coordinator to the one with whom he now works. The difference in feelings is obvious in his comments as well as an opinion of his coordinator's true intentions:

My previous coordinator and I lived near each other. I felt like he was one of my close friends. Like if I saw him in Costco I could go up to him and say, 'Hey I have been thinking about this way of teaching, or get advice, and I felt very comfortable asking him because I never felt like he would judge me as an individual, like 'oh he needs to do better.'

A volunteer may hear coordinators express gratitude, but that expression did not translate into the mind of volunteer 8 as approval. He illustrated this feeling in the following description:

I feel like I don't know. He has never actually said, he's never told me that I am doing a good job, he always says that he is grateful for the work and the sacrifices, but then when all the meetings are about all the things that we need to be doing, so the subtle unspoken message is that no we are not quite there yet. Some volunteers sense and have a negative impression of coordinators who appear to be praising their efforts, but then offer critiques as to how they are performing in their assignment. Coordinators can appear disingenuous and unclear. A volunteer complained in the survey, "In our visits, I sense he is in a hurry to get to the next job. I feel that sometimes he has made unfair assumptions regarding my class based upon a 50 
minute class observation.” Another expressing frustration of unclear standards wrote, "Not much praise. Comments and critiques do not acknowledge current strengths. He also sends observation forms by email with lots of red text highlighting his suggestions, but does not elaborate, defend, or explain his criticisms when asked in person."

A disturbing finding related to self-serving administration to volunteers is the perception of 4 coordinators (Volunteers 7, 9, and 2 survey respondents) who believed their coordinator used manipulation to accomplish their purposes. Volunteer 7 explained how she perceived the action of her coordinator to be manipulative:

He asked me to participate in the last meeting by critiquing his teaching style. I felt a little uncomfortable with that because he is like my leader and so he wants me to critique him which I know he does to open the door for him to critique me in any manner that he feels is necessary.

This type of perceived manipulation has affected one volunteer surveyed to the point of wanting to resign from their assignment. Though the respondent did not expand on how the coordinator was using manipulation in the feedback process, they did offer the following insight:

I have a very strong negative reaction when I see him. It is a serious struggle. I think he means well, but is very manipulative and I'd rather never see him in class. I am ready to be released from this assignment in large part due to this very bad relationship.

Allegiance to policy. Another sub-theme emerged from the data relative to how volunteers perceived of how true the coordinator was to the policies and guidelines of the S\&I program. Volunteer 2 speculated, "I am sure he studies over the S\&I manuals, he 
seems to know the materials very well. I think all coordinators have to memorize the purpose of seminary. They all seem to know it word for word."

Volunteers expected the coordinator to always act in accordance with policies and practices approved by the S\&I organization. Most volunteers felt strongly that their coordinator would not deviate from standard procedures, but a few felt the interpretation of policy by the coordinator was sometimes lacking.

A survey respondent explained their confidence in the way the coordinator followed established protocols. They wrote, "I have never seen him act or ask us to do something I felt was out of harmony with gospel principles."

Interview transcripts indicated that 8 out of 9 volunteers feel they are not experts in the policies and practices of S\&I and so they rely on the coordinator to help them. One volunteer, unsure on how to proceed found that their coordinator explained the policy in a way that empowered them to act for themselves. They recorded in the survey the following example:

He said if this is what you feel you should do, and that is your idea, you are the one that is responsible. I don't have to approve of that make-up work. You are there in the trenches and have the capability to determine what will change their hearts the most. He is not so worried about marking of the days or marking off time, but a change or heart is what he wants to see in the students.

Fickle and unguided decisions. Another sub-theme that emerged from the data was relative to unclear or inappropriate decisions made by coordinators. While 8 of 9 volunteers interviewed indicated they felt the coordinator did things in accordance with policy, volunteer 8 felt he had found flaws in the way the coordinator presented or 
interpreted policy. Seven survey respondents also indicated they had problems with the way their coordinator made decisions. A survey response indicated, "Some decisions seem fickle or poorly thought out. When asked or challenged, his decisions are often reversed or rescinded."

Volunteer 8 was opposed to a new administrative practice mandated by the coordinator. When this volunteer read the policy manual, he discovered the practice directed by the coordinator was an option and not the only way of accomplishing the particular practice. He explained how this experience has impacted how he now responds to the coordinator explanation of practices and policies of S\&I:

I used to just accept everything that he asked us to do because I thought it was coming from the Church and now I wonder in the back of my head, well is this brother so and so teaching or this from the Church? So it's hard for me to know. Another volunteer recorded similar thoughts in a survey response:

My coordinator has asked us to do things that we assumed was counsel directly from Church leaders but we later learned were just his desires for us to do, and weren't required of us at all. Because of the way in which it was presented, and how many times it has happened, I have a hard time trusting his current and future decisions.

\section{Summary of Volunteer Perception of Their Trust of Coordinators}

The interviews and survey data collected from volunteers' revealed three overarching themes related to volunteers' perception of coordinator ability, benevolence and integrity of Effective Teaching, Helpful or Discouraging training and Genuine or self-serving administrating. There were 13 sub-themes tied to the overarching themes 
were identified and labeled, Model teaching, Impactful teaching, Training encourages, Training discourages, Inspired administrating, Informal communication, Unrealistic expectations, Genuine concern, Responding to needs, Coordinator disinterest, Superficial validation, Allegiance to policy, and Fickle and unguided decisions. See Figure 3 for a graphic summary of overall volunteer perception trust.

Multiple volunteers indicated that coordinators were adept at teaching and enjoyed being in places where they could observe the coordinator teach. Volunteers also thought coordinators did a good job of training. The majority of volunteers surveyed and interviewed expressed that they found the coordinators style of training, encouraging and it energized them to perform well in their assignments. Interestingly, the energy often resulted in a large crash of reality when volunteers took what they thought they had learned into the classroom. Multiple volunteers indicated that they struggled to implement training into their own classes, however, they felt this failure was related to their own abilities and they did not place blame on the coordinator. 

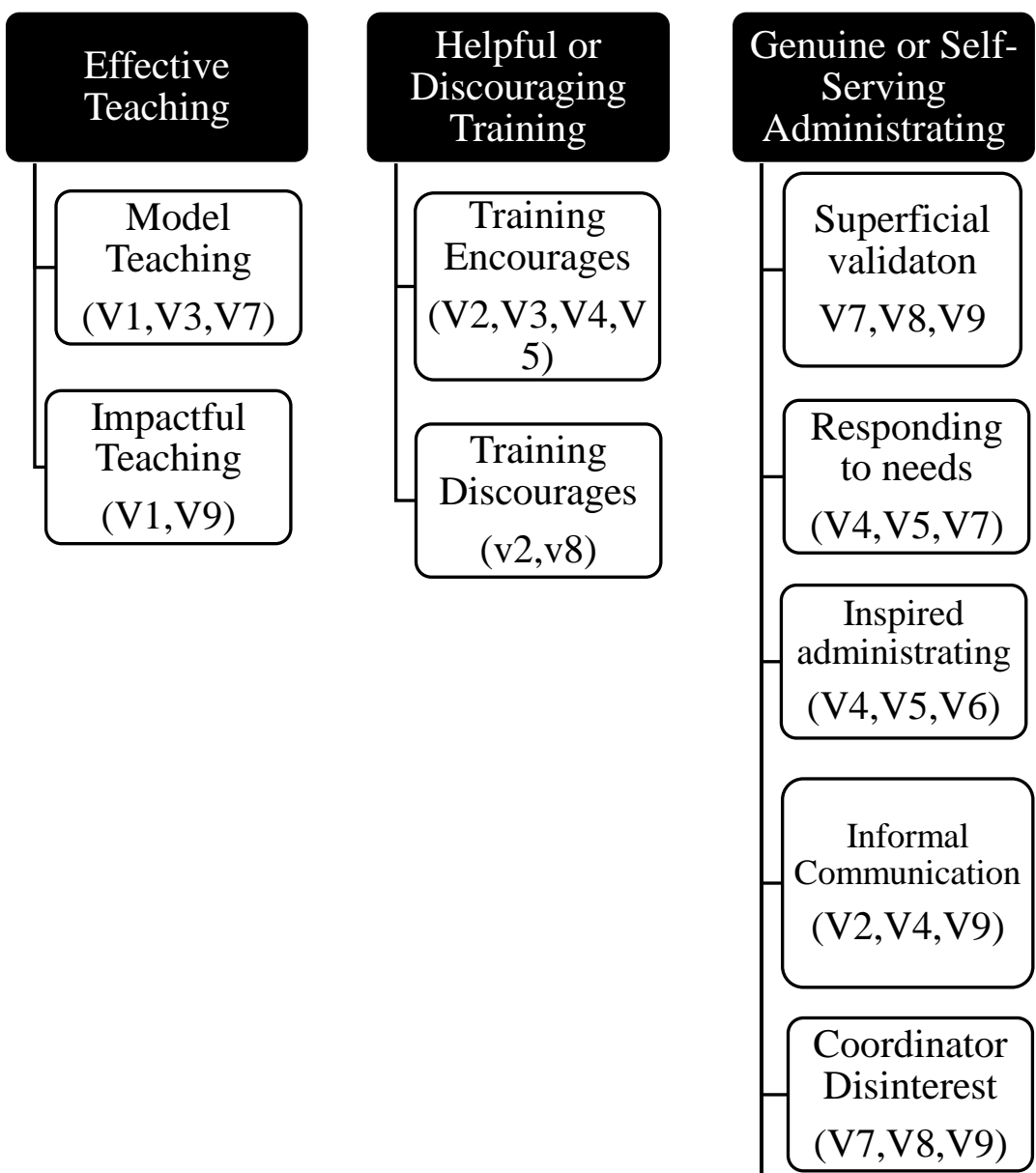

Genuine Concern (V2,V9)

Allegiance to
Policy
(V2)

Fickle and Unguided Decisions (V8)

Unrealistic Expectations (V8)

Figure 3. Summary of Volunteers Perception of Their Trust of Coordinators 
There was evidence that volunteers sensed some expectations coordinators had were unrealistic. Volunteers were appreciative however of coordinators who genuinely sought to understand the concerns and problems. Volunteers could sense coordinators truly cared about them from their personal communication and involvement with the volunteer.

Inversely, volunteers also perceived the coordinator was disinterested in their situation and problems at times. Some volunteers viewed coordinators unapproachable or intimidating because of the enormity of their assignments. Most volunteers felt the coordinator views on teaching and policy implementation were right in line with church standards. A few volunteers also believed that coordinator efforts relative to teaching and policy were not necessarily to help teachers, but to serve the coordinator's own interest.

\section{Coordinator Perception of How They are Trusted by Volunteers}

This section will contain findings collected in survey and interview data. Result of survey data will be presented first. Results from interview data will appear directly after the survey data.

In order to answer the first research question, coordinators responded to questions contained in a LMX-7 survey. Questions from the survey were used to determine the level of exchange between volunteers and coordinators. Point values of 1 (low exchange) to 5 (high exchange) were assigned to each response. The researcher analyzed point total for individual questions as well as point totals for the entire survey.

Additionally, coordinators were interviewed concerning their opinion of the how they felt volunteers viewed them. The researcher formulated these questions to elicit responses that would help him determine whether coordinators felt volunteers perceived 
the antecedents of trust, namely ability, benevolence, and integrity. Categories of Superior teaching, Implementation of instruction, and Maintaining relationships emerged from the data.

\section{LMX-7 Survey Data Results}

A modified LMX-7 survey (Graen \& Uhl Bien, 1995) was administered to coordinators and measured their perception of their leader-follower relationship with volunteers. Results from the survey indicated coordinators sensed a modest relational exchange with their coordinator. An overall score of 23.29 was calculated which placed coordinators near the middle of the moderate level of leader-member exchange category. Figure 4 provides a summary of coordinator LMX-7 survey results.

Only questions 2,5 yielded results of over 3.5. Coordinators scored question 2 highest at 4.0 which indicated they agreed that they are confident in the decisions their volunteers are making. Question 5 asked coordinators to describe their working relationship with volunteers. Scores from those responses totaled 3.71 which indicated coordinators had between an average and better than average relationship with volunteers.

Questions 1,3,4,6, and 7 showed scores that ranged from 3.47 at the highes to 2.47 at the lowest. Coordinators ranked question 1 at 3.47 which indicated they believe there is a moderate to high chance volunteers are intent at helping coordinators accomplish organizational objectives. Coordinators scored question 3 at 3.35. This question dealt with how often coordinators sensed volunteers were satisfied with coordinator efforts. This score correlated with sometimes and fairly often. 

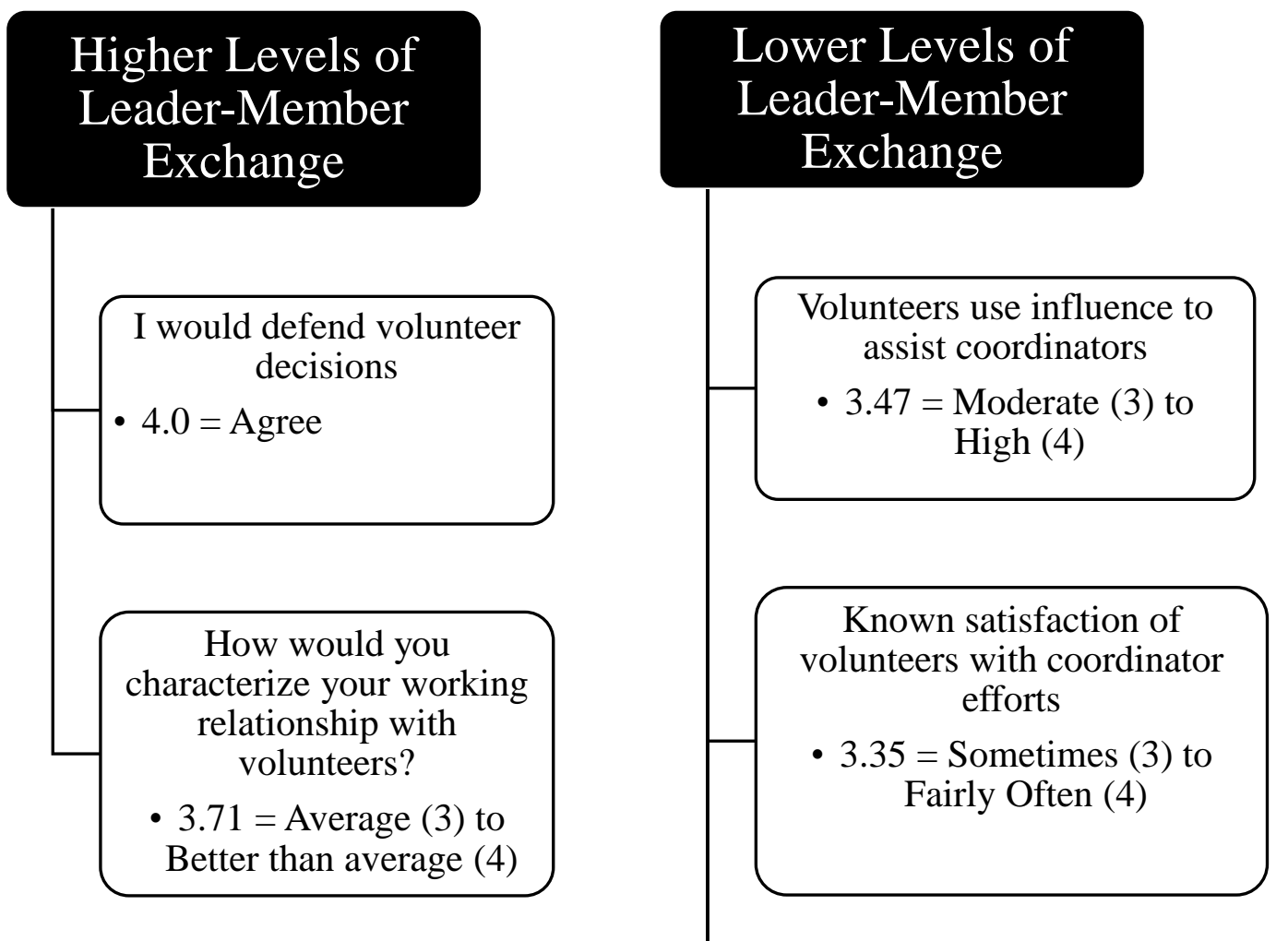

Volunteeer willingness to "bail out" coordinator

- $3.29=$ Moderate (3) to High (4)

Volunteer recognition of coordinator potential

- $3.0=$ Moderately (3)

Volunteer understanding of coordinator needs

- 2.47 = a little (2) to a fair amount (3)

Figure 4. Coordinator results of LMX-7 survey 
Question 4 asked coordinators to indicate how well they felt volunteers understood coordinator needs. This question resulted in the lowest score, 2.47. This score equated with description of a little to a fair amount. Question 6 sought to discover how coordinators thought volunteers recognized the potential of the coordinator. The result of this question was an exact score of three which corresponded to a moderate recognition. Finally, question 7 asked coordinators if they felt volunteers would be willing to help them in difficult situations. Coordinators responded with a score of 3.29 which corresponded to between a moderate and high.

\section{Coordinator Interviews}

In order to address the second research question, coordinators from the US Southern Plains region of S\&I were asked to describe their perceptions of how well volunteers perceived they functioned in their duties. Coordinators struggled to discuss directly feelings concerning how they sensed volunteers felt about their ability, characteristics, and actions. Overarching categories of superior teaching, implementation of instruction, and maintaining relationships emerged from coordinator interviews and surveys.

\section{Superior Teaching}

In the category of superior teaching, a number of sub-themes emerged from survey and interview data. In this section, the sub-themes of Separated by professionalism, and Influenced by ability, are discussed.

Separated by professionalism. Every coordinator (7) interviewed responded that volunteers generally view them as better teachers. Coordinator 2 stated, " $90 \%$ of my teachers think that I am better." He added however, "Many of them have much higher 
capacity to love their students than I do." All coordinators also reasoned that volunteers recognized they were professional teachers and so assumed they were better. Other explanations were given by coordinators and the researcher observed that discussing this topic made the coordinators uncomfortable and they tried to deflect or explain away any praise they observed.

Coordinator 4 noted the common refrain of professionalism as an indicator of high ability, but added that volunteer familiarity with him may lead to a false perception. He said, 'The teachers who know me the least always tell me I am the best teacher. I hear comments like, 'you are a much better teacher, you are a professional teacher' or something like that." Coordinator 3 believed the character of the volunteers led them to believe he had greater ability. He explained:

They feel that I am better because first of all, they are humble, second they feel that this is what I do as a career, that I have more experience and more time and know-how and they would feel that is the thing that benefits me making me a better teacher than them.

Coordinator 1 also alluded to the idea that because he was viewed as a professional, volunteers had tendency to create of more positive view than he felt was reality. I think for the most part they feel that I am a lot better than I really am. They think, you know, I have this infinite scriptural understanding which I don't, or this infinite ability to live the gospel, it's a little awkward sometimes, overall it's pretty positive feelings. Sometimes when I am observing them, their reactions are along the lines of they feel like this expert is in their class. Sometimes they will say something to the students that they will make me sound like someone 
important or something. Most of the time, just the way they refer to me, just the words they used like, well you are a professional you do this for your job. Some coordinators have recognized volunteers may not feel they can understand or relate to them. A coordinator survey respondent said, "I often feel like they are thinking that they have their own little world and I have mine." Coordinator 1 echoed this feeling when he said, "I've taught seminary in a different world and I am asking them to do these things and some of them feel like, if you just spend a week in my shoes then you would understand."

No coordinator interview or survey response indicated the felt they could not relate to volunteers. In fact, all 7 coordinators interviewed specifically pointed out they related well to volunteers. Interestingly, no coordinator interviewed had ever served as a volunteer teacher in the S\&I organization. Coordinator 1 described how he deals with volunteers who do not feel he understands their plight:

I try to show some understanding, you know one thing I try to share when they feel like I [don't understand], is that I took early morning seminary and sometimes I've gone in and taught their class you know. I then say, oh yeah this is tough, let's work on this together, not to go and show them up, if you go in trying to understand and say gosh yeah, the kids don't want to say anything and yeah it's really hard, let's talk about it and we get on the same page.

Influenced by ability. Three coordinators felt volunteers perceived coordinators ability to teach based upon their own abilities. Coordinator 6 sensed the volunteers he worked with highly regarded his ability. He said: 
I think for the most part they are pleased. I am very hands on. I am very much there with them except for the way outlying classes. Some of my teachers are so obedient I could tell them to stand on their head before class started and they would do it, so I have to be careful about what I suggest because they take it so literally.

In essence, if a volunteer perceived their teaching skills or training ability as low, they also perceived coordinators teaching and training skills as low. Coordinator 4 offered this insight:

I think they view my job as making their life easier, that I am supposed to make them better teachers and I am supposed to give them the tools to become better. If they don't see themselves as becoming better then I think they probably view me pretty low. Like I should be doing more. I think the teacher who put the responsibility on themselves to improve, I think they are pretty hard on themselves, more than they need to be and they probably would speak a little high of me.

Coordinator 6 also attributed how volunteers perceived his abilities based upon their character and commitment to improve. "I think it [perception of coordinators abilities] depends on them and how open they are to change. If they don't want to change, there are some that will just think you are an idiot. A lot of it has to do with their heart." Coordinator 7 thought perhaps volunteers who think the coordinator has low ability were defending themselves against admitting their own shortcomings. He stated, "Their ability to improve and become effective teachers leads them to perceive me a 
certain way and also students as well. You will find teachers blaming students for how bad a class is instead of exploring the possibility that it could be them."

\section{Implementation of Coordinator Instruction}

All nine coordinators interviewed believe interaction between volunteer and coordinator is beneficial to success. Within this category, three sub-themes emerged: Training disconnect, Feedback conundrum, Who's the boss and Influenced by ability.

Training disconnect. Coordinators unanimously agreed in interviews and surveys that teachers who attended training meetings enjoyed them and were better teachers that those who did not attend. One survey respondent said, "It kind of pumps them up and gives them some confidence that they can do it." A survey respondent related that the volunteers he works with are excited to attend in-service because they share with him what they want to learn in the training.

Among all the coordinators interviewed and surveyed, only one coordinator explained that teachers were implementing training successfully in the classroom. He wrote in a survey response, "They [volunteers] report that the training I provide is helpful and sometimes share examples of implementation and success. I see improvement in the classroom." The remainder of the coordinators who spoke of training implementation note however, that the benefits of their training may not go further than the in-service meetings they hold. Coordinator 7 felt in-service meetings were helpful to give teachers a boost but also recognized, "They usually don't consistently try to do the things in their class that we practice in in-service.

Coordinator 2 seemed ruffled by the teachers' lack of implementation. He explained, "I've tried to measure any kind of performance on skills that we have 
practiced, and it seems like when we are together and practice those skills, man I think we got them, but then I lose hope when I go and visit their class the next time." When asked if he thought it was his fault or the volunteers he said, "I think its 50-50. I know they are excited to teach and apply the principles, but as a measurement of if they are actually accomplishing it, there is a major disconnect."

Coordinator 4 expressed his frustration at not having teachers attend in-service, while at the same time acknowledging that his teachers really don't implement the training. However, for this coordinator, he feels attendance at in-service signals a desire to improve. He explained:

The ones who contact me and desire help and that kind of thing, they are the ones that try to implement it [coordinator suggestions]. I think there are ones that don't want to do it, 'just let me do my own teaching, just let me get on with the rest of my life'. They want to see the benefit before they implement it.

Feedback conundrum. Coordinators sensed the opportunity to give feedback was important in helping volunteers improve their skills. These feedback session also impact the relationship coordinators and volunteers have with one another. Coordinator 5 said, "I work hard to establish a meaningful relationship because I genuinely care about them and their success."

Coordinators often find themselves in awkward situations considering whether to share negative assessments of volunteer performance. They fear the possibility of hurting feelings and reducing morale, or ignoring flaws and perpetuating bad teaching. Coordinators also recognized that only pointing out positive traits and characteristics may result in volunteers feeling the coordinator is placating or patronizing them. 
All of the coordinators interviewed felt many of the volunteers struggle and fail to meet the standard of the organizational objective, however, they generally feel telling volunteers they are failing will not result in improved results. Coordinator 2 indicated, "I know there are some who feel like they are doing exactly what they practiced and there couldn't be more polarization from what they think that they are doing and what they were actually doing while I was with them in an in-service." Coordinator 6 surmised that $25 \%$ of the volunteers he worked with did not even know there was an objective or purpose in S\&I.

Determining how best to approach volunteers in feedback situations is a concern for coordinators. They want to be completely honest and maintain professional integrity, but can feel conflicted if honesty results in hurt feelings. Coordinator 6 did not find it helpful to hide negative feedback from volunteers. He stated, "I am pretty straight up with people. What good are we doing if we say, 'oh yeah, all of the teachers are doing great' when half of them are not?" Coordinator 2 has not come to a conclusion as to how best to give feedback to volunteers. He recognizes the nature of their assignment as volunteers, but also wants organizational purposes to be accomplished effectively. $\mathrm{He}$ expressed the dilemma when he said, "I sometimes feel like if I were to give them what they really need to hear, even if was not all that critical they would feel just blasted and so more often probably that I should, I don't really know the solution to it. I have gone back and forth, probably more than I have should have."

Coordinator 8 felt like he has discovered a way to provide critical feedback to volunteers without hurting their feelings and causing them to lose confidence in their 
ability to fulfill their assignment. He felt this method also allowed him to be open and honest with volunteers:

It won't do any good to snowball them and just lay it on them. They will tuck their tail and hide basically. So I think I stick with one thing and it comes straight from the manual. We open it up and look through it together and I give them something positive to start with. I ask them to pick something to work on. A lot of times they will pick something that is right on target with what I was thinking. It becomes more of a discussion rather than coming straight from me.

Another coordinator described his positive interaction with a volunteer to improve their teaching this way:

I like to have them point out what they know they are doing well and what they are doing not so well and a lot of the times their concern in my concern as well. I feel like a joint helper for their concern. Then of course I always end with a compliment.

One coordinator indicated they felt useful because of the compliments volunteers shared with them. A survey respondent stated: "They enjoy my leadership style more than others they have encountered. I have received from time to time good compliments from the teachers and priesthood leaders of appreciation for my assistance with their callings and work."

Who's the boss? Organizationally, coordinators are not the head of the seminary and institute program in the areas in which they work. Local church leaders are to oversee the program, yet coordinators sense volunteers recognize them as their leaders and perceive their actions in a leadership role. Coordinator 2 said, "If I show up to a 
seminary class to watch, I always know they will be on their best behavior. They will defer to me in almost any meeting." One coordinator surveyed said, "Many of them see me still as a boss trying to catch them doing something wrong."

Four coordinators interviewed $(1,4,5,7)$ have sensed volunteers may be intimidated by them and reluctant to approach them because they perceive they are subordinate to the coordinator. One survey response noted, "They are still a little distant because they may not trust that my intent is truly to assist them." Another restated a similar feeling, "They are hesitant to take advantage of my assistance as a resource because they don't want to infringe on my time."

\section{Maintaining Relationships}

Data collected indicated, for the most part, that coordinators feel they have a good relationship with volunteers. Within this larger category of maintaining relationships emerged several sub-themes: loyalty to volunteers and personal contact. Following is a discussion of each sub-theme from most often mentioned by the coordinators to the least.

Loyalty to volunteers. All of the coordinators interviewed believe they have a responsibility to defend teachers who strive to improve their ability to teach and have sought to understand policy. Coordinator one commented, "I have no problem defending about half of the teachers I work with. They come to in-service and for the most part they know their stuff. The other $50 \%$, I am not so sure." Coordinators shared examples from taking the side of teachers when upset parents call (coordinator 4) to defending teachers actions when other Church leaders question their actions (coordinator 2). Coordinator 1 shared the following example: 
Now and again there will be an issue, usually it's something that someone has overreacted to something. I try to give the teacher every benefit of the doubt I can. Of course try to find out what is really happening. I talk to the teacher to understand what they are seeing. Anything I can do to protect the integrity of the teacher in that position I try to do. I have never felt like a teacher was trying to hide something or mask a mistake.

Survey results indicated that all coordinators who participated felt they would defend the actions of the volunteer teacher if those actions were ever called into question. Coordinators indicated in interviews and survey responses that teachers feel support and respond positively to it. A coordinator reflected in a survey response:

I just feel that I've tried really hard to establish a true friendship with the volunteers that fall under my stewardship and that they know that I truly care for what they do and the efforts they give. I feel that they see this, and it builds on our working relationship.

Personal contact. Many coordinators perceived that communication with volunteers was a way to establish meaningful relationships. A coordinator responded in the survey, "I feel like I communicate often with them and generally have good, honest and fair discussions during teacher training." Another described how he hoped the volunteers he works with feel about communicating with him. "For many reasons I don't like them to necessarily know that I work with other teachers. I want them to know that my focus is on them."

The LMX-7 survey (Graen \& Uhl Bien, 1995) administered to coordinators measured exchanges between coordinators and volunteers. Results from the survey 
indicated coordinators sensed a relational exchange with volunteers, but well below that which volunteers sensed with coordinators. A score of 23.29 was calculated which placed coordinators into the moderate level of the leader-member exchange category.

For some coordinators, communication is an indicator of how the volunteer feels about them. One coordinator paid attention not only to what the volunteers were saying but also how they were acting. He said in a survey answer, "I can tell how they feel mostly in their interactions with me. Body language says a lot, silence says a lot and eagerness to act upon instruction helps me sense their approval of our relationship." Another coordinator also concluded that communication was a great indicator how well volunteers trusted him. He wrote in a survey response, "I believe that with most working relationships people put up a front to protect themselves until they personally get to know and trust an individual."

Personal communication outside of group settings did not appear as often in the responses of coordinators as it did with volunteers, however Coordinator 1 remarked, "If they have concerns, or it's an area I feel that that teacher needs to work on, then I feel it is very beneficial if we just have a little one on one thing instead of me potentially embarrassing or humiliating that teacher in front of others." Another coordinator mentioned the importance of formal and informal communication in determining how volunteers felt. "The teachers' willingness to communicate with me, either formally or informally, have given me clues as to how satisfied my volunteers are with what I do. Their willingness to participate in teacher trainings and observations has given me clues as well." 


\section{Summary of Coordinator Perception of How They are Trusted by Volunteers}

The interviews and survey data collected from coordinators revealed three overarching themes related to how coordinators perceived volunteer recognize coordinator ability, benevolence and integrity: Superior Teaching, Implementation of Coordinator Instruction, and Maintaining relationships. There were 7 sub-themes tied to the overarching themes were identified and labeled, Separated by Professionalism, Influenced by ability, Training disconnect, Feedback conundrum, Who's the boss, Loyalty to volunteers, and Personal contact. See Figure 5 for a graphic summary of overall coordinator perception of volunteer trust.

The coordinators interviewed in this study perceived that volunteers recognized the coordinators' ability to teach was higher than their own. Coordinators attributed this assumption to their professionalism. Some coordinators also perceived that volunteers correlate their own ability to teach directly to their perception of their coordinators ability to teach.

Implementation of instructions given to volunteers was also discussed by the coordinators. One coordinator felt his teachers were implementing well the training received in formal in-service meetings. All other coordinators who spoke on the issue observed volunteers failing to implement training effectively. Coordinators generally felt that feedback offered to teachers in classrooms was more beneficial to improving volunteers' skills. 


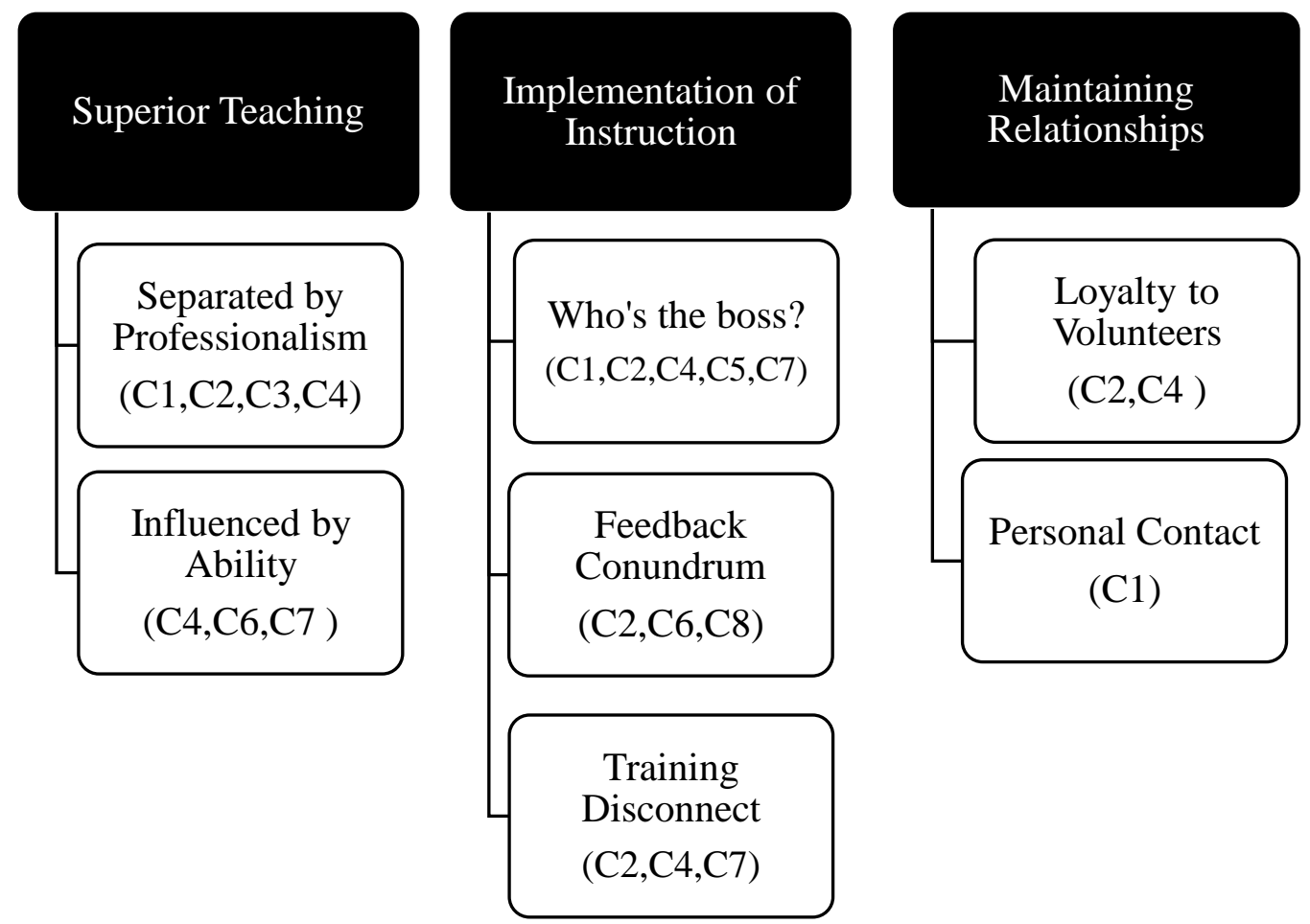

Figure 5. Summary of Coordinator Perception of How They Are Trusted by Volunteers 
The importance of maintaining a good relationship with volunteers was noted among coordinators through their discussions of loyalty and personal contact. Coordinators felt that backing up decisions and practices of volunteers showed their loyalty. Additionally, coordinators recognized that personal and informal communication with volunteers helped reinforce relationships.

\section{Summary}

In Chapter Four, descriptions of how data were collected and analyzed in this project. Six major categories emerged as a result of data analysis: effective teaching, helpful and discouraging training, genuine and self-served administrating, superior teaching, implementation of coordinator instruction, and maintaining relationships. Within each major category emerged a number of sub-themes. The two research questions were addressed through the categories and data collected during the research process.

Contained in Chapter Five is a general overview of the study, and integrated findings relative to the research questions. Limitations of the study are reviewed. Implications for volunteers, coordinators and other administrators in the S\&I organization and suggestions for future research are proposed. 


\section{CHAPTER FIVE DISCUSSION AND CONCLUSIONS}

The study of trust between leaders and volunteers in non-profit organizations is complex and rare. The vast majority of research concerning trust in organizations examines it from the perspective of for-profit businesses that provide pay or other extrinsic benefits for services. Non-profit organizations, such as Seminaries \& Institutes of Religion (S\&I) examined in this study, are not structured to provide such benefits, nor would those benefits necessarily create desired outcomes.

The dearth of research surrounding non-profit organizations and trust compounds the problem of determining what findings and what conclusions leaders within S\&I can implement in their own leadership practice. Additionally, there appears to be no research relative to trust done specifically on religious organizations involved in religious education similar to that which takes place within S\&I. Leaders in S\&I interested in understanding trust are left to sift through previous research on trust trying to identify any study that seems relevant to their work.

Currently, over 400 coordinators are employed by S\&I to work with and provide leadership for over 40,000 volunteers throughout the world (Seminaries and Institutes of Religion, 2013). However, coordinators are relatively untrained in working with volunteers prior to being assigned a specific area. Most coordinators were previously employed as full-time seminary or institute teachers, and did not have experience working with or training volunteer teachers. 
No study was found that determined how or if coordinators and volunteers are able to perceive relationships of trust between each other. Any evidence that is present is anecdotal at best and is not formally collected. Until this study, there has been no research dedicated to how volunteers perceive trust with coordinators in S\&I.

\section{Purpose of the Study}

The intent of this mixed method study was to identify how coordinators and volunteers within S\&I perceive trust between each other and identify the actions these perceptions are based upon. An extensive review of the literature presented in Chapter Two indicated that trust was a large factor in organizational and personal success. An analysis of current research related to trust revealed the importance of leaders being able to perceive when trust is present and what actions indicate that trust is being extended. In the case of this particular study, a mixed method exploration was deemed appropriate due to the sensitivity of the issue and the need for understanding of such issues. Not all participants wanted to engage in a conversation, but many were willing to take a survey.

\section{Design and Procedures}

This phenomenological study of leaders and volunteers in the Seminaries and Institutes of Religion program employed three methods of data collection. A slightly modified version of the LMX-7 (Graen, \& Uhl-Bien, 1995) survey instrument was used to collect quantitative data from 25 coordinators and 60 volunteers. Additionally, field observations took place to view interactions between coordinators and volunteers. Finally, individual interviews were held with both leaders and volunteers. These interviews were transcribed and analyzed relative to the research questions put for in this study. 
The participants used in this study were coordinators and volunteers in the S\&I organization assigned to the US Southern Plains Region (USSP) when the research was conducted. Though S\&I is a worldwide organization, the researcher was asked by S\&I administrators to study a regional sample of coordinators and volunteers. Each of these individuals came from similar geographical areas and societal cultures.

Data were collected by conducting participant interviews. Interview participants included seven coordinators and nine volunteers. Additional data was gathered through the LMX-7 (Graen \& Uhl Bien, 1995) modified for audience, with a space provided for participants to explain their answers. There were 87 volunteers and 17 coordinators who completed the survey.

Interviews were conducted via video conference and were audio taped, then transcribed for further analysis. All participants in the study were given the opportunity to make comments and changes prior to the finalization of data analysis. Potential researcher bias was discussed at the beginning of Chapter One and was noted throughout the entire research process. All data were filtered through the antecedents of trust identified in Meyer et al. (1995) integrative model of organizational trust.

\section{Conclusions}

Within the framework of this study, two research questions were proposed. Each is addressed with a brief conclusion from the data within this section.

1. How do volunteers in a non-profit religious education organization perceive their trust of coordinators in the organization?

The volunteers interviewed and surveyed in this study perceived that they, in some cases, trusted coordinators because of their effective teaching, helpful training, and 
the genuine way they administered the seminary and institute programs. Volunteers who were unable to implement training practices or felt coordinator actions were self-serving, did not perceive trust in the coordinator. Other constraints to volunteers perceiving trust were identified as coordinator disinterest, hidden agendas and unrealistic expectations.

2. How do coordinators in a non-profit religious education organization perceive they are trusted by volunteers in the organization?

The coordinators interviewed and surveyed in this study indicated that, in some instances, volunteers perceived coordinators as having ability, benevolence, and integrity. These three characteristics were characterized by the researcher as being antecedents of trust. Coordinators generally believe that volunteers perceived them as superior teachers. Further, coordinators recognized volunteer attempts to implement instructions and training. Finally, coordinators indicated that they made efforts to effectively promote and maintain genuine relationships with volunteers. The researcher analyzed these findings and discovered evidence of the antecedents of trust.

\section{Conclusions Related to Existing Literature}

A review of the existing literature did not appear to address the issue of trust in non-profit religious education systems. Most of the literature on trust perception has focus on public and private enterprise along with inter-personal relationships. The work of Meyer et al. (1995) on developing a model of trust, identified antecedents of trust set forth a clear distinction of what trust is and when it can be present. Within the context of this study, the antecedents of ability, benevolence and integrity emerged as factors that indicated the perception of trust. 
Existing literature on trust and its perception included discussions and justification on why certain actions or characteristics were considered trustworthy or untrustworthy. The researcher discovered that a study of trust is subjective. In order to study the issue effectively and efficiently, clear parameters had to be established to define what trust was and what trust was not.

A number of leadership theories were studied prior to the onset of this project. A review of leadership theory discovered that multiple philosophies would be relative to this study. The Leader-member exchange theory (Graen \& Uhl-Bien, 1995), became the lens by which data was collected. Meyer et al. (1995) integrative model of trust was used as the lens from which the data was analyzed.

\section{Integrated Findings of the Study}

The findings of this study were organized around the research questions and overarching categories related to those questions. Following is a discussion of the integrated findings across the two groups, coordinators and volunteers, who participated in this study within the context of the antecedents of trust namely, ability, benevolence, and integrity. As the researchers viewed the data through the lens of those antecedents, the following overarching categories emerged: effective teaching, helpful and discouraging training, genuine or self-serving administrating, superior teaching, implementation of coordinator instruction, and maintaining relationships.

\section{Effective Teaching}

Under the category of effective teaching, the sub-theme of model teacher

emerged. All volunteers who discussed the teaching ability of coordinators indicated that they viewed the coordinator as a standard or a model of how they were to perform in their 
own classroom. This finding showed that volunteers perceived coordinator ability which for this study was distinguished as an antecedent of trust.

\section{Helpful and Discouraging Training}

Under the category of helpful and discouraging teaching, the sub-themes of training encourages and training discourages emerged. Volunteers generally appreciated coordinator efforts to train and felt excited to implement the training in their classroom. Volunteers noted however, that lessons learned in training were difficult to translate into classroom success.

\section{Genuine or Self-Serving Administrating}

Volunteers developed perceptions of coordinator ability, integrity, and benevolence through their interactions with the administrating actions of coordinators. The sub-themes that emerged in this category included: Inspired administering, informal communication, unrealistic expectations, genuine responses to genuine concerns, coordinator disinterest, superficial validation, allegiance to policy, and fickle and unguided decisions. Volunteers were mixed in their feelings in how they perceived coordinators relative to administrating. Many relied on and had a large amount of respect for the counsel and correction their coordinator offered. However, other volunteers perceived the coordinators' administrative actions to be manipulative, distant, and without purpose.

\section{Superior Teaching}

Under the category of superior teaching emerged two sub categories: Separated by professionalism, and Influenced by ability. Coordinators explained that volunteers perceived them as having greater ability because they operated as paid employees. 
Additionally, some coordinators supposed that volunteers based their own skills on how they perceived the coordinator's skills.

\section{Implementation of Coordinator Instruction}

Sub-themes from the category of implementation of coordinator instruction emerged and were labeled as: Training disconnect, feedback conundrum, who's the boss? All coordinators interviewed felt that most teachers enjoyed and were encouraged by the instruction given in training meetings and class visits. However, coordinators also noted that most volunteers did not seem to implement improvement suggestions in their classrooms. Additionally, three coordinators noted the difficulty in giving feedback to volunteers in a way that encouraged rather than discouraged. Compounding the difficulty of implementations of training, is the fact that coordinators are not the organizational head of the S\&I programs in their area. Volunteer church leaders are the official head of the program, yet rely on the coordinators to see that the program functions properly.

\section{Maintaining Relationships}

Under the category of maintaining relationships are three sub-categories that emerged during data analysis. These sub-themes, relative to the category include: loyalty to volunteers, personal contact, and responding to needs. Coordinators believed volunteers generally felt they could rely on them to help with problems and concerns. A few volunteers cited negative experiences with coordinators that would prevent them from soliciting help. Many volunteers pointed out personal phone calls, emails or informal conversations as being an integral part of their relationship development with the coordinator. Coordinators sensed those opportunities in similar ways as the 
volunteers. Coordinators indicated they felt it easy to respond with concern to volunteers who needed assistance.

These overarching categories emerged as the researcher viewed the data through the trust antecedents of ability, benevolence, and integrity. As these categories emerged, the researcher also noted sub-themes developing within the main categories. Figure 6 is a representation of the overarching themes, along with sub-themes as the related to the trust antecedents of ability, benevolence, and integrity (see Figure 6).

\section{Discussion}

Through the course of this study, the researcher was able to clearly see elements of leadership theory and practice woven through comments of both coordinators and volunteers. These theories and practices, caused the researcher to consider findings in different ways. Additionally, the results of the survey tool used to quantify leader and follower relationships triggered within the researcher new ways of considering the coordinator-volunteer relationship.

\section{Servant Leadership}

The characteristics and practices of Greenleaf's (2002) servant leadership theory aligned well with the description of coordinators throughout this study. Coordinators seemed to genuinely rejoice over volunteer successes and empathize with their struggles and sorrows. Conversely, volunteers place coordinators into the main leadership roles though coordinators do not directly control the functions of S\&I.

\section{Theory X \& Y}

McGregor (1960) presented Theory Y which posits that leaders who perceive followers as individuals who want to succeed are more likely to have success in that 


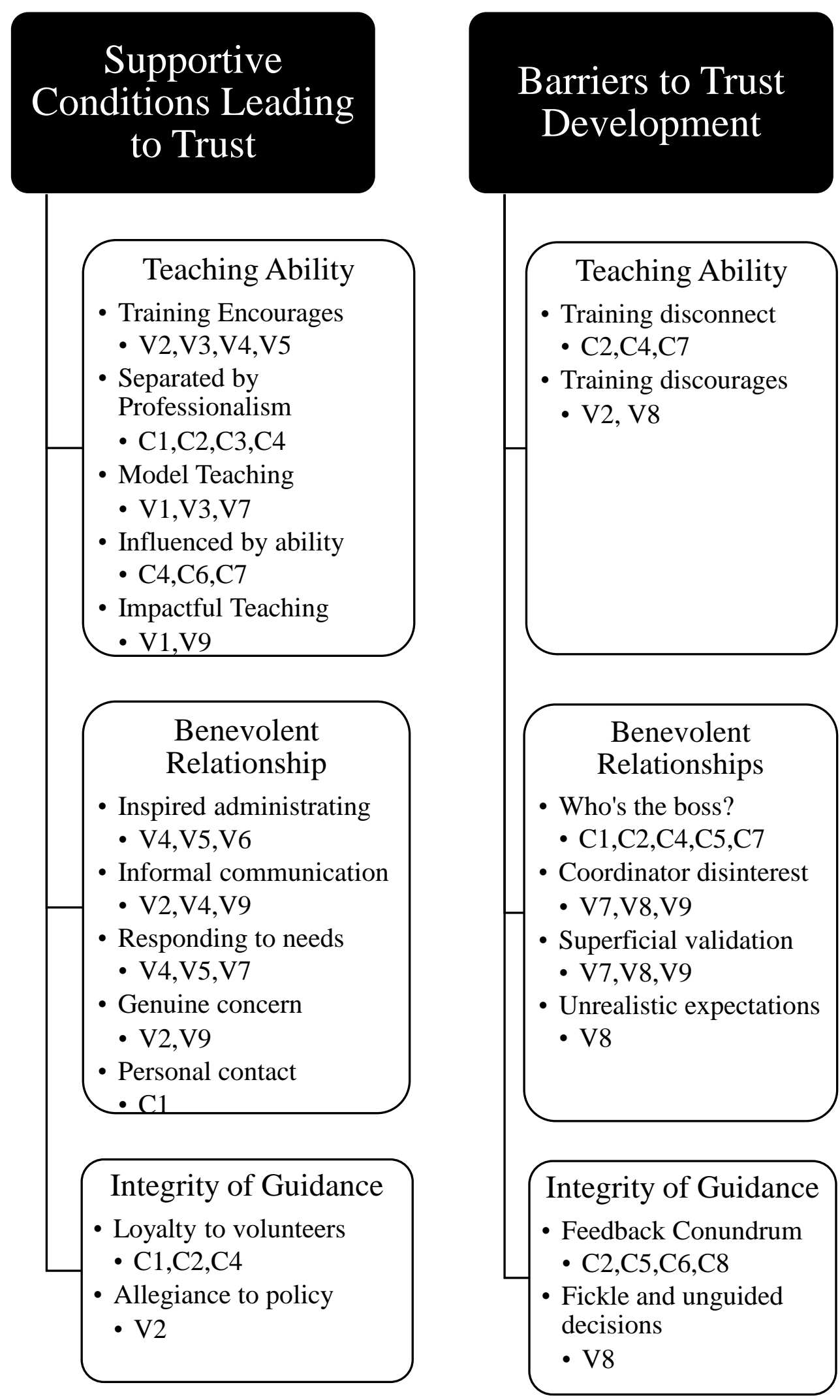

Figure 6. Coordinator and Volunteer Trust 
organization. The findings of this study support this theory. It was interesting for the researcher to note that coordinators who perceived volunteers were trying to get better, indicated that indeed they were getting better.

Contrariwise, some coordinators perceived that a few volunteers through a Theory X lens, feeling some volunteers were lazy or uncommitted to improvement. These coordinators felt those volunteers were a detriment to organizational goals and needed a different assignment. Though this opinion seems harsh or cold, the researcher could not discount these opinions. It very well may be the case that some volunteers are lazy and are not committed to accomplishing organizational goals. Nevertheless, the researcher did not see it necessary for coordinators to treat individuals they perceived as lazy, differently than those who they perceived as committed.

The researcher found throughout the course of this study that viewing a subjective issue such as trust, needed to be done through a very clear and defined lens. Meyer et al. (1995) identified the antecedents of trust namely, ability, benevolence and integrity which became obvious to the researcher as he studied transcripts. Though the antecedents themselves were also subjective, it appeared that this study confirmed Mayer's assumption of trust antecedents.

\section{LMX}

The findings of the LMX-7 survey (Graen \& Uhl Bien, 1995) caused the researcher to reflect on the uniqueness of the outcomes. The researcher found that volunteers sensed the relationship with their coordinator was very strong as noted in the high score on the LMX survey. However, the coordinators did not have the same sense of the relationship with volunteers scoring the relationship much lower. The researcher 
expected coordinators to perceive the relationship with volunteers more firmly because they were typically the ones initiating interaction.

The researcher considered the high LMX score of the volunteers and theorized that volunteers may feel the coordinator they work with is pleased with the way they are accomplishing their assignments. However, the lower LMX score attached to coordinators may be attributed to the idea that coordinators do not feel volunteers are doing well at accomplishing objectives. Coordinators indicated in the LMX-7 survey that volunteers did not understand coordinators needs, however volunteers sensed at high level that coordinators were satisfied with their efforts.

Coordinators rarely provide volunteers with feedback that can perceived as negative. As a result, volunteers may perceive coordinators approve of the job they are doing which causes them to have a more positive view of the relationship. A risk seems to arise then if a coordinator chooses to be more critical of a volunteer. A coordinator may weaken a trust relationship with a volunteer if they choose to be critical, or they may help the volunteer improve which would create trust.

This study of trust in a non-profit religious education organization perhaps provides a starting point to what, up until now, appeared to be a previously non-existent conversation. The researcher discovered that though the breadth of trust research is quite large, this work provides a new phase. Perhaps this research will provide a backdrop for a place to continue conversation related to trust in education.

\section{Limitations}

The S\&I program of the LDS Church is a worldwide organization with thousands of employees all with various styles and approaches. Developing a complete 
organizational evaluation in relationship to trust was impossible to accomplish financially and logistically as part of this dissertation. The researcher was limited to a specific region to study, thereby making findings dependent on a static social and demographic sample.

Additionally, the analyses process the researcher engaged in was subjective in nature. The researcher questioned if it was possible for one individual to observe and identify another individual's perception of trust or its antecedents through statements made in an interview. Though recognizing trusting behavior seemed somewhat obtainable, recognizing when someone perceived trust was difficult.

The researcher was further limited in the method he chose to obtain data. Delicate questions were asked in the interviews which encouraged respondents to share personal feelings about those they work with. The researcher did not have a relationship with the volunteers he interviewed. Volunteers were reticent to share information they felt might result in negative consequences for the coordinator the worked with even though assurances of anonymity and confidentiality were given.

An additional limitation to the study resulted from the difficulty many respondents had in understanding a few questions on the survey. Respondents indicated they had no idea what the question or a phrase in the question meant. The survey questions contained some jargon or euphemisms that were interpreted incorrectly or frustrated some of the participants.

Finally, interviewing participants through web video conferencing presented challenges for a few participants. Some participants had difficulty connecting to the conference while others felt embarrassed or simply uncomfortable having a discussion in 
this format. One participant covered her camera because she had not done her make-up for the day as yet.

\section{Recommendations for Practice}

The findings of this study have implications for volunteers, coordinators, and other administrators in S\&I. Recommendations for organization improvement will be presented in the section. These recommendations have emerged from the researcher's consideration of the antecedents trust identified in the study as, ability, benevolence, and integrity. These antecedents appeared in the overarching themes of Effective teaching, Genuine or self-served administrating, and Maintaining relationships that emerged during data analysis.

\section{Effective Teaching}

Volunteer teachers are overwhelmingly impressed with coordinators' ability to teach. They enjoy being in all types of teaching settings where the coordinator is instructing. Multiple teachers expressed how much they enjoyed and were captivated by the coordinators' willingness to come teach a class while they observed. This practice is not only helpful for teachers from a training perspective, but also allows the volunteer to recognize the coordinator's ability. The recognition of ability is an antecedent of trust and can strengthen that perception within the volunteer (Mayer et al., 1995).

Volunteer teachers can improve their teaching as they spend more time working with the coordinator (Graen, \& Uhl-Bien, 1995). Though formal in-service training meetings do not do much to improve teaching, the relationship that can be built there with the coordinator can lead to informal opportunities to improve teaching. Volunteers should occasionally invite coordinators to teach their class as well as observe them as 
they teach. These practices engage the volunteer in improvement behaviors that will ultimately help them accomplish organizational objectives.

\section{Genuine or Self-Served Administrating}

Volunteer teachers spend many hours preparing for and functioning in their assignments. They not only give of their time, but of their emotion, thoughts, and prayers. Volunteers want to do a good job and often feel like they are failing. Coordinators who view these volunteers through an approach suggested in McGregor's (1960) Theory Y, they will see volunteers as individuals who want to succeed will not be overly critical of their efforts in the classroom.

Coordinators should be careful to provide ample positive feedback to volunteers recognizing that they are not trained professionals. In many cases they are not trained

amateurs. Coordinators need not patronize or be fake with volunteers. Volunteers are quick to recognize such behavior. Perhaps when coordinators encourage volunteers to self-assess how they are meeting established standards, they will create a non-threatening way to address problems or inadequacies.

Coordinators may also encourage volunteers to become familiar with procedures and practices of the seminary and institute programs. As coordinators direct volunteers to the policy manuals for answers, volunteers feel empowered to act rather than to seek to be acted upon. Policy relative to S\&I should be discussed often in formal and informal communication between volunteers and coordinators.

\section{Maintaining Relationships}

Volunteer teachers overwhelmingly like to be around their coordinators. Coordinators become servant leaders (Greenleaf, 2002) by volunteers who perceive them 
as having genuine concern for them. Those who do not perceive a high level of trust toward their coordinator were typically those who did not have the opportunity to interact with him outside of formal meetings. Personal emails and phone calls are long remembered by volunteers. Special efforts to assist volunteers promote perceptions of benevolence and integrity which are antecedents of trust (Mayer et al.1995).

Coordinators may determine that brief exchanges at formal meetings and stressful appearances in classrooms are not the best way to develop strong relationships with volunteers. Coordinators may consider other times to meet personally with volunteers. An occasional email or phone call may result in a much more trusting relationship. Though coordinators may need to be calculated and deliberate about interacting with volunteers outside of formal settings, they need not feel worried or unsure that the informal time they are dedicating to volunteers is wasted and fruitless.

\section{Implications for Future Research}

Through the course of this study, the researcher identified and considered various methods, demographic and organizational aspects that may prove interesting to future research.

\section{Larger Sample Size}

Research may also be conducted on a much larger scale than was this study. As a worldwide organization, if may prove helpful to see if demographic condition plays any part in perception of trust. The current study did not exclude any participant on any demographic factors other than where they lived. Perhaps future studies may include other factors among volunteers such as number of years of church membership and the 
amount of time in their current assignment. Excluding or including volunteers based on if they have had previous coordinators may yield different results.

\section{Gender}

Though the researcher did not use gender as a demographic factor in analyzing survey and interview data, he did informally note in the interview process a pattern among male volunteers. Only male volunteers appeared to be critical of coordinator's ability, benevolence, and integrity. This informal observation caused the researcher to consider the value in separating participants by gender to determine how results vary.

\section{Coordinator and Administrator Relationship}

Another relational aspect of S\&I that can be explored through the lens of trust is the connection that exists between coordinators and the administrators above them. A similar study looking at how coordinators perceive they are trusted by administrators and how administrators view their trust of coordinators may yield results that may strengthen these relationships.

\section{Data Collection}

Future researchers may consider the format by which they gather data. Interviews that ask personal questions are sometimes difficult for participants to endure. However, future researchers may contemplate conducting interviews via online chat. This form of data collection not only assures confidentiality but also allows a pressure free environment for participants to answer reflective questions.

\section{Concluding Thoughts}

The study of perceptions of trust among volunteer teachers and coordinators in S\&I yielded interesting and informative findings. The researcher felt that viewing the 
data through the lens of the trust antecedents of ability, benevolence, and integrity added structure to the study, but not rigidity. Further, coding the data in this way provided the researcher opportunities to understand the lived experiences of those who were participating, without producing any contrived data.

Overarching categories emerged within the lens of the antecedents of trust as transcripts of interviews were reviewed. Those categories included: effective teaching, helpful and discouraging training, genuine and manipulative administrating, superior teaching, implementation of coordinator instruction, and genuine concern. Sub-themes emerged for those larger themes which provided detail to the results.

The informed modified framework which included the trust antecedents of ability, benevolence, and integrity coupled with the LMX-7 survey, advises future research on volunteerism in general as well as teacher-mentor relationships. Future research relative to this study may include using a larger demographic to conduct research. Additional demographic factors such as gender, age of respondents and years of membership in the church may also be considered when selecting participants. A change in the mode of data collection to interviews conducted via online messaging may provide additional findings. 


\section{References}

Argyris, C. (1962). Interpersonal competence and organizational effectiveness. Homewood, IL: Dorsey Press.

Aubert, B. A., \& Kelsey, B. L. (2003). Further understanding of trust and performance in virtual teams. Small Group Research, 34, 575-618.

Axelrod, R. (1984). The evolution of cooperation. New York, NY: Basic Books.

Bandura, A. (1977). Self-efficacy: Toward a unifying theory of behavioral change. Psychological Review, 84, 191-215.

Barker, R. A. (1997). How can we train leaders if we do not know what leadership is? Human Relations, 50(4), 343-362.

Barnard, C. I. (2011). The economy of incentives. In J. M. Shafritz, J. S. Ott, \& Y. S. Yang (Eds.), Classics of organization theory (7th ed., pp. 93-102). Boston, MA: Wadsworth.

Bass, B. M., \& Avolio, B. J. (1993). Transformational leadership: A response to critiques. In M. M. Chemers \& R. Ayman (Eds.) Leadership Theory and Research: Perspectives and directions (pp. 49-80). New York: Academic Press.

Becker, T. E. (1998). Integrity in organizations: Beyond honesty and conscientiousness. Academy of Management Review, 23(1), 154-161.

Bolman, L. G., \& Deal, T. E. (2008). Reframing organizations: Artistry, choice and leadership (4th ed.). San Francisco, CA: Jossey-Bass.

Brungardt, C. (1997). The making of leaders: A review of the research in leadership development and education. Journal of Leadership \& Organizational Studies, 3(3), 81-95. 
Bryk, A. S., \& Schneider, B. L. (2004). Trust in schools: A core resource for improvement. New York, NY: Russell Sage Foundation.

Burke, W. (1986). Leadership as empowering others. In S. Srivastra (Ed.) Executive power, 51-77. San Francisco, CA: Jossey-Bass.

Burns, J. M. (1978). Leadership. New York, NY: Harper \& Row.

Carlyle, T. (1966) On heroes, hero-worship and the heroic in history. Lincoln, NE: University of Nebraska Press.

Chemers, M. M., \& Ayman, R. E. (1993). Leadership theory and research: Perspectives and Directions. San Diego, CA: Academic Press.

Chen, Z., Lam, W., \& Zhong, J. A. (2010). Effects of perceptions on LMX and work performance: Effects of supervisors' perception of subordinates' emotional intelligence and subordinates' perception of trust in the supervisor on LMX and consequently, performance. Asia Pacific Journal of Management, 29(3), 597616.

Chopra, D. (2002). The soul of leadership. The School Administrator, 59, 10-13. Church Educational System. (2003). Administering appropriately: A handbook for CES teachers and leaders. Salt Lake City, UT: The Church of Jesus Christ of Latterday Saints.

Clawson, J. G. (2002). Level three leadership. Upper Saddle River, NJ: Prentice-Hall. Coleman, J. S. (1990). Foundations of social theory. Cambridge, MA: Harvard University Press.

Collins, J. (2001). Good to great: Why some companies make the leap... and others don't. New York, NY: HarperCollins. 
Colquitt, J.A., Cott, B.A., \& Lepine, J. A. (2007). Trust, trustworthiness, and trust propensity: A meta-analytic test of their unique relationships with risk taking and job performance. Journal of Applied Psychology, 92(4), 909-927.

Conger, J. A., \& Kanungo, R. N. (1987). Toward a behavioral theory of charismatic leadership in organizational setting. Academy of Management Review, 12, 637 647.

Cosner, S. (2009). Building organizational capacity through trust. Educational Administration Quarterly, 45(2), 248-291.

Costigan, R. D., Ilter S. S., \& Berman, J. J. (1998). A multi-dimensional study of trust in organizations. Journal of Managerial Issues, 10(3), 303-317.

Covey, S. M. (2006). The speed of trust: The one thing that changes everything. New York, NY: Free Press.

Creswell, J. (2009). Research design: Qualitative, quantitative, and mixed methods approaches (3rd ed.). Thousand Oaks, CA: Sage.

Creswell, J. W., \& Miller, D. L. (2000). Determining validity in qualitative inquiry. Theory into Practice, 39(3), 124-130.

Daft, R. L., \& Lane, P. G. (2005). The leadership experience. Mason, OH: Thomson/Southwestern.

Deutsch, M. (1960). The effect of motivational orientation upon trust and suspicion. Human Relations, 13(2), 123-139.

Deutsch, L. (2009). The case for trust as the foundation for restoring growth. Human Resource Management International Digest, 17(4), 3-5. 
Dickson, P. G. M. (1993). The financial revolution in England: A study in the development of public credit. Aldershot, England: Gregg Revivals.

Driscoll, J. W. (1978). Trust and participation in organizational decision making as predictors of satisfaction. Academy of Management Journal, 21(1), 44-56.

Drucker, P. (2005). Managing the nonprofit organization: Principles and practices. New York, NY: Collins Business.

Dwyer, F. R., Schurr, P. H., \& Oh, S. (1987). Developing buyer-seller relationships. The Journal of Marketing, 51(2), 11-27.

Emerson, R., Fretz, R., \& Shaw, L. (2011). Writing ethnographic field notes (2nd ed.). Chicago, IL: University of Chicago Press.

Ernst, F., \& List J. A. (2004). The hidden costs and returns of incentives-trust and trustworthiness among CEOs. Journal of the European Economic Association, 2(5), 743-71.

Forbes, P. (1991). Are you a born leader? National Petroleum News, (October), 70.

French, J. R., \& Raven, B. H. (1959). The Bases of Social Power. In D. Cartwright \& A. Zander (Eds.), Group Dynamics. New York, NY: Harper and Row.

Fukuyama, F. (1995). Trust. The social virtues and the creation of prosperity. London: Penguin Books.

Gabarro, J. J. (1978). The development of trust, influence, and expectations. In A.G. Athos \& J.J. Gabarro (Eds), Interpersonal behavior: Communication and understanding in relationships, (pp. 290-303). Englewood Cliffs, NJ: Prentice Hall. 
Gambetta, D. (2000). Can we trust trust? In D. Gambetta (Ed.), Trust: Making and breaking cooperative relations (pp. 213-237). New York, NY: Basil Blackwell.

Gardiner, A. H. (1964). Egypt of the pharaohs: An introduction (Vol. 165). New York, NY: Oxford University Press.

Gerstner, C. R., \& Day, D. V. (1997). Meta-analytic review of leader-member exchange theory: Correlates and construct issues. Journal of Applied Psychology, 82, 827844.

Gillespie, N., \& Mann, L. (2004). Transformational leadership and shared values: The building blocks of trust. Journal of Managerial Psychology, 19(6), 588-606.

Glover, E. (2007). Real principals listen. Educational Leadership, 65(1), 60-64.

Goleman, D. (1998). The emotionally competent leader. The Healthcare Forum Journal, 41(2), 36-38.

Golembiewski, R., \& McConkie, M. (1975). The centrality of interpersonal trust in group process. In C. Cooper (Ed.), Theories of group process (pp. 131-185). New York, NY: Wiley.

Graen, G., \& Uhl-Bien, M. (1995). Relationship based approach to leadership: Development of leader-member exchange (LMX) theory of leadership over 25 years: Applying a multi-level, multi-domain perspective. The Leadership Quarterly, 6(2), 219-247.

Greenleaf, R. K. (2002). Servant leadership: A journey into the nature of legitimate power and greatness. Mahwah, NJ: Paulist Press.

Hoy, W., \& Tschannen-Moran, M. (1999). Five faces of trust: An empirical confirmation in urban elementary schools. Journal of School Leadership, 9, 184-208. 
Johnson, R. B., Onwuegbuzie, A. J., \& Turner, L. A. (2007). Toward a definition of mixed methods research. Journal of Mixed Methods Research, 1(2), 112-133.

Joseph, E. E., \& Winston, B. E. (2005). A correlation of servant leadership, leader trust, and organizational trust. Leadership \& Organization Development Journal, 26(1), 6-22.

Julius, D., Baldridge, J., \& Pfeffer, J. (1999) Determinants of administrative affectiveness: Why some academic leaders are more influential and effective than others. The Canadian Society for the Study of Higher Education, 19, 1-17.

Katz, R. L. (1995). Skills of an effective administrator. Harvard Business Review, 33(1), $33-42$.

Kirkpatrick, S. A., \& Locke, E. A. (1996). Direct and indirect effects of three core charismatic leadership components on performance and attitudes. Journal of Applied Psychology, 81(1), 36-51.

Kirkpatrick, S., \& Locke, E. (1991). Leadership: Do traits matter? Academy of Management Executives, 5(2), 12.

Konczak, L. J., Stelly, D. J., \& Trusty, M. L. (2000). Defining and measuring empowering leader behaviors: Development of an upward feedback instrument. Educational and Psychological Measurement, 60(2), 301-313.

Korac-Kakabadse, N., Korac-Kakabadse, A., \& Kouzmin, A. (2001). Leadership renewal: Towards the philosophy of wisdom. International Review of Administrative Sciences, 67(2), 207-227.

Kramer, R. M., \& Tyler, T. R., (1996). Trust in organizations: Frontiers of theory and research. Thousand Oaks, CA: Sage. 
Lencioni, P. (2006). The five dysfunctions of a team: A leadership fable (1st ed). San Francisco, CA: Jossey-Bass.

Lester, S. W., \& Brower, H. H. (2003). In the eyes of the beholder: The relationship between subordinates' felt trustworthiness and their work attitudes and behaviors. Journal of Leadership \& Organizational Studies, 10(2), 168-179.

Lewicki, R. J., McAllister, D. J., \& Bies, R. J. (1998). Trust and distrust: New relationships and realities. Academy of Management: The Academy of Management Review, 23(3), 438-458.

Lewis, J. D., \& Weigert, A. (1985). Trust as a social reality. Social Forces, 63(4), 967985.

Liden, R. C., \& Maslyn, J. M. (1998). Multidimensionality of leader-member exchange: An empirical assessment through scale development. Journal of Management, 24, 43-72.

Likert, R. (1967). The human organization: Its management and value. New York, NY: McGraw-Hill.

Linden, R. C., Wayne, S. J., \& Stillwell, D. (1993). A longitudinal study of the early development of leader-member changes. Journal of Applied Psychology, 78, $662-674$.

Machiavelli, N. (1984). The prince. New York, NY: Oxford University Press.

Mann, R. D. (1959). A review of the relationship between personality and performance in small groups. Psychological Bulletin, 56, 241-270.

Maslow, A.H. (1954). Motivation and personality. New York, NY: HarperCollins. 
Mayer, R. C., Davis, J. H., \& Schoorman, F. D. (1995). An integrative model of organizational trust. Academy of Management: The Academy of Management Review, 20(3), 709-734.

Mayo, E. (1945). The social problems of an industrial civilization. Boston, MA: Harvard Business School Press.

McGregor, D. (1960). The human side of enterprise. New York, NY: McGraw-Hill.

McGregor, D. (1967). The professional manager. New York, NY: McGraw-Hill.

Michie, R. C. (1999). The London stock exchange: A history. Oxford: Oxford University Press.

Morgan, R. M., \& Hunt, S. D. (1994). The commitment-trust theory of relationship marketing. The Journal of Marketing, 58(7), 20-38.

Moye, M. J., Henkin, A. B., \& Egley, R. J. (2005). Teacher-principal relationships: Exploring linkages between empowerment and interpersonal trust. Journal of Educational Administration, 43(3), 260-277.

Northouse, P. (2010). Leadership: Theory and practice. Thousand Oaks, CA: Sage.

O'Neill, O. (2002). Autonomy and trust in bioethics. New York, NY: Cambridge University Press.

Onwuegbuzie, A. J., \& Johnson, R. B. (2006). The validity issue in mixed research. Research in the Schools, 13(1), 48-63.

Quinn, R. E., \& Spreitzer, G. M. (1997). The road to empowerment: Seven questions every leader should consider. Organizational Dynamics, 26(2), 37-48.

Rangarajan, L. N. (1992). The Arthashastra. India, New Delhi: Penguin Books. 
Rotter, J. B. (1967). A new scale for the measurement of interpersonal trust. Journal of Personality, 35(4), 651-665.

Rousseau, D. M., Sitkin, S. B., Burt, R. S., \& Camerer, C. (1998). Not so different after all: A cross discipline view of trust. Academy of Management Review, 23(5), 574599.

Ruvolo, C. M., Peterson, S. A., \& LeBoeuf, J. N. (2004). Leaders are made, not born: The critical role of a developmental framework to facilitate an organizational culture of development. Consulting Psychology Journal: Practice and Research, $56(1), 10-19$.

Sahin, F. (2012). The mediating effect of leader-member exchange on the relationship between theory $\mathrm{X}$ and $\mathrm{Y}$ management styles and affective commitment: A multilevel analysis. Journal of Management and Organization, 18(2), 159-174.

Schriesheim, C. A., \& Cogliser, C. C. (2009). Construct validation in leadership research: Explication and illustration. The Leadership Quarterly, 20(5), 725-736.

Schriesheim, C., Castro, S., \& Cogliser, C. (1999). Leader-member exchange (LMX) research: A comprehensive review of theory, measurement, and data-analytic procedures. Leadership Quarterly, 10, 63-113.

Schoorman, D. F., Mayer, R. C., \& Davis, J. H. (2007). An integrative model of organizational trust: Past, present, and future. Academy of Management Review, 32(2), 344-354.

Seminaries and Institutes of Religion. (2013). Seminaries and institutes of religion annual report for 2013. Retrieved from 
https://si.lds.org/bc/seminary/content/news/announcements/2013 annual_report_for_2013_02-report--8x11_format-for_web3304_eng.pdf

Simons, T. (2002). Behavioral integrity: The perceived alignment between managers' words and deeds as a research focus. Organization Science, 13(1), 18-35.

Spillane, J., Halverson, R., \& Diamond, J. (2001). Investigating school leadership practice: A distributed perspective. Educational Researcher, 30(3), 23-28.

Stodgill, R. M. (1948). Personal factors associates with leadership: A survey of the literature. Journal of Psychology, 25, 35-71.

Tan, H. H., \& Lim, A. K. (2009). Trust in coworkers and trust in organizations. The Journal of Psychology, 143(1), 45-66.

Tschannen-Moran, M. (2001). Collaboration and the need for trust. Journal of Educational Administration, 39(4), 308-331.

Tschannen-Moran, M., \& Hoy, W. K. (2004). A multidisciplinary analysis of the nature, meaning, and measurement of trust. Review of Education Research, 70(4), 547.

Tzu, S. (1963). The art of war, trans. Samuel Griffith. Oxford: Clarendon Press.

Whitener, E., Brodt, S., Korsgaard, M. A., \& Werner, J. (1998). Managers as initiators of trust: An exchange relationship for understanding managerial trustworthy behavior. Academy of Management Journal, 23, 513-530.

Williamson, O. (1993). Calculativeness, trust and economic organization. Journal of Law and Economics, 36, 453-486.

Winter, D. G. (1991). A motivational model of leadership: Predicting long-term management success from TAT measures of power motivation and responsibility. The Leadership Quarterly, 2(2), 67-80. 
Winum, P. C. (2003). Developing leadership: What is distinctive about what psychologists can offer? Consulting Psychology Journal: Practice and Research, $55(1), 41-46$.

Wong, C. S., \& Law, K. S. (2007). The effects of leader and follower emotional intelligence on performance and attitude: An exploratory study. The Leadership Quarterly, 13, 243-274.

Wyatt, W. (2002). WorkUSA® 2002_Weathering the storm: A study of employee attitudes and opinions. Arlington, VA: Watson Wyatt Worldwide.

Xue, Y., Bradley, J., \& Liang, H. (2011). Team climate, empowering leadership, and knowledge sharing. Journal of Knowledge Management, 15(2), 299-312.

Youngs, P., \& King, M. B. (2002). Principal leadership for professional development to build school capacity. Educational Administration Quarterly, 38(5), 643-670.

Yukl, G. (2002). Leadership in organizations (5th ed.). Upper Saddle River, NJ: Prentice-Hall.

Zucker, L. G. (1986). Production of trust: Institutional sources of economic structure, 1840-1920. Research in Organizational Behavior, 8, 53-11. 
Appendix A

Trust: A Phenomenological Study of Leaders and Volunteers in LDS Seminaries and Institutes

\section{FOCUS GROUP OR INTERVIEW CONSENT FORM}

Researcher: This study is being completed by the following John Lawson who is a doctoral student in the Educational Leadership and Policy Analysis Department at University of Missouri.

Purpose of the Study: The intent of this study is to identify how coordinators and volunteers within S\&I perceive trust between each other and identify the actions that these perceptions are based upon.

Request for Participation: This study involves research. Participation in the study is voluntary. You can remove your consent to participate in the study at any time and without any reason. If you wish to participate, please indicate by clicking "Agree" at the end of this form which indicates you give your consent to participate in this research. If you agree to participate at this time, you still maintain the option to withdraw your consent at any time. If you later on wish to withdraw your consent or have questions concerning the study, you may contact John Lawson at 417-380-4307 or lawsonjd@1dschurch.org

Study Method: This study involves being audio recorded in a personal interview or in a group with others depending on your preference. If you are chosen to be part of a focus group I will contact you to confirm the time you have selected. Once a time is arranged, I will send you a link to participate in a video conference. I will assist you connecting to this conference. The group discussion will last about 30-45 minutes. Questions will be asked. You may answer only the questions you want to answer. You may leave the group or end the interview at any time you want.

Privacy: All of the information we collect will be kept confidential. Your name or any information that could be used to identify you in the study will not be used. All recordings and transcripts collected will be stored in a lock file cabinet, in a locked office. Focus group confidentiality cannot be guaranteed because participants may share information during these sessions outside of the group.

Risks: The risks for participating in this study are limited. You might be uncomfortable sharing information about perception of trust in a group or interview. You may answer only the questions that you want to answer. You may leave the group any time you want.

Benefits: There may be no personal benefit from participating in this study. However, the seminary and institute organization may be able to use this study to improve the way 
in which coordinators work with volunteers.

Questions: If you have any questions about this study, please feel free to contact John Lawson at 417-380-4307 or lawsonjd@ @1dschurch.org or Dr. Cynthia Macgregor at CMacgregor@MissouriState.edu. If you have questions about your rights, concerns, complaints or comments as a research participant, contact the University of Missouri Campus IRB, 485 McReynolds Hall, Columbia, Mo., 65211. Phone: 573-882-9585

Yes, I agree to participate [link to selection of options]

No, I do not wish to participate [link to "Thanks for your consideration."] 
Appendix B

Recruitment Email

Dear Seminary and Institute (Coordinator or Volunteer)

My name is John Lawson and I am the Seminary and Institute (S\&I) Coordinator for the Springfield Missouri Area. I am also a graduate student at the University of Missouri located in Columbia, Missouri. I am currently conducting research, under the direction of Dr. Cynthia MacGregor, as part of my doctoral dissertation on perceptions of trust involving S\&I coordinators and volunteer teachers.

I am attempting to interview and survey LDS seminary and institute teachers, as well as coordinators from Texas, Oklahoma, Missouri, Arkansas, and New Mexico. The survey asks teachers/coordinators to describe their interactions with each other. The survey should take no longer than 15 minutes. Interviews and focus groups will take no longer than one hour and will be conducted over video conferencing.

The survey is anonymous. Your name will not be recorded in any part of the survey. Those who choose to be part of an interview or focus group will be contacted by the researcher and have the opportunity to view and agree to a consent form prior to being a part of the research. I will be the only researcher conducting the interviews and analyzing the data. Additionally, I will be the only individual who is able to view transcripts and review audio recordings collected. Information from the study will be kept confidential. You may withdraw from the study at any time. All data collected during interviews and focus groups will be kept in a secure, locked location.

Results of the study will be used for the completion of my dissertation and will be shared with S\&I faculty and administration. Data will be presented or shared only in compiled form with no personal identification of any participants.

Thank you for your consideration about participating in this research. If you have any questions about this study, please contact me.

John Lawson

904 South Kimbrough Ave

Springfield, MO. 65806

(c) 417-380-4307

(w) 417-831-5557

If you understand the reason for and use of this research and agree to participate, please indicate what parts of the research in which you are willing to participate. If you are willing to participate in an interview or focus group, please enter your contact information, and I will contact you with scheduling instructions. Indicating that you agree to participate does not obligate you to participate or to be chosen as a participant. 


\section{Appendix C}

\section{Modified LMX-7 Questionnaire}

1- What are the chances that your coordinator/volunteer would use his or her influence to help you solve problems in your assignment?

\begin{tabular}{|l|l|l|l|l|}
\hline None & Small & Moderate & High & Very High \\
\hline
\end{tabular}

Please describe why you feel they would or would not use their influence to help you.

2- How would you characterize your working relationship with your coordinator/volunteer?

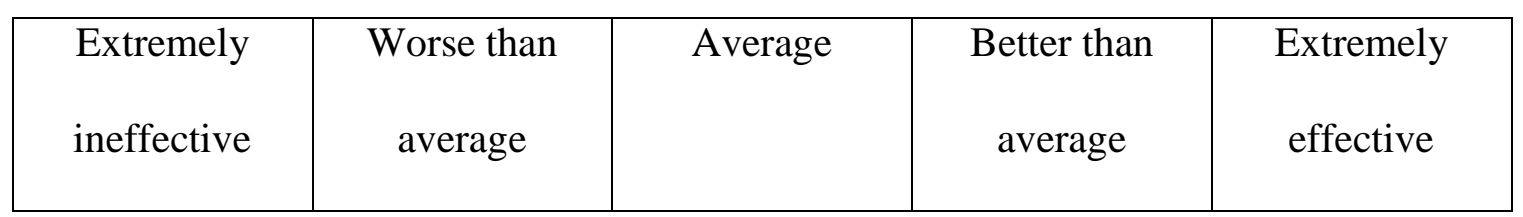

Why would you describe it in this way?

3- Do you usually know where you stand with the coordinator/volunteer and do you usually know how satisfied they are with what you do?

\begin{tabular}{|l|c|c|c|c|}
\hline Rarely & Occasionally & Sometimes & Fairly Often & Very Often \\
\hline
\end{tabular}


When and how have you been able to tell how satisfied the volunteer/coordinator is with you?

4- How well does your coordinator/volunteer understand your problems and needs?

\begin{tabular}{|c|c|c|c|c|}
\hline Not a bit & A little & A fair amount & Quite a bit & A great deal \\
\hline
\end{tabular}

When or how have you sensed your volunteers/coordinator has or has not understood your need?

5- I have enough confidence in my coordinator/volunteer that I would defend and justify his or her decision if he or she were not present to do so.

\begin{tabular}{|c|c|c|c|c|}
\hline $\begin{array}{c}\text { Strongly } \\
\text { Disagree }\end{array}$ & Disagree & Neutral & Agree & Strongly Agree \\
\hline
\end{tabular}

Why do you believe you would or would not defend or justify your coordinators decisions when they are not present?

6- How well does your coordinator/volunteer recognize your potential?

\begin{tabular}{|c|c|c|c|c|}
\hline Not at all & A little & Moderately & Mostly & Fully \\
\hline
\end{tabular}

What experiences have you had with your coordinator that have contributed to your feelings? 
7- What are the chances that your coordinator/volunteer would "bail you out" at his or her expense?

\begin{tabular}{|l|l|l|l|l|}
\hline None & Small & Moderate & High & Very High \\
\hline
\end{tabular}

How do you know they would or would not "bail you out" at their own expense?

Adapted from: Graen, G. B., \& Uhl-Bien, M. (1995). Relationship-based approach to leadership: Development of leader-member exchange (LMX) theory of leadership over 25 years: Applying a multilevel multi-domain perspective. The leadership quarterly, 6(2), 219-247. 
Appendix D

Interview Protocol

Volunteers

1- What are the chances that your coordinator would use his or her influence to help you solve problems in your assignment?

2- How would you characterize your working relationship with your coordinator?

3- What is your coordinators opinion on how you accomplish your assignment?

4- How well does your coordinator understand your problems and needs?

5- When have you felt your coordinator understood your job problems and needs?

6- Describe the level of confidence you have in your coordinators/volunteer ability to help you in your assignment?

7- How well does your coordinator recognize your potential?

8- What actions does your coordinator engage in that signals to you they are interested in your success?

9- How well does your coordinator do his or her job? 


\section{Appendix E}

Interview Protocol

Coordinators

1- When has it been difficult is it to stand up for and defend volunteer teachers? When is it less difficult?

2- How would you describe the attitudes of volunteers when you interact with them?

3- How does the circumstance affect the attitudes of volunteers when you interact with them?

4- When has a volunteer ever been disappointed with any action or decision you have made?

5- How well do volunteers implement directives and counsel you give?

6- Describe differences in how you interact with volunteers that are struggling to perform their assignment.

7- How do volunteers teachers feel about the way you teach?

8- How do your volunteers view your abilities to do what you are asking them to do? 
John Lawson was born May 30, 1975, in Provo, Utah. After attending public schools in Orem, Utah, He received the following degrees: B.A. in Broadcast Journalism from Brigham Young University (1999); M.A. Religious Education from Brigham Young University (2006), and; Ed.D. in Educational Leadership and Policy Analysis from the University of Missouri-Columbia (2014). He is married to Liz Lawson, and has 5 children, Katie, Anna, Sara, Emily, and Sam. Dr. Lawson's loves scholarship related to teaching and learning in both religious and secular settings. He is currently employed by The Church of Jesus Christ of Latter-day Saints as the director of the Springfield Institute of Religion in Springfield, Missouri. 